\title{
Changing Vulnerabilities in a Changing Climate: Farming Opportunity and Constraint in Kilimanjaro Region, Tanzania
}

\author{
Paul O'Keefe
}

Follow this and additional works at: https://researchrepository.wvu.edu/etd

\section{Recommended Citation}

O'Keefe, Paul, "Changing Vulnerabilities in a Changing Climate: Farming Opportunity and Constraint in Kilimanjaro Region, Tanzania" (2015). Graduate Theses, Dissertations, and Problem Reports. 6343.

https://researchrepository.wvu.edu/etd/6343

This Dissertation is protected by copyright and/or related rights. It has been brought to you by the The Research Repository @ WVU with permission from the rights-holder(s). You are free to use this Dissertation in any way that is permitted by the copyright and related rights legislation that applies to your use. For other uses you must obtain permission from the rights-holder(s) directly, unless additional rights are indicated by a Creative Commons license in the record and/ or on the work itself. This Dissertation has been accepted for inclusion in WVU Graduate Theses, Dissertations, and Problem Reports collection by an authorized administrator of The Research Repository @ WVU.

For more information, please contact researchrepository@mail.wvu.edu. 


\title{
Changing Vulnerabilities in a Changing Climate: Farming Opportunity and Constraint in Kilimanjaro Region, Tanzania
}

\author{
Paul O’Keefe
} Dissertation submitted to the Eberly College of Arts and Sciences
at West Virginia University

in partial fulfilment of the requirements for the degree of

\author{
Doctor of Philosophy in \\ Geography \\ Brent McCusker, Ph.D., Chair \\ Karen Culcasi, Ph.D. \\ Robert Maxon, Ph.D. \\ Jeremia Njeru, Ph.D. \\ Bradley Wilson, Ph.D.
}

Department of Geology and Geography

Morgantown, West Virginia

2015

Keywords: Livelihoods, Vulnerability, Climate Change, Tanzania, Kilimanjaro

Copyright 2015 Paul O’Keefe 


\begin{abstract}
Changing Vulnerabilities in a Changing Climate: Farming Opportunity and Constraint in Kilimanjaro Region, Tanzania
\end{abstract}

\title{
Paul O'Keefe
}

This dissertation demonstrates that the vulnerability of households to both socioeconomic and environmental processes is found in unequal, differentiated ability to access the means of social production and reproduction. Place specific environmental and social factors co-produce specific manifestations of vulnerability, but the underlying causes and driving forces are to be found in the social formation and social relations of households in the case study area. The major finding of this dissertation is that changes in the social relations of production and reproduction are creating as much risk to livelihoods as climate change does, or is likely to do in the future. Vulnerability is not necessarily caused at all by a changing climate, rather it is found in the daily struggles over social production and reproduction. Most so called 'environmental sources of vulnerability' are not experienced equally, and their ultimate roots are found not in the 'natural' environment but in social relations. Household exposure and vulnerability to drought varied hugely over small distances, suggesting that environmental conditions do not affect all households equally. Vulnerabilities are experienced locally but are generated in socially scaled processes beyond household control. 


\section{ACKNOWLEDGEMENTS}

This dissertation would not have been possible without the help of many people. My advisor, Brent McCusker has guided me through my doctoral studies with the wisdom of a sage and the patience of a saint. For this, I am eternally grateful.

I must also thank the other members of my committee, Dr Karen Culcasi, Dr Robert Maxon, Dr Jeremia Njeru and Dr Bradley Wilson. They have provided fantastic advice that will stand me in good stead for the future.

The support from those closest to me personally has also been invaluable. Thanks to Jess, who has stuck by me through thick and thin. I cannot thank you enough. Equally, my mother, father and my siblings who have encouraged me, or kept me thinking positively when I thought the end would never come.

Fellow comrades and travellers under the tutelage of Brent: Jenn, Maingi, Josh, Joyce, Naomi and Franklin. We've all made it through or will do soon. I hope at points I can help you as you have helped me.

This has been a journey that simply wouldn't have been successful without the support of all these people, and many more. For that I can only give my humblest thanks, and eternal gratitude.

Paul O'Keefe

Morgantown, 2015 
TABLE OF CONTENTS

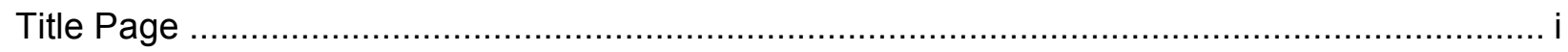

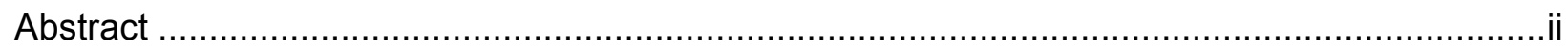

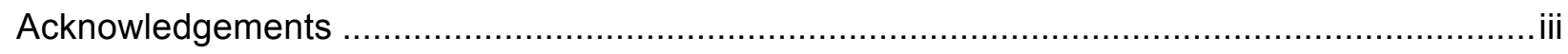

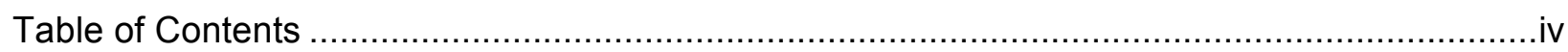

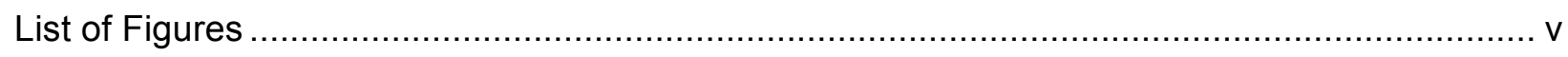

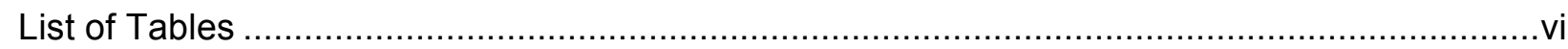

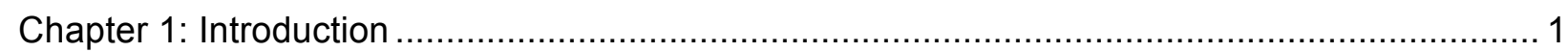

Chapter 2: Climate Change and People Change: Dancing the Dialectic. ................................ 11

Chapter 3: Vulnerability and Capitals Generation in Tanzania: a case study of

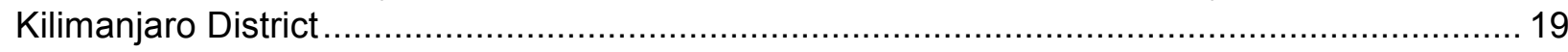

Chapter 4: Vulnerability and Livelihoods on Mt. Kilimanjaro ........................................... 40

Chapter 5: Exploring radical conceptions of vulnerability in Tanzania ...................................... 58

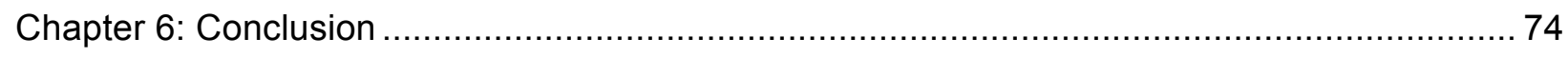

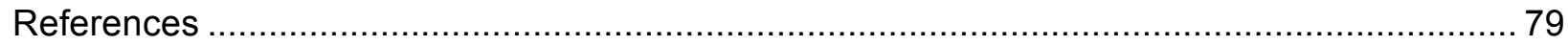




\section{LIST OF FIGURES}

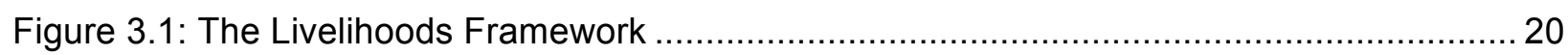

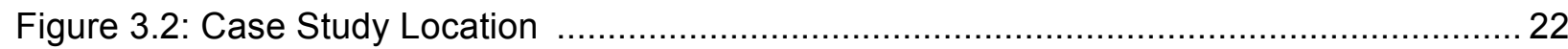

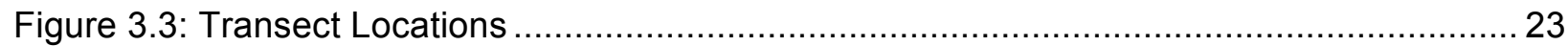

Figure 3.4: Rainfall variability in Rombo District Highlands 1995-2006 ............................... 25

Figure 3.5: Rainfall variability in Rombo District Lowlands 1995-2006 .................................. 26

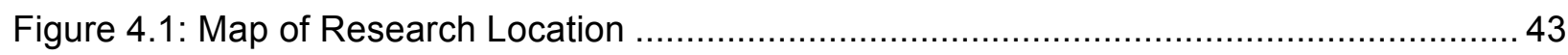




\section{LIST OF TABLES}

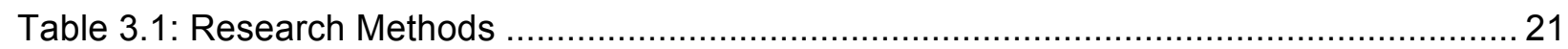

Table 3.2: Last Drought Experienced in Kilimanjaro Region ............................................. 24

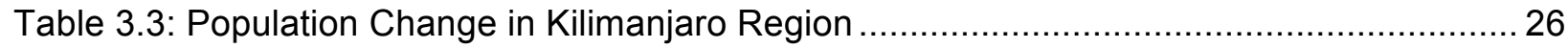

Table 3.4: Results from Seasonality Calendar .............................................................. 28

Table 3.5: Summary of Seasonal Vulnerability................................................................. 29

Table 3.6: Type of Building Material for Main Residence .................................................... 32

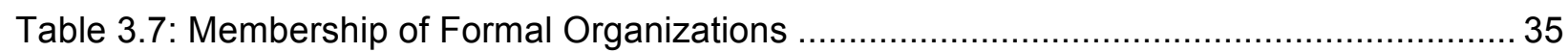

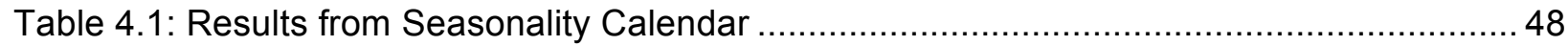




\section{Chapter 1: Introduction}

This dissertation demonstrates that the vulnerability of households to both socioeconomic and environmental processes is found in unequal, differentiated ability to access the means of social production and reproduction. Place specific environmental and social factors co-produce specific manifestations of vulnerability, but the underlying causes and driving forces are to be found in the social formation and social relations of households in the case study area. The major finding of this dissertation is that changes in the social relations of production and reproduction are creating as much risk to livelihoods as climate change does, or is likely to do in the future. Vulnerability is not necessarily caused at all by a changing climate, rather it is found in the daily struggles over social production and reproduction.

Vulnerability is only reduced in absolute terms when real development occurs, and the most vulnerable population groups in this case study are at best, only just coping with multi-scalar processes without the potential for real transformation to occur. Genuine vulnerability reduction will only occur if there are real changes in the mode of production that structures contemporary livelihoods, and most current attempts to identify adaptive pathways to reduce vulnerability within this mode of production are destined to be, at best, 'sticking plaster' temporary solutions. At worst they serve to reinforce existing hierarchies and access to resources and livelihood generation strategies.

This research began as an attempt to understand how climate change impacts on livelihoods. Climate change, understood as a wicked problem (Levin et al., 2012) with no simple, easy solutions - one that relates to many other ongoing processes. The dominant frameworks currently used to understand these issues are adaptation to climate change and the concept of resilience. These concepts, like my research, seek to understand simultaneously occurring socioeconomic and environmental processes. Through my doctoral studies I have increasingly focused on the question of what makes livelihoods vulnerable to both socioeconomic and environmental change This has led to a move away from concepts such as resilience and adaptation, which rest on ecological metaphors that downplay or ignore the social relations that drive exposure to climate risk and livelihoods vulnerability. This dissertation has moved away from consideration of climate change as a major explanatory factor of household vulnerability, as the interpretation of the fieldwork has indicated that the source of vulnerability is actually found in the struggle to produce and reproduce household livelihoods, vulnerability that is rooted in social relations.

The paradigm of climate change has in some sense been 'jumped upon' as a means to explain the continuing crisis of livelihood viability in rural areas of the developing world. There has been a broad rejection of state-led development efforts in recent decades (Ferguson, 1990; Scott, 1998; Smucker et al., 2015), replaced with narrower focus on poverty reduction, livelihood interventions and market-based reforms. Vulnerability in these contexts is understood as narrowly tied to income (Christiaensen and Sarris, 2007), or driven by external environmental factors (Mendelsohn et al, 2007). Where socioeconomic and environmental drivers of vulnerability are considered simultaneously, they are integrated in an additive manner, where a greater number of sources of risk equals a greater risk. 
Options to increase the viability or sustainability of livelihoods are therefore understood in this context: increasing the amount of cash-crops that can be grown, planting of crops more suited to a drier or hotter climate, and access to credit and insurance for farmers in order to survive in a system determined by a global market logic. To a lesser extent, adaptive solutions to climate change have been identified as a means to reduce vulnerability. This dissertation shows that when we look across scales and identify the driving forces and root causes of household vulnerability, we find them in unequal social relations. Class differentiation and consequent variability of entitlements and options for social production and reproduction determine the options people have for adaptation to what is yet an unknown quantity. Three points are critical here. First, there is no acknowledgement that it is precisely the same mechanisms that drive the generation of vulnerability, that simultaneously enable some households to improve their relative wealth and resilience. Secondly, existing options to reduce vulnerability, and more specifically increase adaptive capacity to a changing climate, are at best mechanisms by which marginalized households can cope with the existing context. They contain no transformative potential enabling long term security (Smucker et al., 2015). Finally, many existing interventions are more easily accessed by those households which are already relatively more resilient (Holler, 2014).

At this point it is simply not possible to tell whether households are responding in a causative manner to either broad climatic change or increasing climatic variability. Climate variability has been an aspect of livelihood vulnerability on Mt. Kilimanjaro for as long as agriculture has been practiced, and it appears to be getting somewhat more variable (Ahmed et al., 2011). However, this work argues that climate change has been jumped upon in order to make states address the continued uneven development of their economies and societies. It has been given far too much causal power as a source of vulnerability, which simply does not match up with the experience of household struggles to produce and reproduce livelihoods. The theory of climate change homogenizes rural societies as being broadly exposed to the same threats, which hides vast differences in their ability to cope with a wide range of risks. This, coupled with the rejection of meta-narratives of how development ought to occur and a retreat from state led development efforts, has limited the sense of what is possible with regard to societal change. It therefore over emphasizes environmental root causes of social differentiation and creates solutions that are not transformative, rather at best, they are coping strategies to maintain precarious livelihoods in the contemporary status quo.

In terms of this dissertation, therefore, climate change is something that may exacerbate future household vulnerability, but it is not the means by which vulnerability is generated. So the following chapters decreasingly focus on climatic issues per se, and identify the social drivers of vulnerability. Climate change has been uncritically received by most scholars as an unequivocally transformative, determining influence on rural livelihoods. To paraphrase Harvey (2013), it is easier for most to imagine the apocalyptic effects of climatic shift on rural livelihoods than it is to imagine how capitalist social relations could be transformed to lead to a more equitable, less vulnerable society.

This introductory chapter presents a synopsis of each paper, and then addresses four important points. First, it introduces the key theories that frame the dissertation and explains why they are necessary for understanding vulnerability (Pt.1). Second, it explains and justifies the structure of the dissertation and the importance of reading it dialectically (Pt.2). Third, it demonstrates how 
the four articles are linked to each other, both theoretically and in practice (Pt. 3). Finally, the study site is described as well as some important terminology that recurs throughout the dissertation (Pt. 4)

This dissertation is structured as four independent, yet closely related articles. These are bookended by an extensive introduction and conclusion that place the dissertation within the broad literature of studies of vulnerability.

\section{Chapter Two (Paper One)}

Paper one explores relational and dialectical methodologies, building on my reading during my doctoral studies. It justifies a dialectical methodology as an appropriate basis for understanding both vulnerability and livelihood construction. Separate from this discussion of dialectical methodology is an additional paper, not presented as part of this dissertation, which attempts to put the radical vulnerability, co-produced, into Harvey's (2009) 'six moments' that would demonstrate a change in the mode of production.

\section{Chapter Three (Paper Two)}

The second paper is based broadly within the natural hazards/livelihoods studies/vulnerability analysis nexus. It establishes the pressing contemporary need (as desired by the IPCC WGII) for indicators, methods, and understanding of the socioeconomic processes that to a large extent determine the vulnerability of households to environmental hazards. It combines data gathered from two surveys in 2007 and fieldwork in 2011. It frames the issue of vulnerability within the broader field of livelihoods studies and explores the usefulness of this framework. It explains, in detail, the long term trends and seasonal variability that cause vulnerability.

\section{Chapter Four (Paper Three)}

The third paper explores the issues in Paper 2 in a more relational manner. A special issue of Human Geography that reflected this approach to the coproduction of the environment was produced, and coedited by me. In the editorial to this special issue, the problem of understanding the production of livelihoods and land use change in the global, rural periphery was addressed as the complex interaction of a range of processes, driven ultimately by social relations. Paper three concludes with an exploration of the close relationship between different livelihood asset generating strategies, differentiated access to various resources and exposure to vulnerability, and the importance of using more relational methodologies to better understand livelihoods.

\section{Chapter Five (Paper Four)}

This dissertation begins with an exploration of dialectics as both a method and a framework for fieldwork. The fourth paper is written within this vein, and attempts to provide a dialectical understanding of how vulnerability is both understood and generated, and provides both theoretical and empirical examples. It demonstrates how a radical notion that places its roots strongly in the social relations that determine vulnerability enables climate change to be viewed in relation to other processes It also shows how vulnerability is not liable to be reduced without 
transformation in the production and reproduction of daily life. Paper four can be seen as contributing to emerging literatures around geographies of dispossession.

Considered together, the conclusions of the four papers provide an illustration of how household vulnerability to climate change must be understood within the broad political economy in which livelihoods are generated. It is precisely the same processes which are driving household vulnerability that constrain livelihood capital asset generating strategies. Most so called 'environmental sources of vulnerability' are not experienced equally, and their ultimate roots are found not in the 'natural' environment but in social relations. Household exposure and vulnerability to drought varied hugely over small distances, suggesting that environmental conditions do not affect all households equally. Vulnerabilities are experienced locally but are generated in socially scaled processes beyond household control.

The next section of the introduction explores the relationships between the papers.

\section{Themes in this Dissertation}

\subsection{Social Relations}

This dissertation draws heavily on theoretical explanations of socioeconomic change, alongside empirical data, in order to explain livelihood construction and the generation of vulnerability. The three most important theories are those of development, agrarian change and understanding adaptation to climate change. These three theoretical fields are linked in this dissertation by a focus on social relations, which I expand upon here.

The concept of social relations is inherently dialectical: transformation does not occur because objects or actors have specific causative powers, rather change occurs through the mediation, synthesis, resolution and negation of various factors as a consequence of their interactions. Although this dissertation is heavily influenced by historical materialism and political economy as frameworks for analysis, following Ollman $(1993 ; 2003)$ and Harvey $(1996 ; 2009 ; 2014)$ it is non-teleological, non-economically deterministic and does not conceive of capitalism in the case study area as determinant at all scales.

Therefore in this dissertation the concept of social relations refers to the differentiated positions of individuals, households and places within this global system. Change occurs when these relations are altered. In the case study location, examples of changing social relations include the coming of colonial power, the shift to growing crops that are sold on global commodity markets, the formation and dissolution of the local coffee producers union, and the relationship between the local population and the national government.

Each of the chapters approaches this critical issue of social relations in a different way. Chapter two goes into significant detail as to why a dialectical methodology is appropriate for exploring vulnerability, and why a relational approach is most appropriate. Chapter three shows the relationship between different capital asset generating strategies: how those households able to access secure work and off-farm income are much more secure than those who rely primarily on the natural environment to produce a livelihood. Those who are wealthy also tend to have greater access to social institutions, to sources of pertinent information and education and to 
other indicators of development. Chapter four expands on these findings, and shows how different forms of access to, and control of assets are closely related to each other and to differentiated experiences of livelihood vulnerability. Environmental sources of vulnerability are closely related to the types of assistance and access to resources that households can call upon. Chapter five is written in an explicitly relational manner, and shows how these highly unequal social relations drive vulnerability. The dissertation concludes with an attempt to link social relations in the case study area with multi-scalar processes that partially determine vulnerability on Mt. Kilimanjaro.

\subsection{Development}

Development can be understood as both immanent and intentional (Bebbington, 2004). Most approaches focus on the latter, including the livelihoods framework (Scoones, 2009). This false binary is misleading. Precisely the same processes driving development are also driving new vulnerabilities. This can be illustrated by a focus on agricultural transformation. Tanzanian and regional priorities involve increasing earnings from agriculture. In all places where agricultural transformation has occurred, a minority of people benefit from expanding agricultural opportunities, while agriculture simultaneously becomes unviable for many rural households as the primary livelihood strategy. There are no contemporary examples, in sub-Saharan Africa or beyond, where an increasing commercialization of agriculture has led to widespread improvements in development indicators and a reduction in vulnerability.

This dissertation understands development as inseparable from the uneven expansion of the capitalist mode of production, pace Wainwright (2008) development qua capitalism. There is immanence in this understanding of development, but also an acknowledgement that much intentional, planned development is a consequence of either marginalization of households within the capitalist mode of production, or their inability to engage and obtain the necessities for social reproduction. This dissertation also understands vulnerability as intimately related to the question of development; indeed it is the only means by which vulnerability can be permanently reduced.

\subsection{Agrarian Question}

The implications for Tanzania of the contemporary agrarian question are important for three major reasons. The majority of people still live in rural areas, and most of these are small-scale farmers. A transition is, however, occurring whereby more people are moving to urban areas and there is an increasing emphasis on commercial agriculture as the basis for expanded rural capital accumulation. Theories around the agrarian question are important for this dissertation because of the emphasis that is placed on rural differentiation. Peasant social formations transform, and may dissolve as capitalism becomes established. This is not a linear process, and peasantries may reform in new ways. But they are irrevocably transformed. The World Bank (2008) and the Tanzanian Government (2009) are actively trying to accelerate one side of this process through their emphasis on agricultural transformation. However, there is a willful ignorance about the consequences of this on households that are not capable of benefitting from this transformation. Perhaps more ridiculously, this "rising rural tide" is presumed to lead directly to overall vulnerability reduction in rural areas. Whether this occurs as capital 'trickles down' through rural areas, or because those who can't take advantage cope by moving to other 
(usually urban) locations is not stated. As a consequence of the increasing influence of capitalist relations of production, material transformations occur. Some farmers are able to expand, whilst others are unable to make agriculture profitable and must seek employment. Many who remain in rural areas will find their ability to access land or farm competitively highly reduced. This process is deagrarianization (Bryceson, 2002), and remains almost totally absent from the climate change literature. This is somewhat odd, as a small scale farmer, a commercial farmer, a rural laborer and someone with secure employment will all have very different vulnerabilities to climate change.

Another process related to changing rural areas is deproletarianization. This idea is most closely associated with Tom Brass (2000, 2011b). Its principal importance for this study is the demonstration that rural societies can be determined by capitalist relations of production, even if there are still aspects of the specific social formation that are 'pre-capitalist' or 'peasant'. In the case of the case study area, it is the inability of the local economy to produce secure employment that enables households to mediate the vagaries of climatic variability in their livelihood strategies. It is not meant to indicate that at one point in the past there was steady, waged employment, but rather it emphasizes the constrictions that global capitalist relations engender when scaled down to the household or village level.

Depastoralization is another process that has occurred on the margins of the case study area. It is beyond the scope of this dissertation, but has been demonstrated elsewhere (Smucker et al., 2015). Again, it is of value because it shows how global processes of socioeconomic change, determined by capitalist logics of production and reproduction, transform the local environment and available household strategies. Broadly, these processes can be understood as geographies of dispossession in the service of expanded reproduction of the capitalist mode of production. Whether understood as accumulation through dispossession or a new round of primitive accumulation, these processes are well documented (Harvey, 2003; Glassman, 2006; Fairhead et al., 2012).

\subsection{Adaptation to Climate Change.}

The question, therefore, is how to place climate change within this nexus. The concepts of resilience and adaptive capacity are not useful due to reliance on (metaphors of) society operating along ecological principles (Head, 2010; Cannon and Muller-Mahn, 2011). Much work has focused on the question of mainstreaming adaptation to climate change research, or 'climate-proofing' development. This dissertation shows that at the household level, neither development nor transformative adaptation is taking place at the household scale. It argues that for this to occur, development must occur first, then vulnerability reduction, increased resilience and new adaptive capacity can flow from this. Otherwise much work around climate change adaptation is simply redefining existing coping strategies of vulnerable households.

This dissertation argues that a radical conception of vulnerability is the most appropriate approach. Climate change can't be disentangled from existing processes, therefore mainstreaming it into development has become the desired goal. This returns us to the question of what type of development, and for whose benefit. This is the question that most climate change research skirts around, or simply rejects (Cannon and Muller-Mahn, 2011) 


\section{Method: The Dialectics of Climate and Development}

This is an attempt at a dialectical understanding of household vulnerability and the expected impacts of climate change. It therefore seeks to link empirical and theoretical understanding of vulnerability and change. The dialectic is therefore worth reinvestigating as a function for analysis. Chapter 2 justifies this position in detail, this introduction will spell out how it is utilized. This is important as it shapes both the content of the dissertation, explains why so much focus is given to social relations, and also why the dissertation is structured the way it is.

Smith (2009) argued that much of what became known as the postmodern turn in geography and the broader social sciences was not a rejection of dialectics per se, rather an overly structural, determining and closed dialectic most associated with Levi-Strauss. In terms of this research, the principal outcome is the rejection of broad based, state led development efforts as both a desired and achievable outcome. For many, the state has become the antithesis to the viability of rural households (Scott, 2009; Smucker et al., 2015)

This insight is important as it shows both the value and the limitations of a dialectical approach. This dissertation is in complete agreement with the notion that contemporary and historical conditions can't be extrapolated from the structural machinations that ultimately determine them. Rather, social activity should be understood as being co-produced through the dialectical interaction of the historical (and geographical) context of a place and the structures that determine social differentiation, and in this dissertation, vulnerability.

The conceptualization of dialectics used in this dissertation derives from Marx, through Harvey and Ollman. A dialectical approach underpins virtually all of Marx's work, but is not a rigid framework. Famously, it demonstrates how "Men make their own history, but not in circumstances of their own choosing" (Marx, 1852). This understanding of the interaction between historical and structural processes is the basis for this dissertation's structure. The Chagga on Kilimanjaro became a group, transformed their social formation and experience differentiated household vulnerability as a consequence of the interplay between these different forces.

Marx begins Capital Vol. 1 with a study of the commodity. Although the work is dedicated to unveiling the mechanisms of the capitalist mode of production, he begins with a very empirical description of the material conditions in which people live. Only later in the book does he begin to identify fetishized processes such as use value and exchange value, the labor theory of value, the tendency for the rate of profit to fall, class formation and the relationship between organic and variable capital costs. This dissertation attempts to dialectically explore vulnerability on Mt. Kilimanjaro in a similar way. Following a justification of dialectics, two major empirical case studies are presented. The last two chapters of the dissertation then abstract back into theory from these concrete findings, highlighting the structural processes driving vulnerability and exploring their implications for the study of adaptation to climate change.

Harvey (1996) explicitly engages with dialectics and like Ollman (1993) identifies an open dialectic shaped by a theory of internal relations, in which everything is to some extent is related to everything else, determined in the last instance by capitalist social relations. This is the position this dissertation takes. A dialectical approach enables a range of socioeconomic and 
environmental processes to be considered in relation to each other, whilst still acknowledging that they do not all flow from the moment of production in a capitalist system. This is especially true for social formations that remain on the margins of the global capitalist mode of production.

\section{Contribution to Theory}

The chapters that comprise the dissertation are closely related, all approaching the coproduction of vulnerability and livelihoods but from different perspectives. Theoretical and empirical linkages can be made across the chapters: presented dialectically, they are the synthesis of both the specific context and the abstract structures that together produce and determine differentiated household vulnerability. The challenge to environmentally deterministic narratives, and the naturalization of vulnerability that occurs as a consequence, is one example of a unifying theme that links the papers together.

This dissertation has moved beyond a narrow focus on climate change because of a deep reluctance to embrace an environmentally deterministic understanding of the driving forces of vulnerability, and more broadly rural differentiation and social transformation. These ideas are often latently present in much of the research surrounding resilience and adaptation to climate change, as well as narrow definitions of climatic vulnerability. The major consequence of these explanations is that they naturalize the causes of vulnerability, removing them from the social relations where the real determinants are found.

However, there is still the issue of incorporating real environmental limits into a study of vulnerability that is resolutely focused on the previously mentioned social relations. Rainfall, the area of land suitable for coffee planting, and changes in population are all factors that must not be ignored in shaping livelihood possibilities. Chapters three and four highlight examples of these very real environmental limits, however the conclusion (chapter six) makes the argument that these limits are disproportionately important precisely because the majority of households are unable to jump scales and take advantage of new opportunities.

This dissertation exemplifies this in both theory and practice. In theory, it draws upon the production of nature thesis (Smith and O'Keefe, 1980; Smith, 2009). The relationship between people and societies under capitalism is understood as one of production: very few land surfaces globally remain that are not used for some combination of use value and exchange value. At the scale of both the household and the region, the broad movement is increasing the profitability and surplus value generated from agricultural activities.

Although many livelihood activities do not operate under capitalist principles per se, they are fundamentally dominant and determinant over a range of scales in the case study area. This point is returned to in detail in the conclusion, for now it is sufficient to say that households are still impacted upon by relics of the previous pre-capitalist modes of production that existed on Kilimanjaro.

In practice, the dissertation places these environmental limits in relation to vulnerability and livelihoods in chapters three, four and five. Chapter three identifies the environmental 
constraints of the livelihood strategies used by households, as well as the broad geographic limits on expanding these. Chapter four demonstrates how access to the natural resources needed for social production and reproduction are closely related to household access to stable forms of off- farm income, or flows of remittances or income from outside the region.

In the last instance, production of the environment for social production and reproduction is determined by the relative class position of the livelihoods of individuals or households. Regardless of existing climatic variability or projected future change, opportunities to produce an agricultural surplus are dependent on access to land, water, farming inputs, credit or capital to invest, educational levels, political capital, access to secure employment elsewhere and remitted inflows of money, all of which are socially mediated and determined.

\section{Case Study Location}

The purpose of this section is to give a broad overview of the case study area, and some of the key terms that are used throughout the dissertation. The dissertation is composed of articles, which have space constraints .I have therefore used this section to explain several Kiswahili phrases that crop up throughout the dissertation. They can be understood as direct translations if no additional context is provided.

The research all took place in Kilimanjaro region, Tanzania. The fieldwork in 2011 was conducted in Rombo District, one of six districts in Kilimanjaro Region. Two villages were selected, Ubaa Kati and Ngoyoni, with different socioeconomic and environmental characteristics. Broad socioeconomic differences between the villages occurred because one of them , Ubaa Kati, was much closer to the administrative center of the District in Rombo Mkuu. This meant there were greater opportunities for waged work that was not subject to the vagaries of the environment. However, differentiation of vulnerability within the villages was much more pronounced than between them. Environmentally, the major difference was that Ngoyoni was further down the mountain and was therefore hotter and drier. Because the village boundaries broadly reflect the historical settlement patterns of independent clans, and then the Chagga on Mt. Kilimanjaro, they tend to be elongated rectangles running down the mountain. Historically, boundaries between different clans, and latterly villages, were based on ravines and streams that ran down the mountain.

Each village is comprised of several 'sub-villages', and attempts were made to survey in all of the sub-villages that made up Ubaa Kati and Ngoyoni. An administrative level of 'ward' exists between village and district level. Therefore the administrative hierarchy in the region closely correlated to these demarcations. Each sub-village has a council of elders, who would have significant decision making power at the hyper-local scale. At the village scale, there is also a council, which has power over the sub-villages. At all scales the power relationship is broadly top-down. Problem identification and prioritization of development needs might be identified at the village level, but it is delivered in the context of decisions made in Dodoma (the Tanzanian capital), or Moshi (the regional capital). 
The Chagga are the dominant population group in Kilimanjaro Region, especially in the rural areas, accounting for almost $90 \%$ of people (NBS, 2002). Formed from existing agriculturalists on the mountain, their group construction and identity occurred during the articulation with colonial rulers (Shivji, 2009). The 'typical' Chagga household residence also has a 'kihamba', or homegarden. This is where, historically, coffee and bananas, as well as other vegetables and sometimes livestock are kept. Increasingly, maize is also grown here. These plots of land tend to be smaller than two hectares, and the crops grown here are best suited to areas further up Mt. Kilimanjaro where rainfall is higher and temperatures are cooler. Households often have access to land further down the mountain, which is known as 'shamba' land. Maize, groundnuts and sunflowers are amongst the crops typically grown here. Fodder is also produced for animals, which are kept at the kihamba in 'zero-grazing' conditions. This dissertation also refers to 'kibarua' labor at points, which refers to casualized, non-permanent, often seasonal work. A major example of this is working on larger or more productive coffee producing households at harvest time, or on some of the larger coffee plantations that exist on the mountain.

\section{Dissertation structure and summary}

This dissertation will proceed as follows. The next chapter is a theoretical framing of a dialectical methodology in the context of climate change (Chapter 2), followed by two largely empirical presentations of fieldwork findings, data and case study specific knowledge relating to vulnerability and livelihoods (Chapter 3 and Chapter 4). The final substantial chapter (Chapter 5) is an attempt to present dialectically the theories and findings that have been introduced and explored previously. Chapter 6 concludes the dissertation by integrating the findings into broader literatures of agrarian change and transformation, and identifies the fundamental importance of placing social relations centrally in the study of climate change, and outlines future directions that I would like to take this research. 


\title{
Chapter 2: Climate Change and People Change: Dancing the Dialectic.
}

\begin{abstract}
.
The fifth assessment report of the Intergovernmental Panel on Climate Change (IPCC, 2014) says there is accelerated climate change because of enhanced release of greenhouse gases. It is projected for East Africa that temperatures will increase but there is no agreement on the how precipitation will change. There is acceptance that the weather system will throw up more frequent extreme conditions, including drought. The question of how we can begin to understand how this will materialize in people's livelihood strategies and adaptive choices is critical. This paper identifies theoretical problems in the dominant discourses surrounding human-environment relations and climate change, and argues for a dialectical approach to the subject. It concludes with a brief vignette of what a dialectical study of climate change ought to focus on.
\end{abstract}

Change, transition, movement, articulation.

Tanzania is part of a global capitalist system. It has a disarticulated pre-capitalist mode of production (Shivji, 2009) in which a differentiated peasantry is subject to extra-economic force that is characterized by Harvey (2003), following Luxemburg (1913), as accumulation by dispossession. The differentiation of the peasantry is essentially twofold namely those who have access to a second farm (50 per cent) and those who have significant off-farm employment opportunities (50 per cent). For more detailed discussion see the other papers in this dissertation. This essential disarticulation occurs because wage levels are "bachelor wages" (Shivji, 2009), i.e. paying only for the subsistence cost of the labor not sufficient to cover the cost of the social reproduction of labor. Peasant labor super-exploits itself in multiple occupations and by cutting down on necessary consumption (Moyo and Yeros, 2007). As a consequence, there is no accumulation of surplus value in the process of agricultural production, no expanded reproduction of capital, so there is little industrial investment, which in turn, would modernize agriculture. Dispossession produces disarticulation. That is about to change as the state seeks multinational partners for large scale mono-cropping. Only 10 per cent of land is under permanent cultivation (Coulson, 2013) so the changes in the mode and relations of production will be enormous. 


\section{How can the climate change and people collision be analyzed?}

Observing the world, no matter what part or aspect, involves categorization and prioritization of certain factors. On a philosophical level, it is necessary to ask what role these factors play in determining the direction of change, and what is the relationship between the parts. The conventional approach is to study each part in depth, in order to explore its role as a driving force in relation to other factors, to isolate one aspect and try and understand it as if other forces were not acting it on continuously. This is the entry point at which a dialectical conception of the world offers a clear alternative.

Ollman (1998) uses the analogy of Humpty Dumpty - you can understand and know all the individual pieces of the broken eggshell, but without a sense of how they relate to each other it is nigh on impossible to accurately describe the 'whole' they should resemble when reconstituted. Dialectics, potentially, offers an outline of the world that can consequently inform and shape the research methodologies that are needed to explore change at a local scale. It also provides a means by which to link processes occurring on a range of scales.

Perhaps the most successful geographic work to be rooted in a dialectical methodology is that of Uneven Development by Neil Smith (2009). Identifying the specific means by which society, within the capitalist mode of production, produces both nature and space required a dialectical form of argument that, following Marx, identified and shone light on the contradictions inherent in this mode of production. In particular, the process by which capitalism expands is through the contradictory, yet simultaneous, processes of differentiation and equalization. These terms can in themselves be understood dialectically and provide a much more coherent base on which to structure notions of change than any positivist position has provided.

The dialectical method was central to the modus operandi of Marx. It is unsurprising that the most significant engagement with, and utilization of, dialectics within geography has come from Marxist geographers. David Harvey is arguably the most prominent theoretician in the historicalgeographical materialist paradigm. His specific reading of Marx and Marxist literature, with particular regard given to the dialectical methodology, has enabled a range of new theoretical conceptualizations to be developed. Prominent amongst these are the Spatio-temporal Fix, Accumulation through Dispossession and Uneven Geographical Development (Harvey 1982, $2003,2006)$. These processes have been demonstrated to exist within, and on the periphery of, the capitalist system. This, at the very least, shows the potential to utilize dialectics as a methodology. There is, however, no single dialectic methodology.

Castree (1996) identifies a range of divergent and opposing strands within research that has had a dialectical basis. In particular, he traces a path through the multitude of different conceptions of dialectics David Harvey has made in his work. He identifies Harvey's dialectic as not being influenced by two significant strands of post-Marx Marxism - that of Althusserian 
structuralism and that of analytical dialectics. Rather, the importance of Hegel, and particularly Marx are emphasized. This particular reading means that the criticisms leveled at structuralism and analytical Marxism are not likely to weaken Harvey's style of dialectic significantly (Castree, 1996). Rather, Harvey's dialectic is predominantly 'systemic/epistemological' (Castree, 1996, p.343). They not only explain and diagnose the issues they are seeking to explore, but also place dialectics as the most appropriate means for knowing about the world. Harvey should be judged on this in his in-depth, place based research rather than the internal logical consistency of the dialectic as a method

Harvey's most explicit laying out of a dialectical methodology is contained in his 2009 article. Harvey expands on a footnote in Marx to reveal the forces that explain social change. This article is fundamentally important because it enables a framework to be developed in which relationships between different processes are taken as a given, and exploration can take place within the whole of societal relations. He identifies six moments in which change can occur that can fundamentally alter how other relations manifest. By Harvey's (2009) formulation, change will have really occurred until it is registered at each of the six moments. Focusing just on one moment, as many studies do, will miss change in many ecological problems, how they are problematized, and how they should be related to the dominant form of social organization (capitalism) that exists. He identifies technology, the relation to nature, forms of production, social relations, social reproduction and mental conceptions of the world. The key point is that real change has not occurred, and a transition to capitalism is therefore not complete until change registers in each of these moments. It therefore provides a non-deterministic framework that enables socioeconomic, cultural and environmental issues to be considered simultaneously and in relation to each other. The final part of this paper returns to this framework in order to highlight its relevancy.

\section{Operationalizing the Dialectic.}

In the livelihoods approach (Scoones, 1998), a method that has come to dominate much fieldwork in developing countries, the natural capital of a household is the natural resources that it can command in order to achieve social reproduction and production. In the first instance, it is the capital most impacted upon by climate change. Disregarding questions about what is 'natural', this can be seen to be of huge importance to those societies who still largely rely on small scale, often subsistence agriculture.

It is apparent that this concept could be considered within Harvey's framework, but it is not quite as simple as saying the relation to nature equates to the category of natural capital in the framework. Basing the framework in the production of nature, it is possible to begin to explore the relationships between these different moments of articulation. For example, the link between social relations and the relation to nature is a starting point for investigating how access to resources is decided, enforced and limited. This can go further to explore what is to be exploited, who decides, and on whose terms these decisions are made. The relation between the relation to nature and the reproduction of daily life must be considered. Or, looked at 
another way, how much of what is grown on the farm is used for household subsistence? How much of household subsistence and reproduction relies on producing from nature? What other inputs are required for household production? When these factors change, how does the relationship to nature change? For example, if there is more reliance on off farm income/cash crops then how is biodiversity affected? The relational questions go on and on.

Why should dialectics be preferred as a method as opposed to other conceptualizations to frame research? Two issues arise - the first concerns the appropriateness of using the 'scientific method' as the basis for social science research, and specifically the utilization of systems theory as a means to understand complex, coupled, social-natural relations, and the limits to positivism. The second is the necessity of a 'dialectical dance'.

\section{The Limits of Positivism}

Positivist approaches are derived from theories developed in the natural sciences. The underlying principle is that an objective reality, separated from the researcher, exists and can be understood through suitable exploratory methods (Laws et al., 2003). It is axiomatic within the social sciences (bar economics and psychology) that the scientific method cannot be extrapolated untouched into the realm of social theory and research. The conscious subjectivities and unpredictable aspects of society have meant the idea of a unifying theory, mathematically based, does not exist to explain human behavior. However, this does not mean that positivist methodologies are absent from social science; indeed, much research around the subjects of development, adaptation to climate change and livelihoods in the developing world is still structured essentially within a positivist research paradigm.

The purpose of this dissertation research in Kilimanjaro Region is to understand vulnerability. A large study was recently undertaken on Mt. Kilimanjaro to observe vulnerability (Christiaensen and Sarris 2007); household data was collected, and analyzed through income generation from crops (whether they grow coffee or not) and explored the benefits that insurance could provide for the farmers. The underlying question was whether insurance, an adaptation strategy, would make them more likely to invest time and effort in growing for export.

The remit of the study was somewhat circumscribed the methodology, but here vulnerability was defined simply as the likelihood of being poorer at some point in the future. It is nothing more than a tautology to say people are vulnerable because they are poor, and they are poor because they are vulnerable. It is also indicative of the limits of what can be achieved within a positivist framework-vulnerability, a highly debated and contested term, has now been assigned a universal 'scientific' definition. This a priori assumption means the legitimacy of this research depends on the notion of vulnerability being as uncontested as that of 'gravity' or 'soil'. If it doesn't hold up, then the tenuous strands linking the research together will certainly begin to unravel.

Quantitative methods have long being preferred in positivist research, as they contain the ability to generalize and extrapolate results from the studied sample to the wider population. National 
and international institutions often regard these quantitative methods as more reliable and worthy of response (White, 2002). The focus on quantifiable data may consequentially negate the exploration of factors that are harder to quantify. Chambers (1994) argued that this focus restricts what is defined as reality and prohibits plural explanations of what is important.

One means by which positivist frameworks have dealt with these critiques is to incorporate qualitative research methods. The strengths of these are that they enable a plural range of views to be considered and may even contradict findings generated by other qualitative methodologies (Sarantakos, 2005). Grounded in an acute awareness of the strengths and limitations of each field of inquiry, the utilization of both quantitative and qualitative methods can potentially provide a basis for affirmation, triangulation and enhanced reliability of research findings. Poorly chosen, overt or unintentional application of either quantitative or qualitative methods is argued to lead to low quality research as a consequence (White, 2002). Consequentially, the 'cutting edge' of high quality research in this paradigm is that which can incorporate a range of methods, within a positivist methodology.

A framework designed to explore these process is the notion of double exposure. It is structured in a way that gives prominence to the interaction of multiple processes, and the consequences that result. It does this through the identification of three different pathways through which 'double exposure' can manifest. These are outcome, context and feedback (Leichenko and O'Brien, 2008). What is important to note here is the design of the framework, which is rooted in systems theory, perhaps the most successful attempt by people researching in the positivist paradigm to model complexity. The growth of systems theory has led to the claim that because scientists are now engaging with complexity through these means, dialectics is redundant which Levins rejects (Levins, 1998).

Systems theory and dialectics have a starting point that is of fundamental importance for anyone studying complex human-environment relations - the complexity and web of interrelations are taken as the starting point. In systems theory, relationships and processes are understood as feedback loops and outcomes (Levins, 1998). The concern with process is something that is central to both a dialectical and systems theory approach. The reason why systems theory is reductionist is that it cannot account for historical contingency and cannot truly deal with the concept of interpenetration as opposed to just interaction. The mathematical nature of the modeling that is the crux of systems theory also privileges the collection of quantitative data as the basis for observations and prediction - here the same limitations that apply to all quantitative data collection in social science apply.

\section{The Necessary Dialectic Dance}

Social constructionist epistemologies assert that an external reality, whilst existing, cannot be understood objectively by researchers (Sarantakos, 2005). This is the antithesis to the orthodox positivist thesis. Knowledge is not gained solely through sensory observation but mediated and created by powerful institutions and interests, and the interaction of society with the natural, physical world is what generates meaning (Sarantakos, 2005). 
The reasons why dialectical investigations have been dismissed by the 'academy' in general are multi-faceted, and often have more to do with perceived implications of what dialectics represent than what they actually purport to do. The role of the Cold War, Stalin's reductionist conception of dialectical materialism, the move away from Marxism as a consequence of the horrors of the Gulag have all enabled dialectics to be dismissed as the intellectual basis of a tried and failed system of social organization.

The search for the essential basis of social change has also been a reason why dialectics has not being as widely utilized as it could have been. Dialectics, as previously shown, is most often associated with Marxist modes of analysis; consequentially, and understandably, the motive force of societal change has been identified as the mode and relations of production. Harvey's work (2009) plays such an important role - it bases itself solely in Marx's methodology and yet comes to the conclusion that the mode of production cannot be held to be determinant as the focus and locus of change - change must be registered in a range of moments for it to be conceived of as real. Ultimately, the strength of dialectics as a method of analysis can be summarized by recourse to Marx; his utilization of this methodology was the first time in which capitalism was ever accurately described as an abstract system (Castree, 1996; Harvey, 1996; Ollman, 2003).

To conclude this discussion we return to Harvey (2009). Specifically, a brief illustration from my fieldwork, of production, social reproduction and environmental change, is presented dialectically.

In the Kilimanjaro region, as elsewhere, production is dominated by small holder agriculture. All coffee goes to market, through an auction in Moshi. Control of the quality, and therefore local price, deteriorated as the Union lost control of the supply chain and a series of middle buyers sought to harvest by farm, encouraging farmers to sell early at lower quality. Since the 1970s, the price has substantially declined, particularly if inflation is factored in. But the coffee market is essentially global, dominated by Brazil and with Vietnam now a significant competitor against East African production. Within the Chagga households, coffee as the cash crop is largely under male control.

The critical issue is that the Chagga gardens are small scale production, centered on a single household. Because of extended family relationships, the simplest definition of household is people who eat from the same pot. The strategy of such households is one of risk minimizing rather than product maximization. Risk minimizing is essentially one based on husbanding existing resources rather trying produce a new nature. Such a strategy is successful precisely because it is a social model of production, with risks and responsibilities within and to the community and obligations beyond the individual household. Because they are risk averse, with little savings, they are reluctant to innovate in case the innovations jeopardize production and reproduction opportunities.

With the exception of bananas, little other agricultural produce contributed to household income. Coffee (15 per cent) bananas (28 per cent) remittances from working away (17 per cent) and local off-farm income opportunities (26 per cent) made up the average household income suggesting that off-farm opportunity matched on-farm income in contribution (Authors fieldwork, 206 household survey in Kilimanjaro region). 
Based upon observations from the field, the size of garden appeared to be correlated with external income and with educational level. Those farming larger plots, especially further up the mountain tended t speak English well, an indicator of secondary education, and have had access to financial capital enabling them to expand cultivation (Author's field notes). Educational level correlated with access to formal agricultural advice services: the more educated a household head, the more likely that they had contact with extension officers and knowledge of current ideas of best practice. Access to agricultural advice services correlated with willingness to innovate on the farm.

In short, a relatively privileged elite, who are simultaneously amongst the least vulnerable of households, does exist. This differentiation is based significantly on both income and access to education.

Just over 50 per cent of the Chagga garden farmers have access to shambas. Little production was for sale from the shambas. There had been a shift from lower value carbohydrates, especially sorghum, to improved drought resistant maize but that, when successful, was largely for home consumption. Small protein crops, such as cowpeas, were grown but again for home consumption. The shambas looked poorly maintained and served as an agricultural safety net for some, rather than a production opportunity under peasant production systems (Authors fieldwork, 206 household survey in Kilimanjaro region).

Under colonial rule, German and later British authorities, imposed essentially a poll or hut tax (Coulson, 2014). This was one means by which classically understood peasant social formations are transformed and articulate with the capitalist mode of production. Other coercive methods included the use of forced labor (Potts, 2006). The broad effect was a necessity for households to engage in the pursuit of exchange value for the sake of social reproduction. No Independent Tanzanian government could go down that route. De facto, however, the same thing has happened after independence because social reproduction activities became formal exchange values rather than use values. School fee expenditure falls twice yearly and health expenditure is burdensome across June and July, not because of an increase in disease burden, but because of cash flow problems before harvest. Essentially, the transition from peasantry to paid labor/product is because the government will not pick up costs associated with social reproduction. While Chagga households complain of these costs, government does not have revenues from a subsistence agricultural economy to underpin social reproduction. The cost of social reproduction can only be bought by government if it uses state ownership to move from communal, customary law to individual, statutory law. In short, privatization. This is a debate which resonates in and beyond Tanzania. (Manji, 2006; Shivji, 2006; Shivji, 2009).

The Chagga cannot go up the mountain for the forest line marks the start of the international land use of trekking, costing each tourist US\$ 50 per day just for being there. In addition this area is a National Park although, during fieldwork, there were reports of over 5,000 squatters evicted from the park. The Chagga cannot go down the mountain because, beyond the existing shambas, the government does not currently contemplate any land redistribution. In short, they are squeezed between two parallel restrictions of nature.

In the gardens, the two constraints of nature are altitude and aspect. In general, the richer and most productive farmers sit midway up the profiles facing southeast towards the monsoon bearing rains. This seems most advantageous in the long rains as the short rains have less directionality. Individual households possess their gardens as permanent usufruct under 
traditional, communal law. Tree cover provides for substantial nutrient recycling. Zero grazing on the garden, especially of cows, gives additional inputs.

In contrast, accessing nature on the shambas is increasingly contested. As herders, the Maasai have disappeared from the region. Their original disappearance was generated by the Ujaama policy of turning pastoral area into arid and semiarid agriculture. Originally, the distribution of land, all of it owned by the government, was on the basis of need. That was, however, 50 years ago. The same families have the same shamba arguing, at local level, just like their gardens, they possess them under traditional, communal law. There is little surplus vegetation or animal residue to replenish nutrients and the sandy nature of the soil means water retention is very poor giving field crops a sense of permanent drought. In these conditions perhaps maize was not the most appropriate crop for the shamba.

What has to be admired is the originality of the Chagga three dimensional, multistory, multipurpose agroforestry system, one of the most productive in Africa. What has disappeared, however, is the reciprocal exchange entitlements with the Maasai -, tree products for meat and milk. Nature produced in one social formation can die in another.

\section{Conclusion}

This paper has identified dialectical methodology as being critical to understanding the wide range of forces that shape livelihoods, and the importance of the capitalist mode of production in shaping how people reproduce their livelihoods, their environments and their ideas about the world. Somewhat removed from the orthodoxy of adaptation to climate change and vulnerability studies, it is argued here that there is no more suitable epistemological and methodological framing of the study of socioeconomic and environmental change.

Dialectics is an inherently relational framework, but it is also directional. This is an important difference. The direction is not predetermined or predestined, and a dialectical methodology ought not to be teleological if it is to be of use. An appropriate analogy with physics would be the difference between speed and velocity: social relations, like speed involve movement.

Dialectics, like velocity, involve movement in a particular direction. In the final instance, the relations of production and social reproduction under a capitalist mode of production define a range of opportunities or constraints available to households in the Kilimanjaro Region of Tanzania.

This paper has not explored how mental conceptions of the world are changed through transforming social relations. Wisner (2015) has identified how farmers reproduce top-down, unidirectional ideas of how climate change will affect their livelihoods, even though the material evidence of their existence from this research suggests a much more dynamic situation. This is the direction that genuinely radical conceptualizations of political economy, political ecology, vulnerability and adaptation to climate change should be moving. 


\title{
Chapter 3: Vulnerability and Capitals Generation in Tanzania: a case study of Kilimanjaro District
}

\author{
Abstract \\ This paper explores how livelihoods and vulnerability are constructed on Mt. Kilimanjaro, \\ Tanzania. The methodological framework for the research is the livelihoods approach of \\ Scoones (1998), and expanded upon by DfID (1999, 2000). The paper finds that both \\ vulnerability and capital assets are differentiated geographically, and that those who are most \\ vulnerable tend to rely to a greater extent on sources of natural capital. Social capital, which \\ was historically a strong force for both reducing vulnerability and enabling a degree of \\ redistribution, is weakening as the importance of off-farm sources of income, including \\ remittances, becomes more significant. Limited geographically, sustainable reproduction of \\ Chagga society, especially in the context of already existing climatic variability and potential \\ future climatic change, requires a level of support for rural households that acknowledges the \\ inequities and increased vulnerability caused by greater integration and exposure to global \\ market forces, and the important role played by households in maintaining high levels of \\ biodiversity in the case study location.
}

\section{Introduction}

This article presents the results of fieldwork conducted in Kilimanjaro Region, Tanzania exploring the related concepts of vulnerability and livelihoods. This article addresses the context in which capitals are generated on Mt. Kilimanjaro. It will be necessary to explore the factors that cause and enhance vulnerability, especially with regard to climatic change and variability, in the region. It is based on research carried out in Moshi Rural and Rombo Districts of Kilimanjaro Region. Figure 3.2 shows the research location.

\section{Literature Review}

This paper uses the livelihoods approach to explore the context of, and relationship between, vulnerability and livelihoods on Mt. Kilimanjaro, Tanzania. This approach is taken because sources of vulnerability and the means by which livelihoods are constructed are explicitly linked in the framework. It draws on a definition of vulnerability drawn from the natural hazards paradigm, emphasizing the range of environmental and social sources. These are placed in relation to the livelihoods approach as outlined by Scoones (1998). Figure 3.1 shows the livelihoods framework. 
Figure 3.1: Livelihoods framework

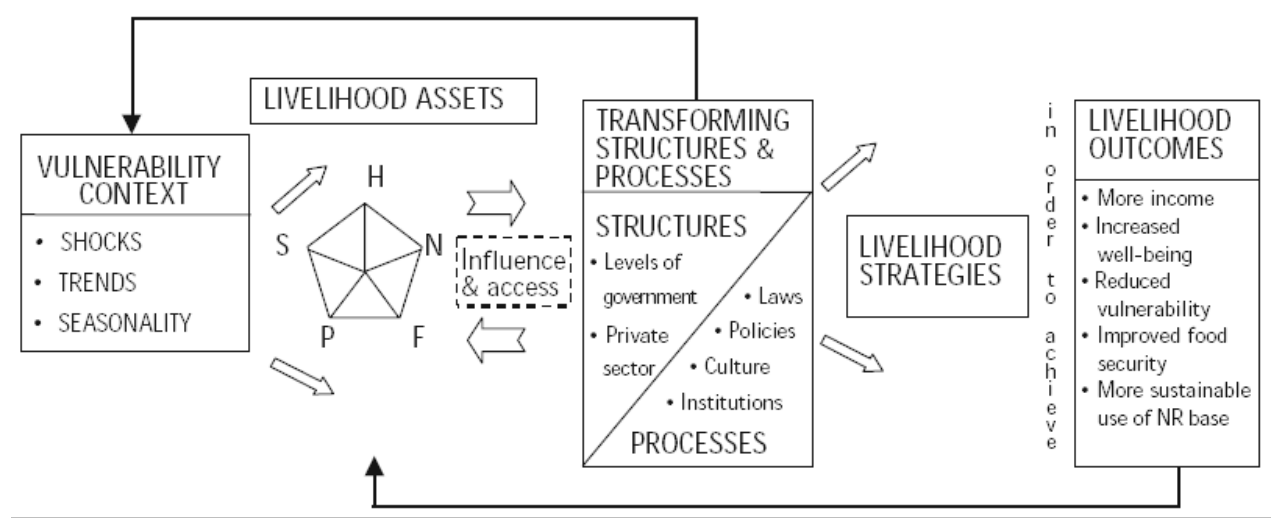

(Scoones, 1998)

The livelihoods framework defines vulnerability as being composed of shocks, trends and seasonality. Shocks that increase the vulnerability of affected populations are short term, rapid onset events (DFID, 2000). In Kilimanjaro Region, these will potentially include drought, flooding, hunger and food insecurity. Long term trends in natural and socio-economic processes can alter the vulnerability of societies. In the context of this research these may include enhanced climatic change, climatic variability, increased impacts of EI Nino Southern Oscillation events, and a decline in prices received for commodities such as coffee. Variation in availability of assets, entitlements, opportunities and requirements throughout the year corresponds with differentiation of vulnerability on a household and collective level (DFID, 1999). Most of the information regarding seasonal vulnerability in the case study location was obtained through the production of a seasonality calendar, which formed part of the supplementary survey. The seasonality calendar enabled exploration of the pressures on livelihoods and how this varies throughout the year.

The framework in which the analysis of vulnerability is located is that of the livelihoods approach. This paper explores the differentiation of vulnerability through assessing households' capacity to respond and adapt to actual and predicted hazards that constrain livelihood construction option (Scoones, 1998; DFID, 2000; Wisner et al., 2004). Identifying the range of capital assets produced and commanded by households enables association between particular livelihood strategies and variation in exposure to natural and socio-economic hazards.

\section{Research Methods}

The principal framework and methodology is the livelihoods approach. This framework enables a range of quantitative and qualitative research methods to be incorporated. Although a dichotomy has been thought to exist between the application of quantitative and qualitative methodologies, recent research, particularly with regard to livelihood studies, has emphasized the possibility and benefits of combining a range of approaches. However, it is imperative to remain aware of the limitations and appropriate usage of each particular research method (DFID, 1999; Ellis, 1998; Ellis and Mdoe, 2004; Carvalho, 1997). 
The project adopted a mixed methods approach in order to both collect and analyze a range of quantitative and qualitative data. Seven different research methods formed the basis of the project. These methods, and the information obtained from them, are shown in Table 3.1.

Table 3.1: Research Methods

\begin{tabular}{ll}
\hline Method & Information Obtained \\
\hline $\begin{array}{l}\text { Primary } \\
\text { Survey }\end{array}$ & $\begin{array}{l}\text { Quantitative data regarding personal information, agricultural methods, income and } \\
\text { expenditure, response to drought, perceptions of climate change and livelihood } \\
\text { construction -1089 households were surveyed }\end{array}$ \\
$\begin{array}{l}\text { Secondary } \\
\text { Survey }\end{array}$ & $\begin{array}{l}\text { Quantitative and qualitative data regarding access to institutions and social networks, } \\
\text { sources of assistance in difficult times, importance of coffee in capital generation, } \\
\text { building type and seasonality calendar -89 households were surveyed }\end{array}$ \\
\hline $\begin{array}{l}\text { Key } \\
\text { Informant } \\
\text { Interviews }\end{array}$ & $\begin{array}{l}\text { Provided the context for findings obtained in fieldwork; provided specific statistics that } \\
\text { could not be obtained anywhere else }\end{array}$ \\
$\begin{array}{l}\text { Physical } \\
\text { Asset } \\
\text { Checklist }\end{array}$ & $\begin{array}{l}\text { Provided an indication of levels of physical capital; later triangulated with findings from } \\
\text { secondary survey }\end{array}$ \\
\hline $\begin{array}{l}\text { Structured } \\
\text { Observation }\end{array}$ & $\begin{array}{l}\text { Provided the researcher with an indication of how livelihoods were constructed in the } \\
\text { case study location, and how this varied between profiles and altitude }\end{array}$ \\
\hline $\begin{array}{l}\text { Transect } \\
\text { Walks }\end{array}$ & $\begin{array}{l}\text { Provided the researcher with an indication of how livelihoods were constructed in the } \\
\text { case study location, and how this varied }\end{array}$ \\
\hline $\begin{array}{l}\text { Secondary } \\
\text { Data }\end{array}$ & \begin{tabular}{l} 
Provides the context in which the primary data is collected \\
\hline
\end{tabular} \\
\hline
\end{tabular}

\section{Research location}

The research took place in Kilimanjaro Region, Tanzania. The household surveys were completed in two districts of Kilimanjaro region, Moshi Rural and Rombo. A small number of surveys were also carried out in Old Moshi, and these are referred to occasionally in this paper. A transect was surveyed at each location, beginning very close to the National Park boundary and ending in the foothills of the mountain. These locations are shown in Figure 3.3. The secondary surveys and transect walks took place in the same areas. Upon returning to Rombo District in 2011 for further fieldwork, conversations were held with 35 farming households in 
order to explore whether there had been any significant changes in the region that would invalidate or question the findings from the 2007 study.

Figure 3.2 Location of study site

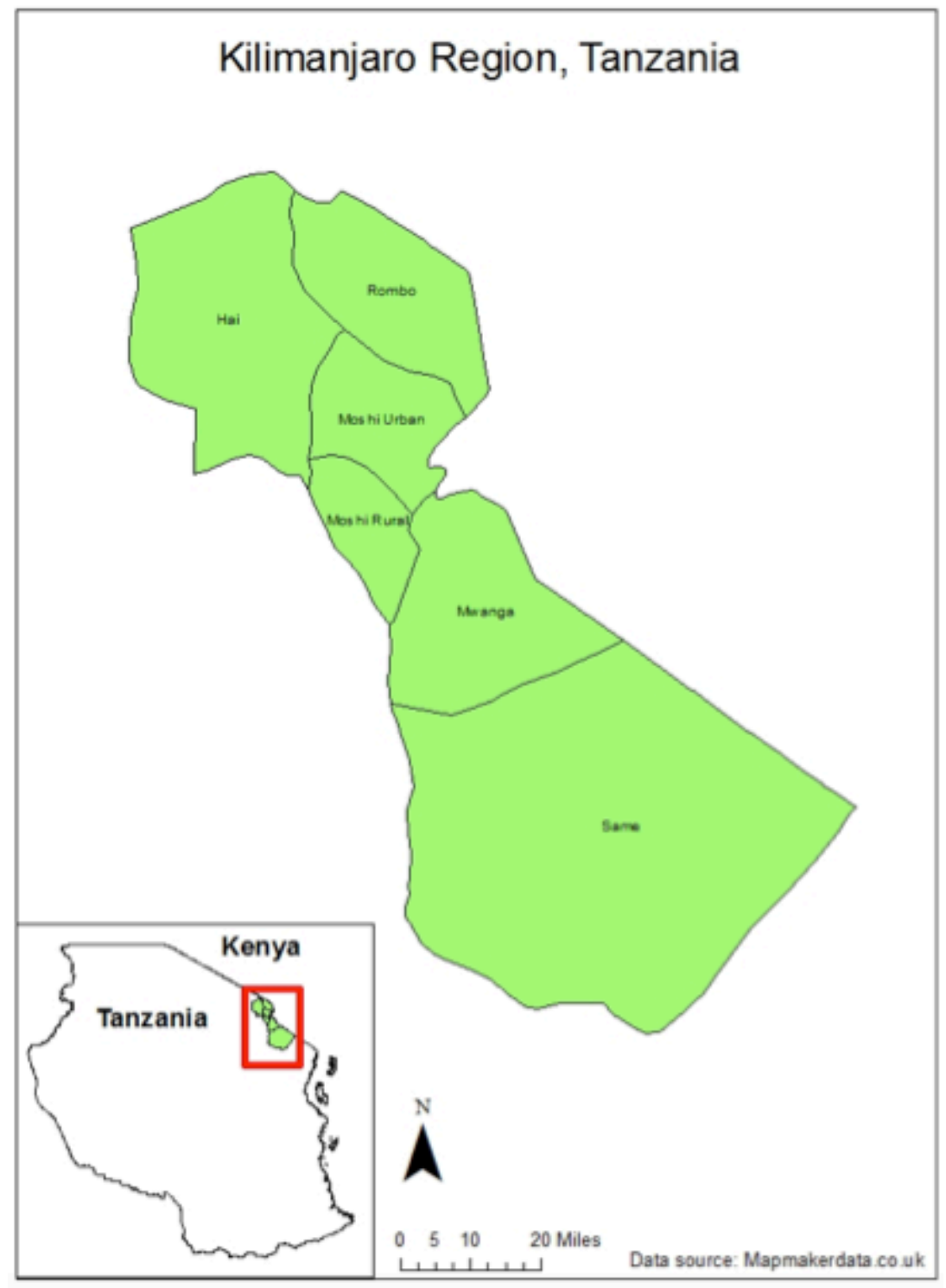

Source: Author

The study was based around collection of approximately eleven hundred household surveys, collected along two transects on Mt. Kilimanjaro. These are shown in Figure 3.3 (the yellow lines). 
Figure 3.3: Transect Locations

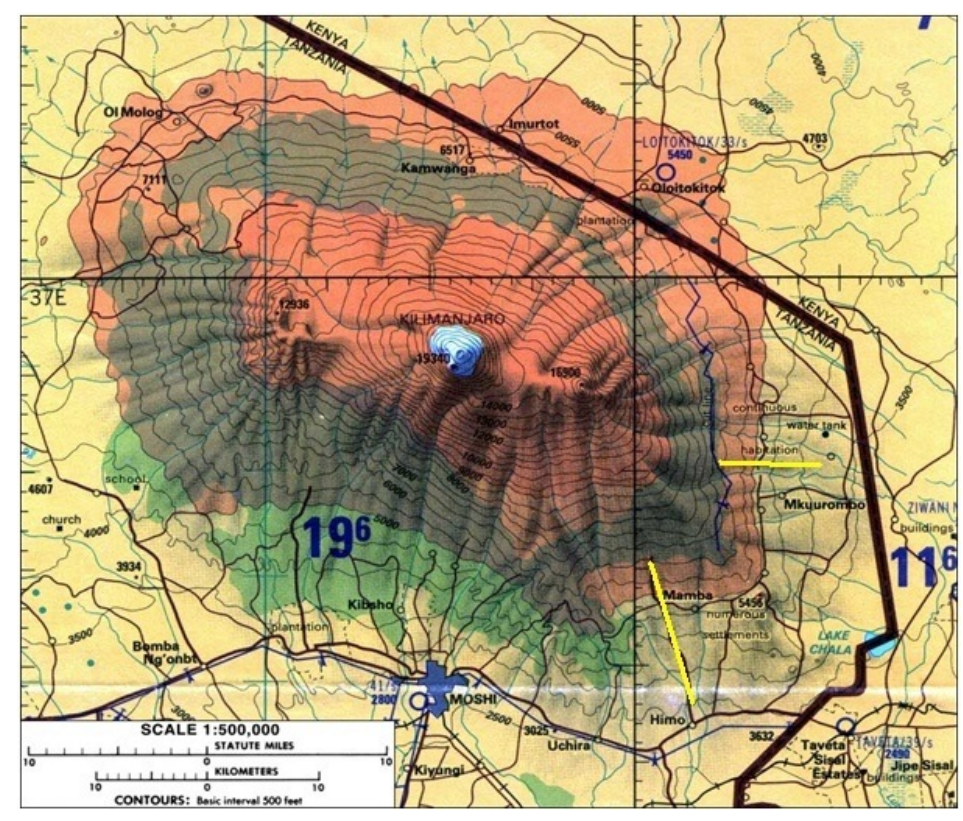

Source: Adapted from Andalkar 2003 


\section{Analysis}

Following Adger (1999), vulnerability can be differentiated between collective and household levels. As the livelihoods approach focuses on household level capital generation, the focus on vulnerability will be on the same scale. This differentiation is related to, but not commensurate with, the distinction made by Wisner et al. (2004) with regard to root causes, dynamic pressures and unsafe conditions in their PAR model of vulnerability. The possibility of intra-household vulnerability is noted, but is not within the scope of this research (Wisner et al., 2004).

Drought is probably the most serious natural hazard that affects the livelihoods of people in Kilimanjaro Region. Seventy two per cent of respondents stated that drought had a great impact on their agricultural productivity; fifty nine per cent claimed that it had a great impact on their health and thirty two per cent perceived it as having a great impact on availability of energy sources. When asked to identify the last time a drought affected the area they reside in, a wide variation of years was recorded, indicating that the effects can be very localized; following Wijkman and Timberlake (1984), drought may simply be an instance of not been able to access enough water to sustain a particular livelihood option. However, some particularly large scale droughts were identified. Table 3.2 shows these findings.

Table 3.2 Last Drought Experienced in Kilimanjaro Region

\begin{tabular}{ccc}
\hline Year of Drought & $\begin{array}{c}\text { Number of Respondents } \\
\text { identifying it as last drought }\end{array}$ & $\begin{array}{c}\text { \% of Respondents identifying it as } \\
\text { last drought }\end{array}$ \\
\hline 1974 & 19 & 2 \\
1984 & 151 & 15 \\
1994 & 34 & 3 \\
2003 & 51 & 5 \\
2004 & 103 & 10 \\
2005 & 296 & 29 \\
2006 & 47 & 5 \\
\hline
\end{tabular}

(Primary Survey Data)

As the survey was designed to identify the last time a drought affected an area it was not possible to ascertain the relative seriousness of each drought year. The phrasing of the question also explains why a majority of responses are since the turn of the millennium. Twenty one per cent of respondents stated that they had never been affected by drought; this suggests that access to different water sources can compensate for a reduction in rainfall in a given year, and also supports the contestation that the effects of drought can be extremely localized. A 
pattern also emerges in which major droughts appear to recur on a decadal basis; 1974, 1984, 1994 and 2004-5 account for fifty nine per cent of responses.

A drought in this research was considered serious when it impacted significantly on production and consumption of food. Fifty one per cent of respondents claimed that very little was harvested during a drought year, and twenty two per cent stated that nothing was harvested at all. Although reduced, or late-onset of, seasonal rains were stated as a drought indicator by sixty seven per cent of participants, the impacts were perceived primarily as a reduction in available food. Eighty two per cent of people regarded food shortages as the main impact of drought, whereas only four per cent considered water shortage the primary effect. Sixty eight per cent of people said that the effects of drought were an increased requirement in agricultural labor, probably because of attempts to produce a different crop.

Increased variability of precipitation may be a more significant issue affecting adaptation of household livelihood strategies in the region than absolute change in either levels of precipitation or temperature. Figure 3.4 and 3.5, which detail the variability of rainfall, during the long rains, in Rombo District highlands and lowlands, Kilimanjaro Region, from 1995-2006, indicate the challenge of agricultural production in an uncertain climate.

Figure 3.4:

Rainfall Variability in Rombo District Highlands 1995-2006

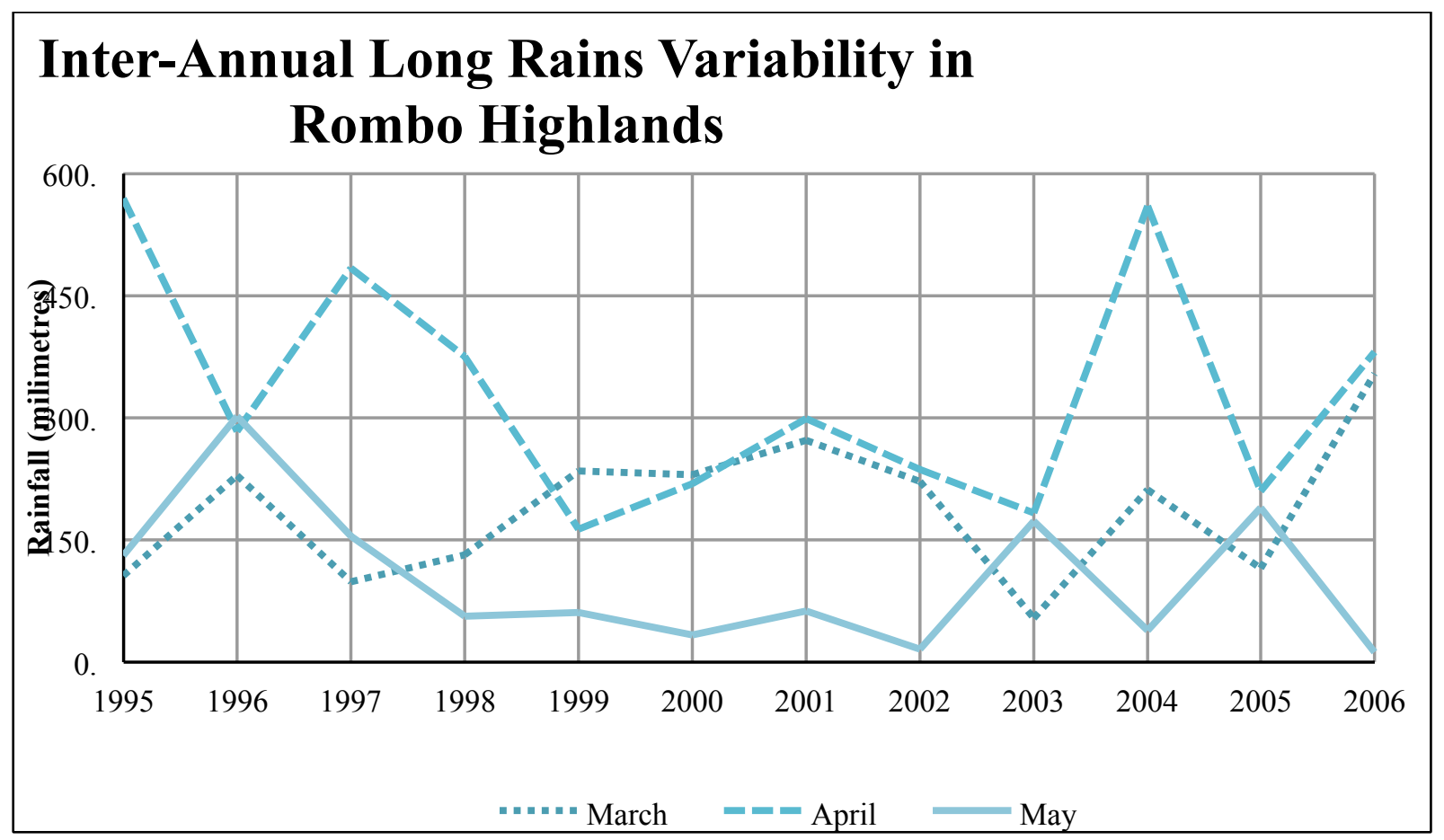

(Rombo District Office) 
Figure 3.5: Rainfall Variability in Rombo District Lowlands 1995-2006

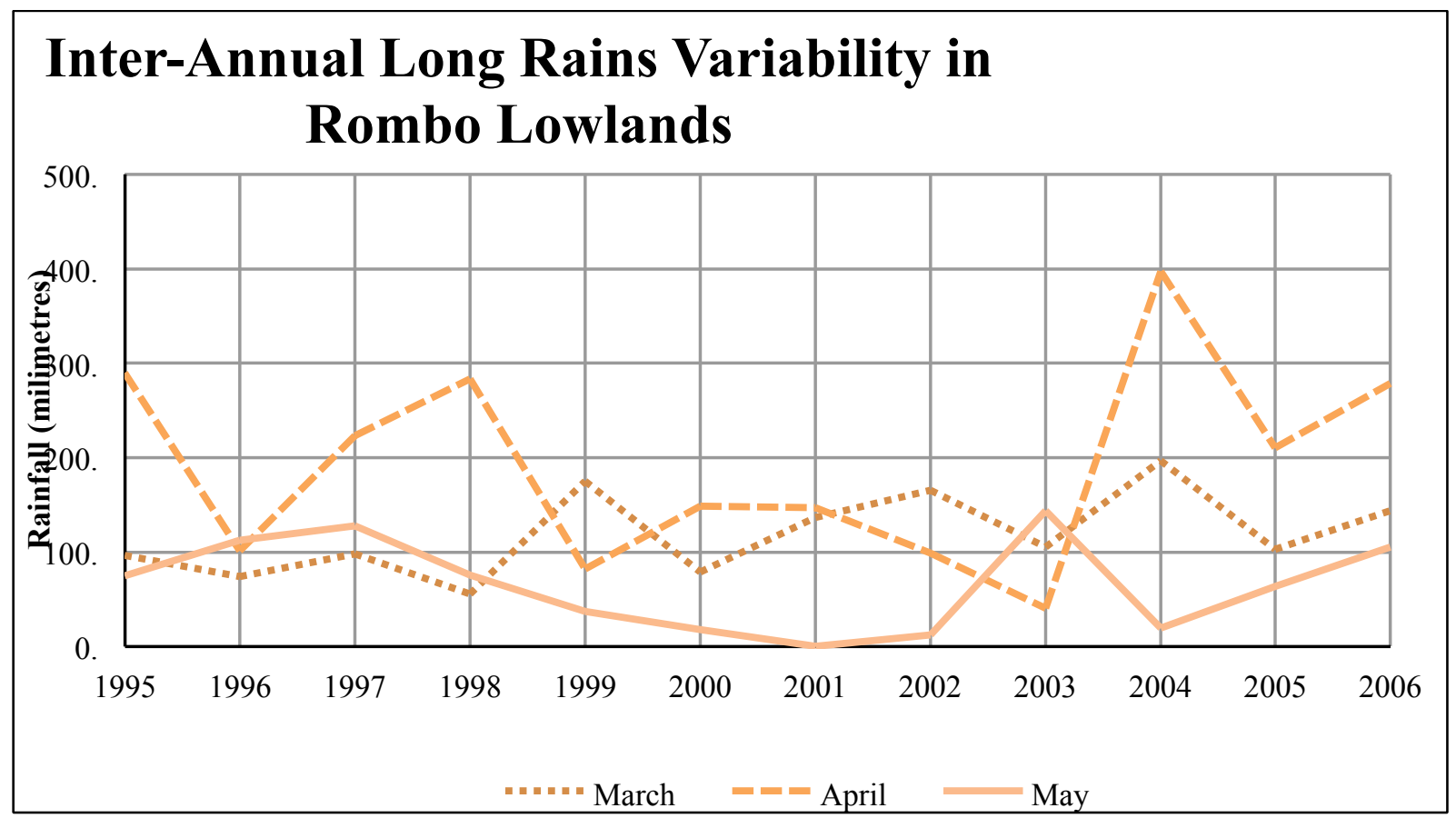

(Rombo District Office)

The population in Kilimanjaro Region has grown significantly since Tanzanian independence. The effects of this process have mainly been perceived by local people as a scarcity of available land; seventy per cent of households complain about the shortage of suitable areas, which is the second highest level of displeasure recorded in the country (URT, 2006). Table 3.3 details population change in the case study area.

Table 3.3 Population Change in Kilimanjaro Region

\begin{tabular}{cc}
\hline Year & Population \\
\hline 1967 & 652772 \\
1978 & 902437 \\
1988 & 1108699 \\
2002 & 2097166 \\
2014 & 2902733 \\
(projected) & (projected) \\
\hline
\end{tabular}

(NBS, 2002) 
Forty six per cent of respondents stated that their farming methods had altered in the preceding five years. Of those who had changed their methods, sixty eight per cent identified a change in the climate as the primary factor; also significant was soil exhaustion, which was the reason for change for nineteen per cent of households.

Variation in availability of assets, entitlements, opportunities and requirements throughout the year corresponds with differentiation of vulnerability on a household and collective level (DFID, 1999). Most of the information regarding seasonal vulnerability in the case study location was obtained through the production of a seasonality calendar, which formed part of the secondary survey. Seventy two seasonality calendars were completed by individual households. The secondary survey took place in the same locations as the primary data collection, but the households visited varied. The main findings are detailed in Table 3.4, and are summarized in Table 3.5. In Table 3.4, yellow indicates a problem for up to a third of the households surveyed, brown is something that affects between one third and two thirds of households and red represents a seasonal issue for over two thirds of households. 
Table 3.4 Results from seasonality calendar

\begin{tabular}{|c|c|c|c|c|c|c|c|c|c|c|c|c|}
\hline Activity & Activity detail & $\mathrm{J}$ & $\mathrm{F}$ & M & A & M & $\mathrm{J}$ & J & A & S & $\mathrm{O}$ & $\mathrm{N}$ \\
\hline Social Reproduction & Paying School Fees & & & & & & & & & & & \\
\hline Social Reproduction & Healthcare costs & & & & & & & & & & & \\
\hline Resource Access & Difficulty Collecting Firewood & & & & & & & & & & & \\
\hline Resource Access & Difficulty in obtaining sufficient Water & & & & & & & & & & & \\
\hline Cultivation & of garden & & & & & & & & & & & \\
\hline Cultivation & of shamba & & & & & & & & & & & \\
\hline Planting & of garden & & & & & & & & & & & \\
\hline Planting & of shamba & & & & & & & & & & & \\
\hline Weeding & of garden & & & & & & & & & & & \\
\hline Weeding & of shamba & & & & & & & & & & & \\
\hline Pest Management & For Coffee & & & & & & & & & & & \\
\hline Pest Management & For Beans & & & & & & & & & & & \\
\hline Pest Management & For Maize & & & & & & & & & & & \\
\hline Harvesting & Of Coffee & & & & & & & & & & & \\
\hline Harvesting & Of Beans & & & & & & & & & & & \\
\hline Harvesting & Of Bananas & & & & & & & & & & & \\
\hline Harvesting & Of crops from shamba & & & & & & & & & & & \\
\hline Processing & Of Coffee & & & & & & & & & & & \\
\hline Processing & Of crops from shamba & & & & & & & & & & & \\
\hline Marketing & Of Coffee & & & & & & & & & & & \\
\hline Marketing & Of Beans & & & & & & & & & & & \\
\hline Marketing & Of Bananas & & & & & & & & & & & \\
\hline Marketing & Of crops from shamba & & & & & & & & & & & \\
\hline Off-farm work & When off-farm employment sought & & & & & & & & & & & \\
\hline
\end{tabular}


Table 3.5: Summary of seasonal vulnerability

\begin{tabular}{ll}
\hline Issue & Findings \\
\hline School Fees & $\begin{array}{l}\text { January and July are when this expenditure is required; no } \\
\text { variation between highlands and lowlands }\end{array}$ \\
\hline Difficulty obtaining & $\begin{array}{l}\text { Hardest to obtain during long rains (April) and short rains } \\
\text { (Nuelwood }\end{array}$ \\
had difficulty obtaining fuelwood at these times, much lower \\
percentage in the highlands
\end{tabular}

At the household level, human capital is a function of knowledge, health, the quality and quantity of available labor, and livelihood relevant skills (DFID, 2000). The percentage of respondents who had received at least primary education was seventy eight per cent. As many of the survey respondents finished their education a long time ago, the current level of ninety per cent enrolment in primary education is indicative of progress towards the second MDG, achievement of universal primary education. Fourteen per cent of female respondents, as opposed to five per cent of male respondents, stated that they had received no formal education; in 2005 it was estimated that twelve per cent of males and fifteen per cent of females in Kilimanjaro Region had never attended school. Fifteen per cent of respondents had received at least a secondary education, compared with the current level of seventeen per cent enrolment in Kilimanjaro Region in 2004-5. Access to education is also differentiated by location, altitude and income.

Respondents were asked to identify which disease most frequently impacts on their household. Malaria can be identified as the primary disease that affects people in Kilimanjaro Region, with forty six per cent of respondents stating that is the major health risk. Thirty six per cent of people 
identified coughs or chest pains as the major problem; this could either be an indication of people who spend a large degree of time in smoke filled kitchens or a possible symptom of a disease such as tuberculosis. Ninety seven per cent of households said they had not been affected by any serious disease outbreaks in the preceding three years, suggesting that when problems do occur they are localized and have the greatest effect within the household, although the cumulative effect on levels of human capital may be significant.

From the total sample, twenty nine per cent of participants indicated that their primary source of healthcare was a district dispensary or hospital. Sixty seven per cent relied primarily on private dispensaries or hospitals. Only one per cent of respondents claimed that they never sought out healthcare. When the results are disaggregated by different areas of the research location significant differentiation of healthcare source emerge. The greatest accessibility of government supported hospitals and dispensaries are found in the three areas that are located in Moshi Rural District. These are Old Moshi, Marangu and Moshi Rural lowlands (thirty nine per cent, sixty per cent and seventy one per cent respectively). In the three areas of Rombo District the figure does not rise above eight per cent. Several potential reasons may assist in explanation. The most prosaic is one of different perceptions of respondents - Huruma hospital in Rombo District is operated by a religious group and therefore perceived as a private institution. However, it receives much of its funding from the Tanzanian government, so could be considered commensurate to institutions in Moshi Rural District. This factor alone does not explain the large discrepancies between regions, as much healthcare advice and product is obtained from dispensaries as opposed to hospitals. In Moshi Rural District many of these are free at the point of use, provided by the government. The same situation does not exist on a large scale in Rombo District, perhaps because of its relative isolation from Moshi town.

The majority of survey respondents (seventy seven per cent) perceive themselves primarily as farmers. It is therefore probable that the means by which people obtain information about improved farming methods and other relevant details is indicative of varying levels of human capital on Mt. Kilimanjaro. The principal sources of farming information are agricultural extension officers (thirty three per cent) and other farmers (thirty per cent). Other sources included seed merchants (five per cent) and the media (four per cent). The percentage that has access to extension workers is comparable with Soini (2005), who stated that sixty nine per cent of farmers had no contact with them. Twenty nine per cent of households claimed that they did not have any external sources of information regarding agricultural practices. The pattern of access to formal sources of agricultural information can be differentiated by several factors; education as a variable is explored as an example.

The importance of education in enabling access to formal sources of agricultural knowledge is apparent. Those survey respondents who had received at least a secondary education had a forty four per cent contact rate with the extension service; this rose to fifty per cent for those with a tertiary education. People with no education had a reduced opportunity of contact (twenty three per cent); the undertaking of adult learning also did not appear to be significant with only twenty per cent of respondents in this category stating access. Above average reliance on other farmers for information is noted in those respondents with no schooling, adult and primary education. The use of seed merchants increases from zero for those with no education to 
eighteen per cent of people with tertiary instruction. Forty five per cent of respondents with no education have no access to external information sources; this figure drops to twenty eight per cent of primary schooled people and twenty one per cent of those with secondary education. An inverse relationship would appear to exist between level of education and access to formal external sources of information; a relationship also exists between a lack of education and a lack of external information. This suggests that various indicators of human capital can reinforce each other, with positive or negative consequences.

The level of biodiversity in Kilimanjaro Region is substantial; the forest and grassland areas above the level of the national park boundary contain many species that are endemic to the location. Since initial cultivation of the homegarden system began over a century ago, the Chagga have identified and retained trees, grasses and plants which serve a practical purpose whilst removing those with minimal utility (Fernandes, 1984).

The range of biodiversity prevalent in a typical Chagga homegarden is evidenced in Fernandes (1984), where over sixty types of plant and tree species, with a huge range of end-uses, are identified. It can therefore be stated that the Chagga have traditionally practiced agroforestry methods, even if that description would not have been utilized historically. Ninety two percent of survey respondents perceive themselves as practicing forms of agroforestry, suggesting that households are aware of the importance of all species on their plots, as opposed to only the food and cash crops produced. Recent research in Rombo District by Munishi (2007) has identified seventy four different tree species in the middle zone of the area, suggesting an even greater level of biodiversity than that identified by Fernandes (1984).

Statistics obtained from the household survey indicate the important role that natural capital has in the construction of livelihoods on Mt. Kilimanjaro; however, there are also results that suggest the natural resource base is limited by a number of factors. Eighty five per cent of homegardens were smaller than two hectares; this compares with the average total area cultivated by a household of 1.74 hectares suggested by Soini (2005). Fifty three per cent of households cultivated another plot on the lowland separate to their homegarden, which is slightly greater than the forty two percent recorded by Soini (2005). Planting in different ecological zones requires a greater range of knowledge than cultivating in one area only, and is also indicative of higher levels of natural capital available to households that have this option.

For ninety seven per cent of households fuelwood is the primary source of energy for cooking and lighting. This indicates a considerable reliance on sources of natural resources, and time taken to collect these products can significantly impact on time available for other productive, and potentially income generating, activities. The secondary survey provided information regarding time taken to collect fuelwood; thirty seven per cent took less than thirty minutes, twenty seven per cent took up to an hour, fifteen per cent took between one and two hours and sixteen per cent took longer than two hours.

Physical capital is a function of the existing infrastructure, which may be freely or nominally accessible to households in the location, and the implements available for assistance with livelihood construction. It is therefore necessary to consider both the existing infrastructure and 
the generation and variation of household physical capital, and how this varies by a range of factors (DFID, 2000).

Infrastructure that is generally accessible to all the population in the case study area includes the road network. Resources that may necessitate payment for usage include water, machinery to assist agricultural production, particular forms of energy consumption and educational establishments. As the survey was focused on the primary source of energy, it was not possible to determine how many households had access to electricity; however, the figures from 1994 of six per cent of households supplied in Moshi Rural District, and two per cent in Rombo District, are not likely to have altered significantly (NBS, 2002). Results from the secondary survey indicated that thirty seven per cent of households could potentially access electricity if necessary, suggesting that even its availability does not necessitate a great uptake amongst those who could potentially utilize it.

Household differentiation of physical capital can be observed through variation of building material, roofing material, farm size, possession of items that may increase agricultural productivity, and means of transporting produce to market. Historically, a stone house was a key indicator of wealth in Chagga society (Soini, 2005). In that survey of forty five households, sixty per cent were constructed of stone and forty per cent were based on a mud-brick design. The secondary survey provided information regarding the type of building materials used. Table 3.6 details these findings. Reasons for the discrepancy between the findings and those of Soini (2005) are probably to do with the wider range of locations on Mt. Kilimanjaro in this study.

Table 3.6 Type of Building Material for Main Residence

\begin{tabular}{ccc}
\hline Type of Building Material & \# of respondents & $\%$ of respondents \\
\hline Stone/Block & 50 & 42 \\
Mudbrick & 61 & 51 \\
Wood/Poles & 7 & 6 \\
\hline
\end{tabular}

(Secondary Survey Data)

Access to a reliable source of water is indicative of relatively high levels of physical capital. Responses from the household survey suggest that over ninety per cent of people have access to piped water for domestic use; fifty seven per cent of respondents had piped water on their own farm and thirty three per cent had access to a neighbor's pipe. The secondary survey confirmed this, with forty seven per cent of respondents with access to piped water in their own household. Three per cent relied on publicly accessible water pipes and seven per cent obtained their requirements from wells, rivers or streams. The secondary survey indicated that sixty one per cent of households took less than fifteen minutes to obtain their water supplies, twenty per cent took up to half an hour and six per cent required up to an hour. Three per cent 
of households took between one and two hours and three per cent took longer than two hours to obtain sufficient water.

In the context of the livelihoods approach financial capital refers to both flows and stocks. As development activities rarely distribute financial aid directly to households, it is necessary to explore indirect ways of enhancing this capital asset; it is unlikely that recommendations of directly enhancing the financial capital of the most vulnerable households are likely to be countenanced by those responsible for distribution (DFID, 2000).

In 2006, income generation in the study area came primarily from coffee (six per cent), bananas (thirteen per cent), milk sales (seven per cent), livestock sales (eight per cent), remittances (fourteen per cent) and off-farm sources of income (forty three per cent). The mean income amongst households surveyed was TSH 370544/-; the median income was TSH 178000/-. The average mean income in Moshi Rural District is more than twice the level of Rombo District. The comparison between the two districts identifies the importance of off-farm income in livelihood construction, and the significantly higher levels obtainable for households in Moshi Rural. Respondents in Rombo district relied significantly more on farm production for income generation.

Cattle are the most financially valuable form of livestock kept in Kilimanjaro region. If fed well, there is potential to earn income through the sale of milk; if they need to be sold the price received is approximately $\mathrm{TSH} 200,000 /-$ per head. Fifty per cent of households surveyed did not own any cattle, and twenty three per cent possessed one. Twenty seven per cent of households owned two or more cattle. Thirteen per cent of households had borrowed at least one cow from another source, but these are less valuable financial assets, as the right to sell does not exist for the recipient in this relationship.

The major difficulty cited by respondents with regard to selling produce was low prices; fifty six per cent identified this as the principal problem when marketing their crops. Twenty eight per cent of respondents stated that they did not sell any agricultural produce. Seven percent of respondents had no problem with selling output. Only two per cent identified transport issues as the primary constriction on selling; this suggests that improvements in existing infrastructure may not have as beneficial an effect as hoped.

As off-farm income has been shown to be a significant part of financial capital generation, it is necessary to further explore the various methods through which households obtain this. The main sources of off-farm income identified by respondents are businesses, waged labor and remittances. Business was the main source of off-farm income for thirty two per cent of respondents, and can take many forms such as running a small shop, providing transport or marketing services to other farmers and production of baskets and other handicrafts. Waged labor is the primary source for twenty nine per cent of households; the major problem with this form of income generation is that the peak demand for labor in the area is likely to coincide with maximum labor requirements on the household farm. For nineteen per cent of households surveyed remittances are the most important source of off-farm income; if these are reliable they can assist in financial requirements throughout the year, but this may not always be the case (Primary Survey). 
Formal and informal networks, groups and institutions are the defining characteristics of social capital in this research. Formal social institutions and institutions include agricultural extension practices, government and NGO assistance during times of drought or hunger, membership of cooperative organizations, access to commercial seed and other input merchants, and active political involvement. Informal institutions comprise the practice of borrowing livestock from wealthier farmers and other customary redistributive measures, informal lending arrangements between friends and relatives, remittances received and reliance on informal networks during times of stress (DFID, 1999). Although it can be difficult to identify useful indicators of social capital several possibilities have been identified from the primary and secondary surveys. These are not exhaustive but provide an indication of both formal and informal networks that exist in the region, and an attempt to assess the strength of them.

Twenty eight per cent of respondents stated that they received remittances in 2005; this rose to thirty per cent in 2006. The amount received varied from zero to TSH 4.5 million/-. In 2006 remittances accounted for fourteen per cent of the total income stated by respondents across the study site. This varied significantly between the two districts studied; in Moshi Rural forty two per cent of participants claimed to receive remittances compared with only nineteen percent of households in Rombo.

In times of need it can be easier to assess the existence of informal 'safety nets' that enable a degree of food security to be achieved that not be accomplished by individual households (Adger, 1999). In the survey, response was differentiated into who provided the assistance and what type of assistance was received. Thirty six per cent of respondents identified relatives or neighbors as the primary source of assistance, twenty nine per cent stated assistance from central government, eleven per cent relied on local level formal assistance and one per cent received help from NGO's.

Historically livestock was transferred from wealthier to poorer farmers. These redistributive measures were associated with cultural disapproval of ostentatious displays of wealth (Howard and Millard, 1997). This informal mechanism provided a mutually beneficial scenario; the richer farmers could distribute some of their wealth whilst still retaining a level of power over their poorer neighbors, and the poorer farmers were entitled to some of the livestock produce, and sometimes offspring. It is therefore an indicator of desirable social capital. Thirteen per cent of households possessed cattle that belonged to other people, ten per cent had borrowed at least one goat and five per cent had a minimum of one sheep that they did not own; for other animals the figures are less than two per cent. As this process of animal transfer was historically very important (Moore, 1986), and has not been replaced by a formalized equivalent, it is possible to infer that this indicator suggests that social capital is under pressure.

Membership of formal organizations indicates a level of institutionalized social capital. The secondary survey explored the level of participation in various groups. Table 3.7 states the responses. A level of formal membership exists across the region, but twenty four per cent of respondents were not involved with any groups, suggesting potential for enhancing participation in these organizations. 
Table 3.7 Membership of Formal Organizations

\begin{tabular}{lcc}
\hline $\begin{array}{l}\text { Organization } \\
\text { \# involved with } \\
\text { it }\end{array}$ & $\begin{array}{c}\text { \% involved with } \\
\text { it }\end{array}$ \\
\hline $\begin{array}{l}\text { Political } \\
\text { Party }\end{array}$ & 26 & 48 \\
Cooperative & 10 & 19 \\
NGO & 0 & 0 \\
CBO & 12 & 22 \\
\hline Other & 12 & 22 \\
\hline None & 13 & 24 \\
\hline
\end{tabular}

(Secondary Survey Data)

\section{Discussion}

A review of relevant secondary literature on the case study location has identified a range of livelihood diversification options that require consideration (Scoones, 1998; Ellis, 2004; Soini, 2005). Examples of these include intensification or expansion of agricultural methods, and increased reliance on off-farm income. The potential for these methods to be used by households will now be assessed.

In the higher and middle zones of the Chagga homegardens potential for intensification is limited by several factors; primarily the unfeasibility of mechanizing production on steep slopes and the difficulty in obtaining chemical inputs, either through unavailability of credit to purchase or removal of previously subsidized supply. Other intensification options include indigenous forms of terracing, use of improved seeds, increased application of manure and compost, cultivation of higher value agroforestry species and higher yielding livestock varieties (Soini, 2005). Although potential for improvement exists in all these areas, there is a significant caveat which must be considered. Mdoe and Wiggins (1997) touch on this issue when discussing smallholder dairying on Mt. Kilimanjaro. With the absence of many direct subsidies for households, the burden of risk in any intensification process is placed almost entirely on the farmer. They discuss this problem in the context of intensifying dairy production, but the problem is equally important with regard to other opportunities for intensification. When the inherently variable climate of Mt. Kilimanjaro is factored in, the risk burden is probably unsustainable and outweighs the potential benefits; provision of formal support networks, for both inputs and as a form of safety net if the intensification process founders, are required if this option is to be pursued.

The potential for expansion of the Chagga farming system is constrained by a number of factors. The upper limit of the homegarden system is the Kilimanjaro National Park. Although there is the presence of a 'half-mile strip', that is jointly controlled and managed by local and national authorities, the possibility for clearance and settlement on higher altitudes does not 
exist. At the lower reaches of the system, what was described as savannah two decades ago (Fernandes et al., 1984; Moore, 1986) is now almost entirely under cultivation. This is either in the form of lowland farms that are usually a mixture of maize, sunflower and beans, or an attempt to replicate the Chagga homegarden system on less watered and fertile land further down the slopes. The former method has existed longer historically, and is based around crops that are perhaps more suited to this agro-ecological zone. The latter technique, as demonstrated by the poor quality of banana plants and other crops when compared with higher up the slope, makes it unlikely that livelihoods can be sustained in these areas by on-farm activities alone. The lack of available land on the mountain, and the difficulty of accessing plots that may be a significant distance away from the homestead, suggests that opportunities for expansion of the system are severely constrained.

Off-farm income has been shown to be the most significant aspect of income generation with regard to livelihood construction on Mt. Kilimanjaro. Due to the previously described restrictions on increasing on-farm production, it is therefore pertinent to explore potential to expand the offfarm income of households in the study area. Off-farm income can be categorized into temporary, seasonal or permanent migration for work. It can occur on a local, regional or national scale. Significant local sources of off-farm income include work related to tourism on Mt. Kilimanjaro, particularly in Marangu in Moshi Rural District, and laboring on other farms. This association with the tourist trade is the primary reason for the difference in average income between Moshi Rural and Rombo districts. These options are restricted geographically and temporally. Regional and national migration, to Moshi, Arusha and Dar es Salaam, provides a greater income earning potential. The relatively high educational attainment of people in Kilimanjaro Region in comparison with other parts of Tanzania indicates that potential exists for quality, salaried work if migration is considered as a livelihood option. The relatively high quality of much of the housing observed, and the relatively high levels of remittances recorded, suggest that much wealth generated elsewhere is transferred back to this region. However, increasing reliance on off-farm income can have significant consequences for on-farm production. The most apparent is the reduction of available labor on the farm, although if off-farm income is sufficient then labor can be hired. As those who migrate tend to be the most active members of a family, those left on the homegarden are likely to be the elderly or young, who may not possess the physical condition or knowledge to cultivate as successfully as possible. The reduction in time spent undertaking agricultural activities can reduce knowledge of the techniques required to maintain the complex homegardens. Consequentially, the cumulative effect of these actions could be a reduction in the biodiversity and biomass of the area could occur, which may then affect the water availability and supply on the mountain.

The research has identified the important factors related to generation of each type of capital asset. It is necessary to explore the inter-relationships between different capitals, as enhancing one could be detrimental to the other assets. Possibilities for enhancing capital assets are considered, along with a discussion of possible consequences for other capitals.

Human capital is relatively high in Kilimanjaro Region, especially when compared with other parts of Tanzania. Primary school enrollment is amongst the highest in the country, and virtually everyone has access to healthcare, although the quality and availability of this varies 
significantly. Potential opportunities for human capital enhancement exist in increasing the amount of people who obtain at least a secondary education, and in concurrence with Soini (2005), improving access towards, and quality of, the extension service. Constraints include financing an expansion of both secondary education and the extension service.

The level of natural capital in the case study location has been shown to be high, and particularly important in the livelihood construction of those households that do not have access to significant sources of off-farm income. As the levels of biodiversity and biomass in the Chagga homegardens play an important, if not defined role in the water management system on Mt. Kilimanjaro and its foothills, the possibility of payment for ecological services should be investigated further. A potential method for financing this would be through an international facility such as the Clean Development Mechanism. The major constraints for enhancing natural capital in the area are the previously discussed restrictions on intensifying and extensifying the homegarden farming system, and sourcing sustainable funding for the concept of payment for ecological services.

The quality and quantity of physical capital, particularly infrastructure, varies markedly between districts in the case study area. Although there are relatively high levels of infrastructure when compared with other parts of Tanzania, the areas with greater stated income generally had greater levels of infrastructure. This was observable for public assets such as roads as well as personal assets such as private water pipes. A process which will be completed within three years in Rombo District, to tarmac the road to the Kenyan border, is the greatest opportunity observed for enhancing physical capital. The primary constraint to expanding physical assets elsewhere is the high initial and ongoing expenditure. Individual indicators of physical capital are likely to increase as a result of increases in other capitals, particularly financial capital (Soini, 2005).

Over half of financial capital generation on Mt. Kilimanjaro is made up of off-farm income sources including remittances. Therefore, a focus on opportunities to increase the level of offfarm income, particularly for those households in Rombo District, is a potential pathway to enhancing financial capital. An example of how this could be achieved is through the promotion and support of local businesses. There is potential for increasing on-farm production, particularly with regard to adding value to primary produce, and increasing output and hence financial returns, through intensification of agricultural and agroforestry activities.

Commensurate to all these goals is the possibility of expanding various forms of micro-finance and micro-credit schemes, which are currently accessible by a small minority of households. Constraints are the high level of investment required when instigating these schemes and the increased burden of risk placed on households if appropriate safety nets are not also enacted.

Social capital, particularly in the form of informal networks, appears to have declined in importance from the pre-colonial era (cf Moore, 1986; Howard and Millard, 1997). Those households in the lowlands that may be considered most vulnerable to the effects of drought rely more on formal government support in times of need than the relatively wealthier respondents further up the mountain. They are more vulnerable to drought not only because it is on average drier in this part of the area, but also because they are less able to pursue livelihood 
strategies that would enable a reduction in this vulnerability. Opportunities for enhancing social capital, as the livelihoods framework understands it, are likely to be greatest in supporting and funding local NGO's, CBO's and formalizing local institutions. An example of this is the work Envirocare, a Tanzanian NGO, is doing with women's groups in Kilimanjaro Region. Collective action can provide the individual members with greater income generating opportunities, with regard to both on-farm and off-farm capitals generating activities. Ensuring sustainable funding, the initial capital requirements to create these groups and problems with ensuring equal access are the main constraints to enhancing social capital.

Increasing the quantity of individual capital assets can affect the level of other capitals. This can occur in a positive manner; an increase in human capital can provide information on best practice farming techniques, therefore enhancing levels of natural and financial capital. An increase in physical capital could provide better access to markets and more reliable sources of water, with positive effects for levels of financial and human capital. Increasing social capital might improve dissemination of best practice, provide access to appropriate tools and strengthen the position of producers; this can potentially increase levels of human, physical and financial capital. However, the process can work in the opposite direction. Enhancing human capital may persuade people that improved livelihood options exist away from the homestead, with subsequent negative effects on natural capital. Increasing financial capital through additional sources of off-farm income can reduce the quantity of natural capital through neglect of the farm. It can also affect human capital through a reduction in location specific agricultural knowledge and negatively influence social capital because of a lack of previously shared common interests between households. Therefore any interventions need to be carefully considered for all potential consequences.

\section{Conclusion}

This research has established two main findings. The first is that vulnerability on Mt. Kilimanjaro is highly differentiated, and is experienced primarily by households dependent on the natural environment for their livelihoods. The second is that households that can possess high levels of some capitals also tend to possess high levels of others. This section explores the implications of these two findings.

The research has identified the capital assets that enable livelihood construction on Mount Kilimanjaro. The importance of various capitals has been considered, alongside the variation within different districts in Kilimanjaro Region. Potential opportunities and constraints with regard to capital enhancement have been explored. With this information collated, it is necessary to consider the potential for the Chagga society to adapt to climatic change in the case study location.

When considering adaptation options it is important to differentiate between genuine adaptive measures and an expansion in coping mechanisms that are already prevalent in Kilimanjaro Region. Following Adger (1996), coping mechanisms occur within existing institutional and power arrangements, whereas adaptation often involves modification of the structures in which the transformation of livelihood takes place. As the most vulnerable groups who have been 
identified through the research process are generally those with relatively low levels of capital assets, and also affected more by shocks, trends and seasonal factors, they would presumably be the people who would benefit most from successful adaptation measures. The livelihoods framework is an excellent set of methods for describing these processes, but it is severely lacking when it comes to explaining why these households remain vulnerable and how they can become more resilient. The argument made in this conclusion is that it is precisely because of the way questions of 'political capital' and power and conceptualized within the framework that they cannot be understood as driving forces of vulnerability. This builds upon criticisms made of the livelihoods framework by Collinson (2002), and acknowledged by Scones (2009).

The fundamental weakness of the livelihoods approach for understanding household vulnerability is that it only indicates the possibilities and limitations of expanding existing coping mechanisms. There is no mechanism by which transformation in livelihood options is possible, except for being negatively affected by external sources of vulnerability. The evidence this paper has presented has indicated that in fact these sources of vulnerability are not external, but rather found in household struggles to secure livelihoods. This vulnerability is highly varied amongst households, and closely related to the capital assets they are able to command. The most vulnerable households are those with a significant tolerance on their natural capital, and an inability to generate or access other capital assets. They also have the least ability to access social networks, and transform institutions in their own interest.

Without this ability to access and change institutional structures that have a bearing on their own livelihood construction, adaptation remains a concept that can only be imposed through top-down, external structures. Successfully enhancing the adaptive capacity of the most vulnerable is essentially a process that requires understanding of the socio-economic and political conditions that create vulnerability, and attempts to identify pathways through which adaptation can be realized. Potential focus should be on enhancing the resilience of vulnerable societies, through disaster risk reduction and capacity building approaches. This could enable a level of preparedness and response to biophysical hazards that is currently not achievable, and possibly achieve a more appropriate entitlement to livelihood. The livelihoods approach enables identification of the most vulnerable, and those with the lowest levels of capital assets to draw upon for social reproduction and production. Attempts to reduce vulnerability, enhance resilience, adaptive capacity and the level of different capital assets households can command must therefore by necessity draw upon a sense of social and environmental justice, and accept that some form of redistribution alongside increased production at the household level is a vital factor in improving the lot of the poorest. 


\title{
Chapter 4: Vulnerability and Livelihoods on Mt. Kilimanjaro
}

\begin{abstract}
Livelihoods in Tanzania are constructed through a diverse range of practices. This paper draws on the Livelihoods Approach alongside the 'double exposure' framework in order to explore how households on Mount Kilimanjaro construct their livelihoods, and are constrained by the local and wider political economy. Specifically, it uses these frameworks in order to explore how people may in future adapt to an increasingly changing climate. Most households in the case study region are found to be highly reliant on the natural base of the area, and are liable to be highly vulnerable to future climate change. Means by which households can reduce vulnerability are explored, and the most feasible are found to be those that involve a reduction in reliance on direct production from nature. The paper concludes with a discussion of the appropriateness of the research framework, and argues that a dialectical approach may enable more appropriate questions to be posed and engaged with.
\end{abstract}

\section{Introduction}

This paper is based on research that sought to explore how rural societies, however defined, might attempt to adapt to project future climatic shifts, and consequently how this may affect the ability of these people to sustainably (re)produce their livelihood strategies with regard to constraints and diversification. The livelihoods model of Scoones (1998) was utilized; it contained a framework for the research methodology through which the socio-economic and environmental sources of vulnerability, the natural and social basis of livelihood construction, and the institutions, structures and processes that mediate and differentiate the relationship between them could be explored. This livelihoods approach is important because it is the basis of much current thinking in development theory and practice - and it is commensurate with a broad political ecology framework, and draws heavily on many of the same concepts in order to explore society-nature interactions. The research was also heavily informed by the 'double exposure' conceptualization (O'Brien and Leichenko, 2000) and the Wisner et al. (2004) notion of vulnerability and how it is constructed.

This paper introduces two critical theoretical concepts into a framework for exploring how livelihoods are created. The intention is to explore how these theories of rural transformation can be linked to the livelihoods framework by focusing on the relationships between different factors of livelihood construction. Throughout this paper the assumption is that social relations determine vulnerability to a large degree, an idea expanded upon in chapter five. Conventional analyses of livelihoods are limited when it comes to understanding the dynamics of how change occurs. Insights that can be gained from this approach include identification of a range of potential exogenous sources of vulnerability, and identification and classification of a range of productive/reproductive measures and things and classify them as a type of capital. Then, because of the classical economism of the framework, and the livelihoods model in general, it is assumed that by raising the marginal productivity of one capital asset can lead to a more 
sustainable productive system. However, relations of power and political access, amongst many other processes, negate the usefulness of the livelihoods approach. Although the livelihoods approach framed the study, it has been possible to return to the data obtained and, with the benefit of a new critical framework, examine what it established but also what it misses out.

The basis for this critique is two fold. The first is an attempt to expand and explore the limits of the explanatory power of livelihoods approaches, following Scoones (2009). The livelihoods framework also intends to explore linkages within livelihood construction, particularly with regard to the formal and informal institutions that 'transform' structures and processes (DFID, 1999). However, the contention of this paper is that the framework, which focuses on the identification of tangible capital assets and specific shocks that can threaten livelihood variability, is not relational enough. Secondly, this is an attempt to use field data to explain Harvey's (2009) article, on change in the mode of production. He expands on the conception of a critical historiography of technology making it possible to reveal the forces that explain and are indicative of social organization. This article is fundamentally important because it enables a framework to be developed in which relationships between different processes are taken as a given, and exploration can take place within the whole of societal relations.. This paper has explored just three of the 'moments' described by Harvey - and this has been enough to render the livelihoods approach problematic. It is unable to determine what drives change using both the livelihoods framework and the conceptualization of climate change as a single thing. By Harvey's (2009) formulation, change will have really occurred until it is registered at each of the six moments. Focusing just on one moment, as this research originally intended to do (environmental change, specifically climate change), will miss change in other factors (such as relations of production). As explained in chapter two, positivist models of change can also not comprehend that the root of ecological problems, and how they are problematized, is the dominant form of social organization (capitalism) that exists.

Returning to the issue of adaptation to climate change, it will be shown that the use of the livelihoods approach framed in this context can only see climate change as an external threat that causes vulnerability. The double exposure framework struggles to overcome this and results in a binary view, if not a tautology, where increased exposure to environmental risks may make someone more vulnerable to socio-economic process, and vice versa. The wider point for adaptation to climate change is that change is not likely to fundamentally lead to societal transformation, if change is conceived as needing to register in all of Harvey's six moments, unless it causes changes in all six moments. Therefore, it is impossible to say that climate change has the potential to fundamentally alter social organization unless the potential for transformation is first identified, and then manifested, in Harvey's six moments.

Impacts of climate change likely to affect those in sub-Saharan Africa more than most, due to their socio-economic standing and commensurate vulnerability. Those for whom agricultural production is a primary form of subsistence activity are at particular risk in terms of the vagaries of the climate because of the nature of their relationship to nature. However, the impact of any change will be mediated by a whole other range of factors that affect the basis of reproduction of livelihood choices available to people. Specifically, the feasibility or profitability of small scale agriculture, alternative employment opportunities both within and external to the household 
location, the role of wider trends in affecting livelihood choices and how natural hazards and processes interact with these factors.

Therefore, investigation of how people try and attempt to adapt to the impacts of potential climate change is both necessary and potentially informative to other facets of development theory. As projected impacts are not yet on an appropriately small scale, and must always be treated as what they are (predictions, not predetermined preordained outcomes), then a proxy for how people may adapt to future climatic change is sought. That proxy is adaptation of livelihood strategies in response to climatic variability. This is justified on the assumption that a rural population, or peasantry, that can adapt successfully to the vagaries of an unpredictable climate on a recurring basis is better placed to withstand any future effects of Climate Change than a social group who cannot. The rhetoric of adaptation is commensurate with that of reducing vulnerability and enhancing resilience in the natural hazards paradigm. Successful adaptation should be sustainable; therefore livelihood choices that engender a greater degree of sustainability are more resilient and less vulnerable.

Construction of livelihoods in geographic locations that experience great climatic variability predominantly involves a range of different strategies to enable social reproduction. The purpose of the research was to establish how people had responded to climatic variability in the past, how this vulnerability of was differentiated amongst households with a range of capital asset generating strategies in the case study area. It was found, as hypothesized, that those who were most vulnerable to the effects of climatic variability were those that relied primarily on agriculture for subsistence production, in contrast to the relatively less vulnerable whose available livelihood strategies did not rely primarily on the vagaries of the climate. Households that could access a diverse range of livelihood options, and had relatively good access to the range of capital assets, were much more resilient to the effects of environmental hazards. However, in seeking to avoid the potential tautology to studying vulnerability - that people are vulnerable, and they are vulnerable because they are poor (O'Keefe and Middleton, 1998), the livelihoods approach is critiqued for how different ideas are conceived, whether any significant factors are 'missed' by the framework, and whether a more relational approach could perhaps shed new insight on exploring construction and reproduction of rural societies. The idea of deproletarianization is introduced to provide a potential explanation for the trends identified through the research.

\section{Research Method and Context}

The framework in which the analysis of vulnerability is located is that of the hazards paradigm. The research explored the differentiation of vulnerability through assessing households' capacity to respond and adapt to actual and predicted hazards that constrain livelihood construction option (Wisner et al., 2004). It was also important to explore the range of capitals produced and commanded by households; this allowed relationships between particular capital generating strategies and variation in exposure to natural and socio-economic hazards to be explored. The research was framed using the livelihoods approach. This framework enabled a range of quantitative and qualitative research methods, including two semi-structured household surveys (one of 1089 households, one of 89), structured observation, and key informant interviews and transects walks, to be analyzed, compared and triangulated. The livelihoods 
approach used in this study drew heavily upon Scoones (1998) and DFID (2000). This mixed methods approach was intended to capture as much detail as possible regarding how livelihoods are constructed in the case study area. Figure 4.1 shows the research location.

Figure 4.1 Map of research location

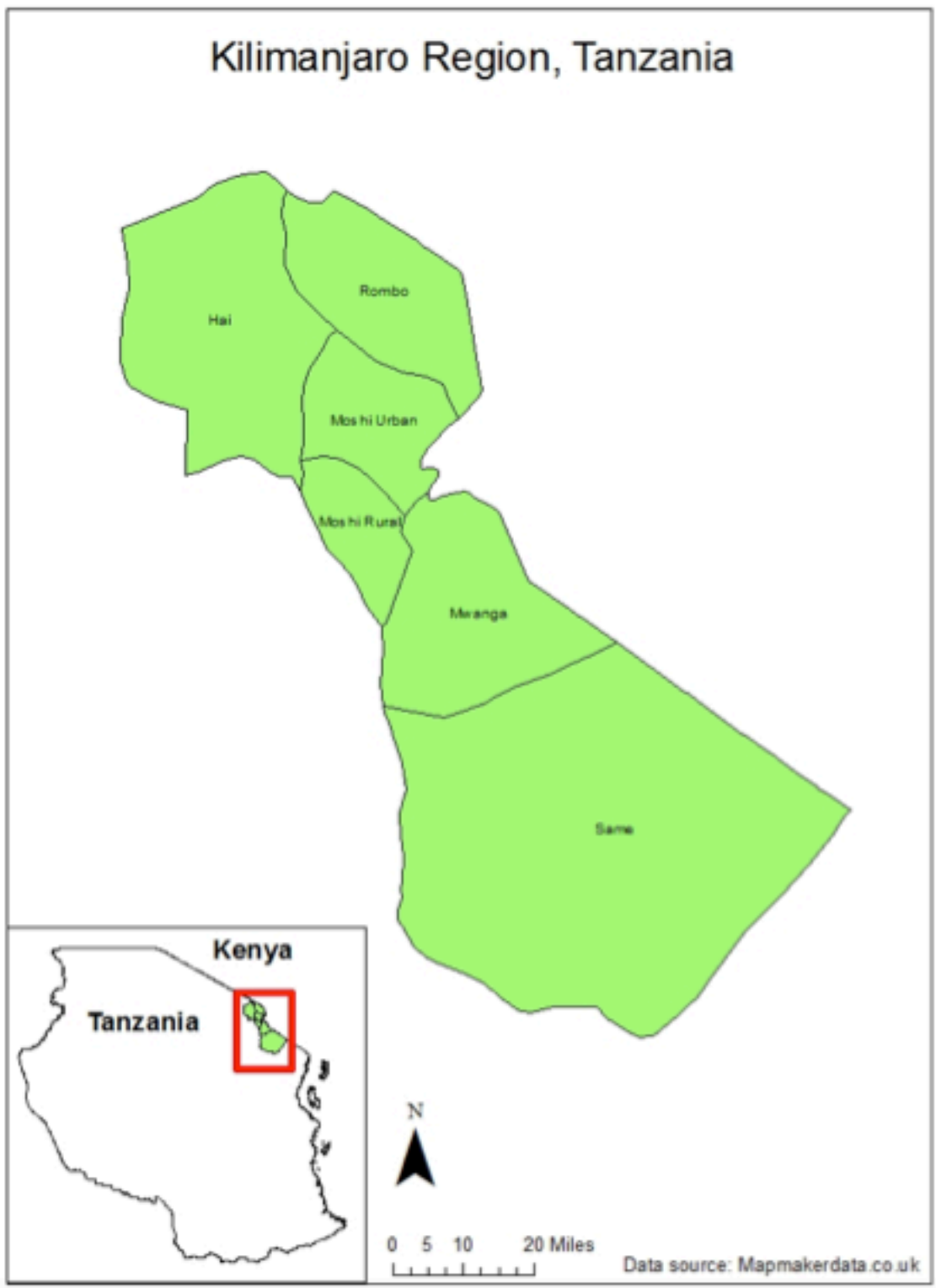

Source: Author

The slopes of Mount Kilimanjaro were amongst the most productive areas in what was to become mainland Tanzania. The Chagga people became one of the most advanced societies in the region, and were amongst the first to establish and develop chiefdoms. This was primarily due to the surplus production of banana crops (Coulson, 1982). The most significant impact of the colonial period was the transition to a cash-based economy. The German colonialists 
achieved this through the imposition of a hut tax, a policy that required indigenous people to sell either their labor or surplus produce. Following the independence of Tanganyika in 1967 President Nyerere announced that the country would pursue a policy of 'Ujamaa', a form of African socialism. The main facets of this process were nationalization of industry and a process of 'villigization' where peasant farmers were resettled, sometimes forcibly (Coulson, 1982). This proved effective in some contexts; levels of literacy and access to healthcare increased nationwide, however the economy was affected significantly and many people, including the Chagga, generally disapproved of the process.

The low, and sometimes negative, levels of economic growth throughout the 1980s were succeeded by higher rates; there has not, however, been a commensurate reduction in indicators of poverty to complement these economic gains. Reduction of poverty is the priority of the current administration and it is thought that the most appropriate method to achieve this is through enhancing the GDP of the country (URT, 2005). The current socio-economic climate in Tanzania is characterized by an increasing integration into the global economy and a wide prevalence of poverty in the country (Ellis, 1998; Ellis and Mdoe, 2004).

Kilimanjaro Region is located in northern Tanzania and consists of six districts: Rombo, Mwanga, Same, Moshi Rural, Hai and Moshi Urban. The population at the time of the 2002 census was 2,097,166 (NBS, 2002). The region covers an area of $13,209 \mathrm{~km}^{2}$, the smallest region in Tanzania. It has a population density of 159 persons per square kilometer (NBS, 2002). The population density varies dramatically from up to 650 in the Chagga homegardens to less than 50 in the lowland plains. The topography of the area ranges from Kibo peak, the highest point on the African continent (5986m.a.s.I.), to the lowlands of the Maasai steppe (700900 m.a.s.I.) (NBS, 2002). The climate on the southern slopes of Mt. Kilimanjaro is characterized by a bimodal rainfall distribution; the 'long' rains occur from March to May and the 'short' rains are between October and November. Total annual rainfall primarily depends on the success of the short rains and the onset, intensity and duration of the long rains.

The people who became the Chagga initially practiced a form of what would now be regarded as agroforestry; trees that were not deemed useful were cleared whilst those that served a practical purpose were retained and managed (Fernandes et al., 1984). The Chagga became influential in the caravan trade that traversed the African continent from the Indian Ocean inland. Through this process they acquired tools, weapons and other implements that enable the society to develop its productive and reproductive forces (Coulson, 1982). A consequence of this relationship was the receptiveness of the Chagga with regard to acceptance of new ideas, products and beliefs of different cultures. This aspect of their society was to prove significant when Europeans colonized the area at the end of the nineteenth century.

The effects of colonialism in Kilimanjaro Region qualitatively changed the social relations that previously existed. The arrival of Catholic and Lutheran missionaries was accompanied by the arrival of coffee, the crop that became the major export crop of the area (Coulson, 1982; Moore, 1986). The German period of colonial rule from 1886 to 1916 changed many customs, culture and laws. Military defeat by the Germans meant the chiefs had to rely on colonial power to maintain authority. The introduction by the chiefs of a cattle tax is one example of how social relations were transformed in this period. (Moore 1986). 
The colonial period saw the introduction of formal education as well as the introduction of coffee. This accelerated in the 1920s (Coulson, 1982). At this point the colony was a British protectorate. As the climatic and topographic conditions were ideal for this crop, production spread and increased. Within twenty years there were estimated to be significantly more than five million coffee trees planted on the slopes of Mt. Kilimanjaro (Coulson, 1982). The British protectorate period also saw the creation and development of the Kilimanjaro Native Cooperative Union (KNCU), which enabled a good price to be received by growers but also resulted in the Chagga becoming one of the most educated societies in East Africa. Levies were charged by the union to support primary, secondary and tertiary education for members and their families (Coulson, 1982).

The population living on the slopes of Mt. Kilimanjaro increased significantly during the colonial period. Howard and Millard (1997) suggest that religious teaching, particularly Catholic, contributed to this; cultural taboos had previously existed regarding the spacing of children and women were not expected to become pregnant until they had finished breastfeeding their previous child. These social pressures were usurped by religious edicts emanating from Europe.

At independence many Chagga people held important roles in the new government due to their relatively high levels of education (Coulson, 1982). When Tanzania was unified, and then Nyerere embarked on his 'Ujamaa' program, the Chagga were amongst the most rigorous opponents, and in parallel saw the influence of their union ebb (Coulson, 1982). Livelihoods in the region since have been affected by the impacts of structural adjustment, declining commodity prices and the continued growth in population (Soini, 2005). It is necessary to consider how they are currently constructed.

Livelihoods in Kilimanjaro Region are constructed primarily through agricultural methods. The average household size is 5.2 hectares and eighty four per cent of households are male headed (URT, 2006b). The Kilimanjaro region has the highest percentage of literacy in Tanzanian rural areas of eighty six per cent (URT, 2006b).The typical Chagga family would have a 'kihamba', or homegarden, that would comprise their residence and on which bananas and coffee were usually the principal crops. The kihamba would often also have a vegetable garden on which various green vegetables could be grown for consumption and for sale. A homestead would also usually have access to an area of lower altitude land, a 'shamba', on which the main crops grown would be maize, beans and sunflowers. The homegardens would have a large range of tree and plant species alongside the primary crops; Fernandes et al. (1984) identified over fifty species that were utilized by the Chagga for various purposes. The farming is fairly intensive, although prices received by farmers for some produce is significantly higher than other parts of Tanzania (URT, 2006a). In Kilimanjaro Region seventy per cent of households state that there are inadequate quantities of land for them to sustain their livelihoods, which is the second highest proportion in Tanzania; eighty five per cent of the population are thought to be involved in agriculture on a full time basis (URT, 2006b).

Livestock husbandry is a significant component of livelihood construction for most households in Kilimanjaro Region. The number of pigs, sheep and goats in the region is moderate to low when compared with the rest of Tanzania but the density of animals is amongst the highest. Access to 
livestock and agricultural extension services is also amongst the highest in the country. Diseases affecting livestock and the use of animals for draught are relatively low (URT, 2006a).

One of the significant problems that afflict people living on Mt. Kilimanjaro is that of food insecurity. Howard and Millard (1997) discuss the paradox of one of the wealthiest regions in Tanzania suffering from one of the highest levels of malnutrition; causes are suggested to be social factors that stigmatize the food insecure and malnourished, and culturally inappropriate responses that do not appreciate the role of shame in preventing hungry people from receiving assistance publicly. HIVIAIDS is having a significant effect on the economic and social relations and capabilities of the region. It is estimated that seven per cent of fifteen to forty nine year olds are affected by the disease (UNDP, 2006), but these figures are uncertain due to reluctance to be tested and the potentially negative consequences that can result from a positive diagnosis; eighty three per cent of the population have not been tested for the disease (NBS, 2005).

Kilimanjaro region has been described as facing significant risks from climate change (Agrwalia et al., 2003; Mwandosya et al., 1998). It is projected that there will be a rise in mean temperature, while the changes in precipitation levels are yet uncertain. Development of more specialized computer models that work on a scale as small as the Tanzanian slopes of Mount Kilimanjaro are required before it is possible to ascertain either way. The changes could have both positive and negative effects with regard to agricultural production. With this understanding it is predicted that coffee and cotton production could be expanded whereas maize production could see a marked decrease. Adaptation can not only guard against adverse impacts but harness potential benefits. Adaptation and coping mechanisms should not only be considered in terms of climate change in isolation but through a wider ranging analysis of exogenous and endogenous pressures (Agrwalia et al., 2003; Mwandosya et al., 1998). Climate change, its impacts and the options for adaptation should be understood in the context of household livelihood construction.

\section{Discussion of Vulnerability}

Vulnerability emerged as a focal concept through the natural hazards paradigm, specifically from the acknowledgement that 'natural' disasters were not affecting social groups in a uniform manner; socio-economic factors differentiated the (likely) impact of a hazard on a heterogeneous society. In the context of disaster risk reduction, resilience is often construed as the 'flipside' of vulnerability, without being necessarily tautological (Manyena, 2007) Adaptive capacity is a corollary of hazard studies, so is of fundamental importance to explorations of how people construct livelihoods in a dynamic, variable environment.

The livelihoods approach can be placed within a broad political ecology framework, and this in conjunction with the definition of vulnerability provided by the book At Risk produced a conceptual basis for understanding the challenges to the sustaining of livelihoods on Kilimanjaro under a varying, and potentially changing, climate. The Scoones (1998)/DfID (2000) framework, conceptualizes vulnerability as comprising shocks, trends, and seasonality. Vulnerability is initially discussed using this framework, and the important findings from the research are identified. The framework is subsequently critiqued for its appropriateness in identifying and establishing the full range of multi-scalar processes that constrain or enable livelihood options. 
Shocks that increase the vulnerability of affected populations are short term, rapid onset events (DFID, 2000). In Kilimanjaro region, these will potentially include drought, flooding, hunger and food insecurity. The research explores two factors that can both cause and illustrate features of vulnerability: drought and times of hunger.

Drought is probably the most serious natural hazard that affects the livelihoods of people in Kilimanjaro Region. Seventy two per cent of respondents stated that drought had a great impact on their agricultural productivity, fifty nine per cent claimed that it had a great impact on their health and thirty two per cent perceived it as having a great impact on availability of energy sources. When asked to identify the last time a drought affected the area they reside in, a wide variation of years was recorded, indicating that the effects can be very localized. However, some particularly large scale droughts were identified. As the survey was designed to identify the last time a drought affected an area it was not possible to ascertain the relative seriousness of each drought year, however, a pattern emerged in which major droughts appear to recur on a decadal basis; 1974, 1984, 1994 and 2004-5 account for fifty nine per cent of responses to the question 'When were you last affected by drought?'. Twenty one per cent of respondents stated that they had never been affected by drought; this suggests that access to different water sources can compensate for a reduction in rainfall in a given year, and also supports the contestation that the effects of drought can be extremely localized.

Long term trends in natural and socio-economic processes can alter the vulnerability of societies. In the context of this research these may include enhanced climatic change, climatic variability, increased impacts of El Nino Southern Oscillation (ENSO) events, and a decline in prices received for commodities such as coffee.

Other potential impacts of climatic change include the possibility of increased incidence of drought and flooding, which may be associated with a complementary rise in ENSO activity. This implies that the increased variability of precipitation may be a more significant issue affecting adaptation of household livelihood strategies in the region than absolute change. Rainfall records obtained in the case study area indicated that variability in both the time of onset of rains and the absolute amount received was substantial on a year to year basis. This indicates that livelihoods are already being constructed in the face of a dynamic climatic context, and although climate change may exacerbate these trends it is not likely to produce new threats.

The population in Kilimanjaro Region has grown significantly since Tanzanian independence. The effects of this process have mainly been perceived by local people as a scarcity of available land; seventy per cent of households complain about the shortage of suitable areas, which is the second highest level of displeasure recorded in the country (URT, 2006). Forty six per cent of respondents stated that their farming methods had altered in the preceding five years. Of those who had changed their methods, sixty eight per cent identified a change in the climate as the primary factor; also significant was soil exhaustion, which was the reason for change for nineteen per cent of households. Another trend that has to be considered is the declining importance of coffee production in the construction of livelihoods in the case study location. The declining real price of coffee, once the exchange rate is taken into account, and the declining importance of coffee grown in Kilimanjaro relative to Tanzania as a whole are symptomatic of 
the challenges of achieving a sustainable livelihood on Mt. Kilimanjaro which remains highly reliant on agriculture.

Variation in availability of assets, entitlements, opportunities and requirements throughout the year corresponds with differentiation of vulnerability on a household and collective level (DFID, 1999). Most of the information regarding seasonal vulnerability in the case study location was obtained through the production of a seasonality calendar, which formed part of the secondary survey. Seventy two seasonality calendars were completed by individual households. The secondary survey took place in the same locations as the primary data collection, but the households visited varied. The main findings are detailed in Table 4.1.

Table 4.1 Results from seasonality calendar

\begin{tabular}{|l|l|}
\hline Issue & Findings \\
\hline School Fees & $\begin{array}{l}\text { January and July are when this expenditure is required; no } \\
\text { variation between highlands and lowlands }\end{array}$ \\
\hline Difficulty obtaining fuelwood & $\begin{array}{l}\text { Hardest to obtain during long rains (April) and short rains } \\
\text { (November/December); 85-90\% of respondents in lowlands } \\
\text { had difficulty obtaining fuelwood at these times, much lower } \\
\text { percentage in the highlands }\end{array}$ \\
\hline Difficulty obtaining water & $\begin{array}{l}\text { In upper zone August and September most difficult times; in } \\
\text { lower zone at least three quarters of respondents have } \\
\text { difficulty obtaining water between July and October }\end{array}$ \\
\hline Marketing Coffee & $\begin{array}{l}\text { Coffee primarily marketed in July and August; more people } \\
\text { marketing coffee in the highlands than the lowlands }\end{array}$ \\
\hline Seeking off-farm \\
employment & $\begin{array}{l}\text { In the highlands marketing of bananas occurs throughout the } \\
\text { year; greatest amount is marketed in May. In the lowlands less } \\
\text { people produce bananas for market and in January, } \\
\text { September and October no respondent stated that they } \\
\text { marketed bananas }\end{array}$ \\
\hline $\begin{array}{l}\text { August was the month when most work was sought in the } \\
\text { highest reaches of the highlands; in the lowlands most } \\
\text { respondents sought off-farm employment between August and } \\
\text { January }\end{array}$ \\
\hline Banas
\end{tabular}


The research identified the important factors related to generation of each type of capital asset. It is necessary to explore the inter-relationships between different capitals, as enhancing one could be detrimental to the other assets. Possibilities for enhancing capital assets are considered, along with a discussion of possible consequences for other capitals.

Human capital is relatively high in Kilimanjaro Region, especially when compared with other parts of Tanzania. Primary school enrollment is amongst the highest in the country, and virtually everyone has access to healthcare, although the quality and availability of this varies significantly. Potential opportunities for human capital enhancement exist in increasing the amount of people who obtain at least a secondary education, and in concurrence with Soini (2005), improving access towards and quality of the extension service. Constraints include financing an expansion of both secondary education and the extension service.

The level of natural capital in the case study location has been shown to be high, and particularly important in the livelihood construction of those households that do not have access to significant sources of off-farm income. As the levels of biodiversity and biomass in the Chagga homegardens play an important, if not defined role in the water management system on Mt. Kilimanjaro and its foothills, the possibility of payment for ecological services should be investigated further. A potential method for financing this would be through an international facility such as the Clean Development Mechanism. The major constraints for enhancing natural capital in the area are the previously discussed restrictions on intensifying and extensifying the homegarden farming system, and sourcing sustainable funding for the concept of payment for ecological services.

The quality and quantity of physical capital, particularly infrastructure, varies markedly between districts in the case study area. Although there are relatively high levels of infrastructure when compared with other parts of Tanzania, the areas with greater stated income generally had greater levels of infrastructure. This was observable for public assets such as roads as well as personal assets such as private water pipes. A process which will be completed within three years in Rombo District, to tarmac the road to the Kenyan border, is the greatest opportunity observed for enhancing physical capital. The primary constraint to expanding physical assets elsewhere is the high initial and ongoing expenditure. Individual indicators of physical capital are likely to increase as a result of increases in other capitals, particularly financial capital (Soini, 2005).

Over half of financial capital generation on Mt. Kilimanjaro is made up of off-farm income sources including remittances. Therefore, a focus on opportunities to increase the level of offfarm income, particularly for those households in Rombo District, is a potential pathway to enhancing financial capital. An example of how this could be achieved is through the promotion and support of local businesses. There is potential for increasing on-farm production, particularly with regard to adding value to primary produce, and increasing output and hence financial returns, through intensification of agricultural and agroforestry activities.

Commensurate to all these goals is the possibility of expanding various forms of micro-finance and micro-credit schemes, which are currently accessible by a small minority of households. 
Constraints are the high level of investment required when instigating these schemes and the increased burden of risk placed on households if appropriate safety nets are not also enacted.

Social capital, particularly in the form of informal networks, has declined in importance from the pre-colonial era. Those households in the lowlands that may be considered most vulnerable to the effects of drought rely more on formal government support in times of need than the relatively wealthier respondents further up the mountain. Opportunities for enhancing social capital are likely to be greatest in supporting and funding local NGO's, CBO's and formalizing local institutions. Collective action can provide the individual members with greater income generating opportunities, with regard to both on-farm and off-farm capitals generating activities. Ensuring sustainable funding, the initial capital requirements to create these groups and problems with ensuring equal access are the main constraints to enhancing social capital.

Increasing the quantity of individual capital assets can affect the level of other capitals. This can occur in a positive manner; an increase in human capital can provide information on best practice farming techniques, therefore enhancing levels of natural and financial capital. An increase in physical capital could provide better access to markets and more reliable sources of water, with positive effects for levels of financial and human capital. Increasing social capital might improve dissemination of best practice, provide access to appropriate tools and strengthen the position of producers; this can potentially increase levels of human, physical and financial capital. However, the process can work in the opposite direction. Enhancing human capital may persuade people that improved livelihood options exist away from the homestead, with subsequent negative effects on natural capital. Increasing financial capital through additional sources of off-farm income can reduce the quantity of natural capital through neglect of the farm, affect human capital through a reduction in location specific agricultural knowledge and negatively influence social capital because of a lack of previously shared common interests between households. Therefore any interventions need to be carefully considered for all potential consequences.

Examples of diversification options that could potentially be utilized include intensification and extensification of agricultural methods, and increased reliance on off-farm income. The potential for these methods to be taken advantage of by the Chagga will now be assessed.

In the higher and middle zones of the Chagga homegardens potential for intensification is limited by several factors; primarily the unfeasibility of mechanizing production on steep slopes and the difficulty in obtaining chemical inputs, either through unavailability of credit to purchase or removal of previously subsidized supply. Other intensification options include indigenous forms of terracing, utilization of improved seeds, increased application of manure and compost, cultivation of higher value agroforestry species and higher yielding livestock varieties (Soini, 2005). Although potential for improvement exists in all these areas, there is a significant caveat, which must be considered. Mdoe and Wiggins (1997) touch on this issue when discussing smallholder dairying on Mt. Kilimanjaro. With the absence of many direct subsidies for households, the burden of risk in any intensification process is placed almost entirely on the farmer. They discuss this problem in the context of intensifying dairy production, but the problem is equally important regarding other opportunities for intensification. When the inherently variable climate of Mt. Kilimanjaro is factored in, the risk burden is probably unsustainable and 
outweighs the potential benefits; provision of formal support networks, for both inputs and as a form of safety net if the intensification process founders, is required if this option is to be pursued.

The potential for extensification of the Chagga farming system is constrained by a number of factors. The upper limit of the homegarden system is the Kilimanjaro National Park. Although there is the presence of a 'half-mile strip', that is jointly controlled and managed by local and national authorities, the possibility for clearance and settlement on higher altitudes does not exist. At the lower reaches of the system, what was described as savannah two decades ago (Fernandes et al., 1984; Moore, 1986) is now almost entirely under cultivation. This is either in the form of lowland farms that are usually a mixture of maize, sunflower and beans, or an attempt to replicate the Chagga homegarden system on less watered and fertile land further down the slopes. The former method has existed longer historically, and is based around crops that are perhaps more suited to this agro-ecological zone. The latter technique, as demonstrated by the poor quality of banana plants and other crops when compared with higher up the slope, makes it unlikely that livelihoods can be sustained in these areas by on-farm activities alone. The lack of available land on the mountain, and the difficulty of accessing plots that may be a significant distance away from the homestead, suggests that opportunities for extensifying the system are severely constrained.

Off-farm income has been shown to be the most significant aspect of income generation with regard to livelihood construction on Mt. Kilimanjaro. Due to the previously described restrictions on increasing on-farm production, it is therefore pertinent to explore potential to expand the offfarm income of households in the study area. Off-farm income can be categorized into temporary, seasonal or permanent migration for work. It can occur on a local, regional or national scale. Significant local sources of off-farm income include work related to tourism on Mt. Kilimanjaro, particularly in Marangu in Moshi Rural District, and laboring on other farms. This association with the tourist trade is the primary reason for the difference in average income between Moshi Rural and Rombo districts. These options are restricted geographically and temporally. Regional and national migration, to Moshi, Arusha and Dar es Salaam, provides a greater income earning potential. The relatively high educational attainment of people in Kilimanjaro Region in comparison with other parts of Tanzania indicates that potential exists for quality, salaried work if migration is considered as a livelihood option. The relatively high quality of much of the housing observed, and the relatively high levels of remittances recorded, suggests that much wealth generated elsewhere is transferred back to this region. However, increasing reliance on off-farm income can have significant consequences for on-farm production. The most apparent is the reduction of available labor on the farm, although if offfarm income is sufficient then labor can be hired. This process is highly gendered. As those who migrate tend to be the most active male members of a family, those left on the homegarden are likely to be female, the elderly or young, who may not possess the physical condition or knowledge to cultivate as successfully as possible. The reduction in time spent undertaking agricultural activities can reduce knowledge of the techniques required to maintain the complex homegardens. Consequentially, the cumulative effect of these actions could be a reduction in the biodiversity and biomass of the area could occur, which may then affect the water availability and supply on the mountain. 


\section{Discussion}

The potential for enhancing livelihoods options identified through the livelihoods approach methodology has been identified. However, it is necessary to critically interrogate the findings of this research and the nature of how available options for change are manifested. It is also important to attempt to reconcile the recommendations of the research output with theories of development, social transformation and differing conceptions about what this means for 'peasant' societies. Three factors are considered here in relation to the fieldwork observations; an increasing reliance on off-farm sources of income as a method of reducing vulnerability to the effects of climatic change or variability, the relationships between the case study location and surrounding urban areas, and whether these processes can be characterized as an increasing proletarianization of the peasantry.

Returning to Leichenko and O'Brien's (2000) conceptualization of 'double exposure', it is apparent, and not necessarily paradoxical, that an increased reliance on off-farm income is likely to reduce (direct) impacts of climatic change/variability on livelihood construction, but may increase the vulnerability to socio-economic factors. This will be particularly relevant if social reproduction is made more difficult or precarious because of an increasing reliance on insecure income generating opportunities. However, those who do manage to obtain stable streams of off-farm income will be less vulnerable to both socio-economic and environmental processes, in comparison both with their previous livelihood strategies and with those within the case study location.

This differentiation suggests that a focus on proletarianization as a process involving the increase in reliance on selling labor at one pole, and increasing concentration of wealth within society at another pole, may provide a framework for exploring the relationship between livelihood construction on Mt. Kilimanjaro and processes of uneven capitalist expansion, expropriation and beneficiation. In view of this insight, perhaps it would be productive to move beyond a binary on/off farm sources of income. A focus on availability or requirement of agricultural production and petty commodities for subsistence, reliance on wage labor as primary source of social reproduction, or ability subsistence, reliance on wage labor as primary source of social reproduction, or ability to command labor and control the products of said labor is more instructive than simply whether work takes place on or off the farm. Off-farm income, in the form of working for other farmers, or in the non-agricultural economy, can be justifiably characterized as an aspect of the process of differentiation of a society that was originally primarily subsistence based. Tom Brass's (2011a; 2011b) ideas of deproletarianization are highly relevant here, as very few households in the case study are able to commodify their labor at a level that enables adequate levels of household reproduction.

\section{(Adaptation to) Climate Change}

Processes of households relating to nature, as well as their social relations of production and reproduction, should be understood dialectically. The livelihoods approach is an appropriate methodological framework for exploring people's potential capabilities, opportunities and constraints regarding capital asset generation. It is a less appropriate framework for 'scaling up' from this household level focus and linking environmental and socio-economic sources of vulnerability to considering the political economic context which constricts and determines 
available coping mechanisms for the most vulnerable social groups in response to environmental risk (Scoones, 2009). The critique most regularly applied to the livelihoods approach is that it fails to account for the political relations, and hence political capital possessed by different persons within a given socio-economic context. Alternative, adjusted versions of the livelihoods approach have been suggested. One alternative version is proposed by Collinson et al (2002); it includes an 'asset hexagon', political capital being included as the sixth asset. However, livelihoods approaches say very little about how these asset generating strategies relate to broader ideas of rural transformation. Livelihood diversification, for example, is one means by which (in the livelihoods approach) households are attempting to increase the sustainability of their asset generating strategies. However, introducing the concept of deproletarianization raises a new question: what if livelihood diversification strategies are actually a consequence of the inability of rural households to commodify their labor in order to achieve household reproduction?

Increasing the quantity of individual capital assets can affect the level of other capitals. This can occur in a positive manner; an increase in human capital can provide information on best practice farming techniques, therefore enhancing levels of natural and financial capital. An increase in physical capital could provide better access to markets and more reliable sources of water, with positive effects for levels of financial and human capital. Increasing social capital might improve dissemination of best practice, provide access to appropriate tools and strengthen the position of producers; this can potentially increase levels of human, physical and financial capital. However, the process can work in the opposite direction. Enhancing human capital may persuade people that improved livelihood options exist away from the homestead, with subsequent negative effects on natural capital. Increasing financial capital through additional sources of off-farm income can reduce the quantity of natural capital through neglect of the farm, affect human capital through a reduction in location specific agricultural knowledge and negatively influence social capital because of a lack of previously shared common interests between households.

This research is underpinned by several concepts and theories that are fundamental to both the nature of what is being studied and the areas of focus that it identifies. Emphasis is placed on the relationship between different processes, identification of contradictions or tension within and between these processes, and potential pathways through which these contradictions may play out in the material realm. In studies that seek to explore society-nature interactions, it is not always the case that the conception of how 'nature', and societies relation to it, are clearly theorized. Following from Smith's (2009) conception of the production of nature, under capitalism production is the process by which the society-nature dualism that permeates much social science can be overcome. What needs further exploration is how far the concept of production of nature can be extended into societies that are not totally integrated into the capitalist system. First, let us consider the relationship between the two frameworks.

The natural capital of a household is those natural resources that it can command in order to achieve social reproduction and production. Disregarding questions about what is 'natural', this can be seen to be of huge importance to those societies who still largely rely on small scale, often subsistence agriculture. It is apparent that this concept could be considered within 
Harvey's framework, but it is not quite as simple as saying the relation to nature equates to the category of natural capital in the framework. Basing this framework in the theory of the production of nature it is possible to begin to explore the relationships between these different processes. For example:

- The relationship between social relations and the relation to nature would appear to be a good starting point for investigating how access to resources are decided, enforced and limited. This can go further to explore what is to be exploited, who decides, and on whose terms, these decisions are made.

- Is the relationship to nature (conceived of as production) undermined by unsustainable use of the natural resource/ecological base? O'Connor's (1998) $2^{\text {nd }}$ contradiction of capitalism would argue yes, under capitalism. But is the system on Mt. Kilimanjaro truly capitalist? Is the presence of some kind of capitalism all that is required for the contradiction to hold?

- The relation between the relation to nature and the reproduction of daily life. Or another way, how much of what is grown on the farm is used for household subsistence. How much of household subsistence and reproduction relies on producing from nature. What other inputs are required for household reproduction? When these factors change, how does the relationship to nature change? For example, if there is more reliance on off farm income/cash crops then how is biodiversity affected?

- The relation between mental conceptions of the world and the relation to nature. There must be space for plural conceptions of the same material factor. For example, in the case of land, the perception of the relation to land is likely to vary depending on the level of subsistence, alienation from the land, the labor undertook on the land and the time spent away from the land amongst other things.

It is argued that these examples show the many linkages that exist between the two frameworks. Many research methods are also commensurate with both approaches. All things that are described in the livelihoods approach can be studied in the Harvey framework, but with an added emphasis on how changing one aspect of a livelihood strategy can affect all other factors of which it is related to. The original livelihoods framework and my original research highlighted the importance of linkages between different types of assets and explored whether they could be mutually constitutive - Harvey provides the framework to flesh out and explore these relationships.

An ability to see that a change in one of the processes (say, mode of production), necessitates a change in the relations with other processes (relation to nature, technological change etc.). Moving beyond a binary of seeking the causative/principle agent in a process, or holding that all relations have a contingent basis in place or space are dependent on that very contingency for signification of importance, this framework seeks, and I believe enables the researcher, to not only hold (conceptually) the notion that these reflections of dynamic processes can (indeed must) be understood together, but also enables an assessment of what relationships appear to 
be of greatest importance in understanding social development and transformation, if and when it has occurred.

An example of this can be seen with a focus on the relation to nature. The growth of cash cropping (primarily coffee) on the slopes of Kilimanjaro, not only changed the relation to nature (primarily 'husbandry' to a mix of 'husbandry' and 'mastery'). Social differentiation occurred within the Chagga society as those households that successfully grew coffee achieved a hitherto unprecedented level of income. The general shift in diet with regard to the primary carbohydrate source shows the power of mental conceptions in both shaping, and being shaped by, the idea of plantains vs. maize as a more less reliable source of social reproduction (likelihood of crop failure, likelihood of achieving enough to subsist on rather than necessarily maximizing yield), production (profit maximization, access to markets, role of producer in relation to middlemen, processors) and technology (can one crop or the other be produced more effectively given new technology, has technology enabled planting of crops in areas previously unsuited - again necessitating a change in the relationship to nature) etc.

These then need to be thought through whatever normative assumptions of the theory that is both underpinning and being shaped by the research. From the perspective of the livelihoods framework, the professed goal is more sustainable (vaguely defined) livelihood outcomes. Within the context of the framework several 'classical' small-scale development interventions were identified that could potentially (if not definitely) enhance metric measurements of any of the five capital assets. With careful regard as to how interaction between different capital asset generation strategies could negatively or positively affect 'stocks' of other capital assets (the initial kernel for me for being drawn to more dialectical ways of thinking about this issue), and exploration of the role of formal and non-formal institutions in mediating this access to livelihood options, a set of feasible, achievable, pragmatic options can be produced and recommended. The actor-centered livelihoods framework is likely to provide actor-orientated development objectives that simultaneously essentialize, and freeze in space and time the whole range of existing social relations that may be as important as actor-opportunities in shaping the livelihood options open to different societies. Human, physical, natural, social and financial capital can be conceived of as 'containers' in which we fill in all the data points for the representative categorical indicators, attempt to crudely ascertain the marginal utility of each factor, explore the limitations to a vaguely defined 'more sustainable future', and assess which of these factors is most likely to provide the most receptive to a development intervention.

This argument, if justifiable, is very similar to the conception of absolute space described by Harvey. Much like Harvey's conceptualization of space, the idea of relational space must be held at the same time as the idea of absolute space. In the case of the livelihoods framework, the absolute conception of these capital assets is all that is available for consideration therefore social relations, particularly between class interests as they emerge or other forms of more populist resistance are not merely downplayed in the framework, but impossible to consider using its non-relational categories. This is why simply attempting to consider 'political capital' as a sixth asset, and then to explore its importance is not only a highly difficult task, it is proffering an unsuitable solution. Political power, both formal and informal, hidden and visible, legitimate or not, is prevalent in entitlement to, access to, and proceeds of the production process at varying stages, and ultimately is an expression of the social relations that determine 
livelihood options. Different mental conceptions (be they spiritual, aesthetic or otherwise) of the value of different parts of a livelihood system undoubtedly exist, but the struggle (and specifically ability) to make these discourses hegemonic (or at least be heard) is the struggle of differentiated groups to establish (a form of) control over the means to socially produce and reproduce. This interface cleaves along many different aspects (gender, age, race), can be celebrated as a good thing in itself (Scott, 1978), and can be the basis of identity celebration of different groups based on temporarily stabilized conceptions of essentialized social groups. The argument made here is that a focus on the relation is fundamental, and in agreeing with this it is also apparent that this provides an entryway for the ideas of Brass (2011a; 2011b). What links the livelihoods on Mt. Kilimanjaro with countless others globally is the fact that they have been exposed to a greater or lesser degree to the expansion of the capitalist mode of production. This interaction has fundamentally altered, in almost every conceivable case, existing relations to nature, of production and reproduction, of technological usage and advancement, and of mental conceptions of social and individual identity. Therefore, if livelihoods studies are to be of greater use they have to tease out the relationships between broad theories of social change and the snapshot of day-to-day activities that a livelihoods approach provides.

With this in mind, it is necessary to return to the original issue, that of adaptation to climate change, and explore: 1) Where it fits into this theoretical framework, 2) What are the fundamental questions to be asked when climate change is placed in this framework, 3) What are the important social relations that are driving the need to respond to a changing climate, the relations that require or encourage people to undertake livelihood options that are imperiled by projected swings in both variability and extremes of climate, and who is likely to benefit if existing adaptation proposals are implemented. The makeup of society on Kilimanjaro will always be dynamic, and simply focusing on those who work the land now neglects both those who have already left, through force or (lack of) choice, and the different social relations within the society. Is it really that likely that climate change is going to be a threat of much greater magnitude alone than the interaction of Structural Adjustment Policies and prolonged drought in the 1980's, or abrupt and devastating drops (alongside a long term general downward trend) in commodity prices. In conjunction with these, it may. But these other processes are currently retarding the livelihood options available to most of the world's population regardless of future climatic change, and many potential measures to mitigate or adapt to climatic change (protection for biodiversity, natural resource conservation) may simply entrench, or worse, increase the differentiation between peripheral regions and the core (nationally/globally/locally).

With regards to issues of vulnerability, resilience and adaptive capacity therefore, the following issues are now center place. If development is conceived of as a material increase in the wellbeing of a given society (with specific focus on how the most vulnerable and marginalized can both improve (and have improved) their livelihoods then it is evident how development relates to the goals and the concepts of resilience, especially if perceived not reactively ('bouncebackability') but proactively ('bounceforwardability'). Subsistence producers, smallholders, peasants, farming households (however defined) are undoubtedly marginal in the context of the global centers of financial capital (classically defined, not as per the livelihoods approach), but this is not at the expense of highly differentiated strata within societies.

Development interventions which focus on maintaining current, or slightly adapted modes of 
production are likely to be favored by both the 'development community' and many local people whose livelihoods are the object of this intervention. Without a proper appreciation of who stands to benefit and lose on a local level from development interventions (i.e. those who already have land, those who can command labor) may well have the effect of increasing the vulnerability of the worst off in these societies whilst simultaneously generating larger surpluses of capital for those who can claim it. 


\title{
Chapter 5: Exploring radical conceptions of vulnerability in Tanzania
}

\begin{abstract}
This paper challenges the conventional notion of how vulnerability is addressed. It extends and deepens the conventional critique of how the coupled nature of environmental and economic change are understood. It integrates theory and empirical evidence dialectically to demonstrate the centrality of social relations to transformation of vulnerability in rural livelihoods, using examples from Tanzania. It concludes with an exploration of the question of scale in studies of climate change, in order to chart a path between livelihoods studies and larger scale studies of climate change.
\end{abstract}

\section{Introduction}

Global contemporary debate is focused on accelerated climate change because of the increase in anthropogenic emissions of greenhouse gasses. At a global level, analysis is focused on the Intergovernmental Panel on Climate Change (IPCC), specifically IPCC5 (IPCC, 2014), and the evidence offered to them by interested groups (SREX IPCC, 2012). In relation to adaptation to climate change in Tanzania, the work of Working Group 2 is of particular interest. Increasingly, with an emphasis on adaptation, these reports address the issue of vulnerability (Tschakert et al., 2013). There have been a proliferation of papers exploring the vulnerability of individuals, households, communities and societies to the impacts of climate change. The notion of vulnerability is multi- faceted (Adger, 2006) but is also contested (Kelman, 2008).

Conventional studies of vulnerability assign both 'social' and 'natural' drivers of vulnerability as essentially equal in their determining potential. Understanding vulnerability in this context is essentially a question of identifying and quantifying the relevant sources, then adding them together. This is dangerous because the supposed mathematical, neutral approach, posits an apolitical nature, and disguises the social relations and processes that drive differentiated vulnerability. The argument advanced is that many studies of vulnerability fail to identify the structural causes of vulnerability, particularly their specificity under a capitalist mode of production.

One specific version of vulnerability, derived from the natural hazards literature, has existed as a research position since the 1970s. (O'Keefe et al., 1976). It is only with recent iterations of the IPCC Assessment Reports that the importance of vulnerability, for both the political and scientific implications of understanding societal adaptation to climate change, has begun to be appreciated (Tschakert et al., 2013). This paper seeks to reinforce the validity of this version of vulnerability, making it central to any studies of climate change. It contextualizes the claims made by Tschakert et al. (2013) about the need to place structural-relational ideas of vulnerability at the heart of adaptation to climate change research, and broader development and disaster risk reduction goals. It does so by presenting a tripartite division of the vulnerability literature, into conventional approaches, critiques of conventional approaches, and radical 
approaches, and provides summaries of these classes of literature. It then explores the characteristics of each literature using case material from Tanzania. This case material is generated both from secondary sources and field data addressing vulnerability. These are analyzed and discussed in relation to how household vulnerability is structured and differentiated in rural areas of the developing world. The paper concludes with the importance of changing social relationships under a capitalist mode of production to understand the opportunities and constraints of disaster risk reduction, and broader adaptation strategies.

\section{Literature Review}

The study of vulnerability encompasses a large range of disciplines and is therefore contested and operationalized for different purposes. This paper is specifically focused on how vulnerability has been used as a framework that links coupled socioeconomic and environmental transformation. Typically these include both scientific knowledge and social science perspectives, and may be couched within geography, sustainability science, political ecology, or development studies. Central concepts in these discussions include sustainable development, resilience, vulnerability, mainstreaming adaptation into development, and sustainable livelihoods (WCED, 1987; Manyena, 2006; Wisner et al., 2003; Adger, 2006; Huq, 2004; Scoones, 1998; 2009). In terms of the leading disciplinary and interdisciplinary literature, studies of vulnerability are highly heterogeneous in defining theoretical terms, the methods used and the implications for policy. This paper draws heavily on Bassett and Fogelman (2013) in their characterization of how interdisciplinary approaches and journals engaged with vulnerability and adaptation to climate change simply ignore social relations as explanatory variables. Only three percent of articles across Global Environmental Change, Climate and Development, Climatic Change and Mitigation and Adaptation Strategies for Global Change identify root causes of vulnerability in social relations. The implications for this paper are stark: it is either contributing to a minority discourse that has no relevance to the wider climate change community, or it is part of a tradition that links radical theory with strongly affirming empirical evidence linking socioeconomic status to vulnerability, that needs to find a wider audience. This paper categorizes the different usages and understandings of vulnerability into three groups: these are the conventional, the critical and the radical notions of vulnerability.

\section{Conventional Approaches}

The conventional notion of vulnerability is broadly quantitative, model reliant, mainstream research. (Turner et al., 2003; Kelman; Collier and Dercon, 2014; Basset and Fogelman, 2013). These studies generally draw upon a particular view of how human actors operate within a given ecosystem, identify appropriate quantitative indicators, use regression and other statistical methods to identify correlation and causality, and model the data to demonstrate and predict the rate and direction of change and possible limits, constraints and feedback loops of the system.

The conventional notion of vulnerability is defined and bounded by a quantitative, positivist rationality for understanding vulnerability. It is perhaps best illustrated by the theoretical work of Hare, Kates and Warren (1977). In the natural hazard paradigm, founded by White (1945), the 
second generation of scholars directly addressed these issues. Burton (1962) wrote enthusiastically in support of the quantitative revolution. Hare, Kates and Warren, using the work of economist Herbet Simon (1972), introduced a psychological understanding of human behavior into risk taking, arguing that human action was essentially of a satisficing rather than an optimizing nature. This literature incorporates ecologically derived metaphors, especially resilience, and models how systems produce and drive change. These models give undue determining force to environmental processes, not least because they are more easily quantifiable. They tend to emphasize historical impact and current exposure to the event, rather than to a changing environment-society relationship. The paradigm remains best represented by Burton et al. (1993).

These discourses can be represented schematically as:

$\mathrm{V}=\mathrm{E} \Delta+\mathrm{S} \Delta$, where $\mathrm{V}=$ Vulnerability, $\mathrm{E}=$ Environmental Change and $\mathrm{S}=$ Socioeconomic Change.

Conventional studies can easily lean on this formulation, emphasizing the environmental and thus leading to a form of environmental determinism. Popular presentations of climate change tend to revalidate such determinism, and allow criticism from climate change denialists.

Environmental catastrophism is embraced by many seeking social transformation, and risks a return to the debates surrounding environmental determinism that were thought to have been overcome within critical human geography (Peet, 1985; Swyngedouw, 2013).

\section{Critical approaches}

Critical insights to conventional approaches attempt to avoid environmental determinism but do not necessarily capture the drivers and direction of changing social relationships. The best of the critical insights is associated with the livelihoods approach, where vulnerability is made up of numerous external sources that are categorized as shocks, trends, or seasonality (Scoones, 1998). At best, the livelihoods approach captures a snap-shot of conditions of vulnerability but it is no movie: for the movie to exist, it is necessary to use Sen's (1981) ideas on entitlements. Within the climate change debate, the double exposure framework identifies economic and environmental drivers of vulnerability, but barely articulates what is the motive force behind change. They fail to do this because they identify surface phenomena such as drought, difficulty constructing livelihoods and strategies used to cope and adapt, and give these things causal power. They fail to identify, or ignore, the underlying processes that are driving the generation of vulnerability. These processes are best highlighted through the use of a dialectical methodology, which captures transformation in relationships much more effectively than systems based theories can (Levins, 1998).

Part of the problem is that, in trying to capture the social issues that underlie vulnerability, the focus rapidly becomes economic. Specifically, economic factors that are isolated from the social process which shape them. Economic definitions of vulnerability equate vulnerability with an absence of financial capital limiting participation in capitalist markets. The limits of these discourses are exemplified by the research using the double exposure framework (O'Brien and 
Leichenko, 2008) broadly critiqued O'Keefe (2013). Adger (1999; 2006, Adger et al., 2003; 2009) is perhaps the dominant author who defines this field although, in places, he has been roundly criticized (Kelman, 2008).

This critical literature incorporates a range of socioeconomic and environmental processes into an analysis of how vulnerability and opportunities regarding climate change adaptation are differentiated and determined by a range of socioeconomic factors. Relevant works include Adger (1999; 2006), Adger et al. (2003; 2009), Eakin (2005; 2006), Eakin and Wehbe (2009), Conway (2011), Engle (2011), Folke (2006), Leichenko and O'Brien (2008; 2010), Mertz et al. (2009), Eriksen et al. (2005), Paavola (2008), Silva et al. (2010), and Sithole and Murewi (2009). Many examples highlighting and linking socioeconomic and environmental processes exist. This literature does not consider the question of how processes of societal differentiation and transformation will produce particular vulnerabilities to climate change alongside the varying capabilities to adapt (Shove, 2010). Essentially, the notions of vulnerability and development assume a certain predicted type of societal organization, and specifically do not accept or value the notion that contradictions in the socioeconomic system create specific, and differentiated, vulnerabilities to environmental processes. Essentially, while avoiding explicit environmental and economic determinism, these studies are brokered in the same discourse as conventional ones. Additionally, much research does not consider the power of collective social action to produce transformative change in our relation with the environment, and relies instead on ecologically derived metaphors and models to illustrate peoples relationship to the environment and projected societal responses to climate change (Head, 2010).

These studies are valuable in their own right, but also limited. Social relations are seen only as another additive that needs to be incorporated as a constituent component of vulnerability. Two major criticisms can be leveled here. The first is that they often imbue place-specific power relations and other local scale factors with too much determining capacity. Rather than scaling out from the household and village level to broader conditioning factors the presence of inequality in access and exchange of natural resources, employment opportunities and household vulnerability at the local scale is used to explain away structural difference and drivers. The second problem is that they fail to acknowledge that it is capitalism itself that creates and conditions both the context of vulnerability, environmental change and economic change but also limits and directs the range of potential responses.

It is perhaps a little unfair to categorize these works as essentially tending towards an economic determinism, just as the conventional approaches tend towards environmental determinism. It is worth noting that they make huge assumptions about human agency and the drivers of transformation. However at root they all possess an ideology whereby collective action is simply an agglomeration of individual actors making rational choices. The vulnerability people experience is assumed to be the result of unequal exposure to a range of quantifiable, known processes, a large proportion of which are naturalized. 
These discourses can be represented schematically as:

$\mathrm{V}=\mathrm{E} \Delta+\mathrm{S} \Delta+\mathrm{SR} \Delta$,

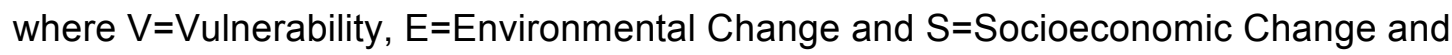
$\mathrm{SR}=$ Social relations.

This schematic is represented in the livelihoods framework by the concept of social capital, and in the work of Adger by the differentiation of vulnerability into individual and social/collective vulnerability. They choose conventional economic indicators in order to explore broad based social relations, of which the single most important is income opportunity. Social relations may be understood as social capital, political capital, formal and informal networks and institutions, which inform both social production and social reproduction. The difficulty in quantifying these social relations has not stopped people from trying, but they are restricted by an epistemology whereby collective action is understood as the agglomeration of individual actions. For example, the concept of social capital is often explored through quantifying membership of formal and informal groups. Questions of who gets to decide, and how, are negated.

A radical approach must make social relations determinant in the final instance, and explain exactly how capitalism conditions and differentiates this vulnerability as it materializes in individuals and households.

\section{Radical Approaches.}

Defining what a radical approach might be makes it easier to judge the range of radical literature. The range goes from what is now termed political ecology which, within itself, has a large range of approaches, many of which are not radical, to studies in the political economy of environmental change. Vulnerability in this schema is a function of a range of socioeconomic processes. The key difference from the first two bodies of literature is that social relations of various sorts and scales are the key explanatory variables. Much political ecology research is concerned specifically with identifying the specific structures and processes that determine place specific livelihood options, but frequently without reference to the materialist base (Bassett and Fogelman, 2013). The best empirical political ecology studies of long term agrarian change demonstrate how rural societies experience vulnerability caused precisely because of their relative position in the local and broader political economic context (Basset, 1988; Watts 1983; Berry 1993; Peters, 2007). They show that relations with a broader political economy can determine the differentiated exposure and vulnerability of livelihoods, and the importance of power relations at all scales in facilitating these processes. It is into this complex understanding of rural societies that efforts to understand adaptation to climate change must be placed.

In this context, adaptation is usually explored through first taking the predicted impact on a range of sectors in a given location. This may be the impact of a change in variability or absolute temperature and precipitation levels on agricultural production, food security, livelihood diversification opportunities, or changing vulnerability amongst other processes. The connection between the means by which livelihoods can become less vulnerable and better adapted to 
potential changes in precipitation and temperature are such that the relationship between development and adaptation is vital here. There is a rich tradition of authors in the hazards literature (Blaikie, 1985; Wisner et al., 2003; Cannon and Müller-Mahn, 2011, O'Brien and O'Keefe, 2014) in seeking to establish the fundamental significance of socioeconomic relations in determining the production and reproduction of differentiated vulnerability in the contemporary rural global South. The relationship between individual livelihoods and broader socioeconomic processes is key (O'Keefe and Middleton, 1998; McCusker and Carr, 2008; Scoones, 2009; Birkenholtz, 2012).

Adaptation to climate change is predicated on understanding its relation to processes of vulnerability generation. For now it suffices to state that climate change is predicted to represent a real, dynamic, threat to the ability of millions of households to sustainably construct their livelihoods. Those livelihoods that are already vulnerable are likely to be amongst those that are most vulnerable, and unable to adapt, to a highly variable and rapidly changing climate. A developing consensus argues that if adaptation to climate change is to be successful and sustainable, it should be mainstreamed into broader development policy and planning (Cannon and Muller-Mahn, 2011; Huq and Reid, 2004; Klein et al., 2007; O’Brien et al., 2008; Ayers and Dodman, 2010).

A broad approach to the political economy of the environment avoids both environmental determinism implicit in much of the conventional literature, and the economic determinism that underpin most of the previously identified critiques of the conventional approach. Cannon and Muller-Mahn (2011) state, '...that it is pointless (or even irresponsible) to consider the risks resulting from climate change in isolation from...food prices, unstable markets for cash crops, debt or state failure' (p.625). Adaptation to climate change must be understood in the context of the wider political economy and the specific, material manifestations of livelihood risk and opportunity. The problem of adaptation is at root the problem of poverty. The problem of poverty cannot be disassociated from the structural causes of it (O'Brien et al., 2008; Cannon and Muller-Mahn, 2011).

This approach can be represented schematically as:

$V=f E \Delta+f S \Delta+S R \Delta$,

where $\mathrm{V}=\mathrm{Vulnerability,} \mathrm{fE}=\mathrm{a}$ function of environmental change, $\mathrm{fS}=\mathrm{a}$ function of socioeconomic change and $\mathrm{SR}=$ Social relationships of production, reproduction, and towards the environment. Environmental change and socioeconomic change are fundamentally a function of these relationships.

In short, the issue of people and climate change is one of the production of risk in the production of nature (Smith and O'Keefe, 1980; Smith, 2009). The production of nature itself is regarded as a critical contribution of capitalism itself. Dialectically, therefore, this requires an understanding of how capitalism in its production of nature produces uneven opportunity of access to adaptation possibilities and thus risk reduction. 
Tanzania: National and Local exploration of Vulnerability

The literature review has demonstrated the validity of a radical concept of vulnerability being necessary to understand who is actually most vulnerable, the reasons why this is and the processes that drive this. It has shown the importance of understanding vulnerability as a process and not just a (temporary) state of livelihood.

\section{Conventional Approaches}

Mongi et al. (2010) understand vulnerability in Tanzania explicitly as the risk of crop failure caused by a changed climate. The environmental basis of vulnerability in this formulation is overt. An external environmental event causes new vulnerabilities to emerge. A linear process occurs whereby the climate changes, crops become more vulnerable, therefore people become more vulnerable. To quote from their paper,

"A vulnerability assessment of rain fed agriculture to climate change and variability in semi-arid parts of Tabora Region in Tanzania was conducted in 2009...Results indicate that the overall rainfall amount was found to decline while distribution was varying both in time and space. Interseasonal dry spells between January and February appeared to increase both in duration and frequency. Temperature has shown an increasing trend....Major implications on rain fed agriculture are possible shrinking of the growing season, increasing moisture and heat stress to common food and cash crops, increased insects and pests and eventually low income and food insecurity. This study concludes that there is strong evidence demonstrating the vulnerability of rain fed agriculture to negative impacts of climate change and variability in the study area (p.371)".

Agrawala et al. (2003) provide another example of the conventional understanding of vulnerability, relating to both climate change and the case study area. It is broadly emblematic of a range of global studies seeking to quantify the impacts of climate change on agricultural productivity, and the subsequent consequences for livelihoods. These studies seek to quantify precisely how much of a threat climate change is to agriculture, which de facto makes livelihoods more vulnerable. It is difficult to escape the determining power of the natural environment in these formulations. Mendelsohn et al. $(1994,2007)$ are at the forefront of these efforts globally, and they remain highly influential. If we are to commit investment towards reducing the predicted impacts of climate change, then it is of course necessary to explore what changes may occur. However, framing these issues as being driven ultimately by the vagaries of the climate misses the complex of factors such as local, national or international marginalization of people, trends in commodity production, government support for agriculture, international efforts to achieve certain types of development that all play a significant role in determining vulnerability. 
The overwhelming problem with these approaches, is that change in livelihoods and vulnerability is driven by a changing environment. The social relations that determine vulnerability in the first and last instance are barely mentioned. It may be highly appropriate science for exploring the relationship between crop yields and environmental factors and change, but it is rather weak social science when it comes to explaining the very existence of highly differentiated vulnerability.

\section{Critical Approaches}

In seeking to avoid environmentally determinist explanations of vulnerability, other authors have specifically addressed social issues.

Christiaensen and Sarris (2007) approach the concept of vulnerability from a strictly economic perspective, "...the likelihood of being poor in the future" (p.1). This is an important corrective to previously discussed work, as it focuses both the sources and the impact of vulnerability strictly in the realm of socioeconomic relations, but it also recapitulates some questionable assumptions. The first point to make is that this paper explicitly repeats the tautology that Middleton and O'Keefe (1998) allege is present in Blaikie et al. (1994): vulnerability simply becomes synonymous with poverty. The poorer you are, the more vulnerable you are, and vice versa. This evidently has a factual basis, as the poor on average are much more likely to be vulnerable. However, the processes by which this vulnerability manifests is not simply that lack of capital equals vulnerability. It highlights the close linkages between socioeconomic position and broader vulnerability, but provides no explanation as to why these processes occur.

The paper does highlight the coupled nature of vulnerability coming from exposure to both commodity price fluctuations as well as rainfall variability, which is important, but it places the question of vulnerability in the future. The linking of vulnerability with future, expected poverty, completely missed the means by which structural and historical events hugely determine both contemporary and future vulnerability. It may be ironic (to some) to have an argument couched in Marxist ideas to accuse other authors of economic determinism, but following Harvey (2009) the claim is made that neither Marx nor Marxism need be economically determinist.

There have been a wide range of studies seeking to explore more critically the relationship between livelihoods, vulnerability, exposure to environmental hazards and options for coping and adaptation. Two approaches are sympathetically critiqued here, which are the double exposure framework and the livelihoods approach. Both have been used to highlight the 'coupled' aspects of socioeconomic and environmental sources of vulnerability (double exposure), and vulnerability and livelihoods (Livelihoods approach).

Holler (2014), in his work of the Kilimanjaro Region, defines vulnerability specifically as "[the] susceptibility to be harmed by a hazard" (p.527). This draws heavily on the dominant view of vulnerability represented by Adger, O'Brien, Leichenko, and Paavola amongst others. This view 
holds that vulnerability is the combination of exposure, sensitivity and adaptive capacity (Paavola, 2008). This is scaled from the individual to the social to frame the Holler (2014) study.

The key findings from the Holler study are that those who can take advantage of measures to increase adaptive capacity tend already to be relatively less vulnerable than others, and consequently adaptation measures already undertaken on Kilimanjaro are reproducing, rather than reducing social vulnerability. Regarding vulnerability specifically, he identifies "at least" four processes driving it on Mt. Kilimanjaro: "climate change, land and forest degradation, economic change... and population increase". Importantly, the sources of vulnerability are coupled, but there is no indication of the mechanisms by which these processes structure and differentiate livelihood vulnerability.

The livelihoods framework (Scoones 1998; Scoones, 2009) defines vulnerability as a combination of both economic and environmental forces that make livelihoods more vulnerable. They are classified as being shocks, trends, or seasonality. Chapter three of this dissertation used this framework to explore vulnerability on Mt. Kilimanjaro. Using the framework along with evidence from the field, major shocks were identified as being health events and drought (matching the findings of Christiaensen and Sarris (2007)), major trends were associated with a shift in household food production towards maize (from bananas, cf. Maghimbi, 2007) and fluctuating commodity prices (especially coffee), and significant seasonal variation in precipitation, household expenditure requirements and opportunities for income generating activities. The argument made here is not that these processes are not indicative of vulnerability, rather that they identify the source of vulnerability as completely external to the social relations that enable, mediate and restrict access to the different capital assets of the livelihoods framework.

To expand, the heart of this critique lies in this externalization, and partial naturalization of the sources of vulnerability. Drought is probably the most serious natural hazard that affects the livelihoods of people in Kilimanjaro Region. Seventy two per cent of respondents stated that drought had a great impact on their agricultural productivity, fifty nine per cent claimed that it had a great impact on their health and thirty two per cent perceived it as having a great impact on availability of energy sources. When asked to identify the last time a drought affected the area they reside in, a wide variation of years was recorded, indicating that the effects can be very localized; following Wijkman and Timberlake (1984), drought may simply be an instance of not been able to access enough water to sustain a particular livelihood option. This was especially true in the more arid parts of the case study area, where drought was simply not an issue for 22 per cent of households that were able to access piped water. Of course, drought is a climatic process, but the ability of people to adapt and cope with its effects is a function of existing social relations that have permitted some households to access adaptive measures, but prohibit their widespread adoption.

These examples are not intended to belittle the value of research carried out by (often African) physical scientists and social scientists. Indeed, some of the same authors are engaged in work 
that can be placed in both the conventional and the conventional critique categories, showing reflexive dynamism in trying to understand the 'wicked problem' of climate change.

\section{Radical Approaches}

Wangui et al. (2012), in a political ecology study, do not specifically engage with vulnerability in Kilimanjaro region, but explore many of the same this issues that this paper engages with: livelihoods, climate change, coping with environmental stress and capacity of people to adapt. Even though vulnerability is a hugely important component of many of the authors' works (Wisner et al., 2003; Smucker and Wisner, 2007; Mascarenhas, 2010), it is curiously absent in this paper. Although it is neither environmentally or economically deterministic, the factors that shape vulnerability, which fundamentally underpin differentiated risk in Kilimanjaro Region, are barely mentioned. Rather they place the process of adaptation itself at the center of livelihood diversification as a response to vulnerability (p.13).

Mascarenhas (2010), part of the group that produced the Wangui et al. (2012) paper, perhaps comes closest to defining, specifically in this region, what this paper is exploring. He asks, "How significant is climate change in understanding vulnerability and resilience... among farmers in Kilimanjaro Region - Tanzania?... with or without climate change, the vulnerability and resilience is more dependent on socio-economic alignments rather than on physical factors alone" (p.4). This next section will attempt to elucidate this version of understanding both vulnerability and its determining constituents.

One radical approach to understanding the relationship between climate change and livelihoods is to focus on the role of the state in defining the drivers of vulnerability, along with the prescription for increasing resilience. In another paper by the same group as Wangui et al. (2102), Smucker et al. (2015) identify the roots of naturalized discourses regarding the understanding of climate change and vulnerability as emanating top-down from government and technocratic formulations. These are then recapitulated by farmers, who as yet do not seem to have universal knowledge of the institutional (Kiswahili) definition, even when accounting for their intimate knowledge of their immediate environment (Wisner et al., 2012).

This rejection of the state as an agent with the interests of rural livelihoods as an object of development derives heavily from Ferguson (1990) and Scott (1998). It raises the question of what exactly is being made less vulnerable or more resilient: the livelihoods of people or the institutions of government (O'Brien, 2005; Wisner et al., 2012; Smucker et al., 2015). In the case study area the role of the government and associated technical knowledge in defining the language of climate change becomes critical and determining. The failure to differentiate rural livelihoods in the face of a monolithic climate threat both naturalizes the sources of vulnerability and removes local capacity to interpret and adapt to change. Moreover, many proposed adaptations to climate change are likely to reinforce existing forms of social relations and processes of differentiation (Holler, 2014). 
This is an important insight but it leads to a conclusion that is diametrically opposed to that which most radical approaches to vulnerability reach. Smucker et al. (2015) argue that linking state driven development with undifferentiated adaptation policies, "[cast] doubt on the presumed benefits of integrating adaptation into development policy" (p.48). This is an unusual conclusion for a radical approach for two reasons. First, it argues that adaptation has already been mainstreamed into existing development policy, something that other scholars have argued must be done in order to reduce vulnerability (Cannon and Muller-Mahn, 2011). Second, the argument appears to be made that adaptation ought to be disassociated from existing development practices if it is to succeed, as successful adaptation is an inherently local process. Essentially, a rejection of the state, rather than capturing the state for development purposes is the goal.

\section{Vulnerability, political economy, scale and climate change on Kilimanjaro}

Coulson (2014), restates the need for political economy along with history to understand changing social relations. These debates are not over even if they are not being made at the present moment. O'Keefe (2015) attempts to do this using primary and secondary sources. He argues that vulnerability is intimately tied to the relationship between households, the specific historical and environmental context and the wider socioeconomic processes that structure and differentiate it. Which people are most vulnerable, and consequently have least capacity to adapt? O'Keefe (2015), along with others (O'Keefe, 2013, O'Brien et al., 2008) has demonstrated that vulnerability is perceived and experienced by households in a range of ways: as heightened exposure to the impacts of drought, as an inability to adequately provide food for all household members, (increased) reliance on sufficient rainfall to sustain livelihoods, and lack of financial capital.

One example of a structural shift, rooted in both socioeconomic and sociocultural processes, is a dietary one. The transformation from bananas to maize as the staple carbohydrate on Mt. Kilimanjaro has occurred in the past thirty years (Maghimbi, 2007). The effect of this is most pronounced on the mountain where the coffee and banana groves have existed for most of the last century. This is important because it is almost impossible to achieve high levels of efficiency with a crop like maize in small plots like that found on the upper slopes of Kilimanjaro where household kihambas (homegardens) are found.

Overall, average food security on Mt. Kilimanjaro is fairly high. However, pockets of deprivation exist, and historically this has been unusual as Kilimanjaro region has been one of the relatively richest regions but has had a disproportionately high level of malnutrition (Howard and Millard, 1997). The reason for this unexpectedly high level of food is suggested to be a consequence of changing social relations on the mountain through the twentieth century. Previously dominant clan obligations, and redistributive cultural practices reduced the increasing inequality in a society that was gradually becoming incorporated into the global capitalist system. This development of capitalist relations, and the consequent rural differentiation that occurred, that has led to the presence of higher than expected levels of malnutrition. 
It has had effects on household vulnerability in a range of ways, most noticeably in reducing options for generating income through the sale of export orientated agricultural crops, rather than maize production for household or local consumption.

The most typical historical pattern of transformation in rural areas articulated to the capitalist mode of production is that of differentiation. Small-scale farmers, of which $85 \%$ of households in the area, are an analytical category that hide as much as they describe. It has been known for a long time that agricultural self-sufficiency in rural households is rarely achieved, or even desired (Bryceson, 2000) - ostensibly 'farming' households, both in the literature and in O'Keefe (2015) are compelled out of necessity to seek out a range of income generating strategies.

Diversification of household livelihood strategies is on its own, not particularly novel. O'Keefe (2015) presents results comparable with those of Mueller (2011): of the 206 households surveyed, only $5 \%$ stated that it was possible for the household to meet all its food requirements without working outside the farm. This indicates that across all wealth categories household members are required to engage to some form of off-farm income.

What follows is a 'cameo' of the characteristics of 'typical' vulnerable households on Mt. Kilimanjaro. It is based upon observations from the fieldwork of those households that struggle most with producing and reproducing their livelihoods.

On Kilimanjaro, vulnerable households are not landless in the literal sense. Most have at least a very small amount of land accessible, and many have a degree of land tenure security. However, they lack the ability to access credit for investing in agriculture, and are unable to access more land close to existing plots: their place based social networks have been eroded and they haven't been able to take advantage of new technologies (particularly cell phones). Previously communal access to resources has been restricted or made prohibitively expensive (water, firewood/charcoal), and are not able to grow enough for subsistence or a surplus to sell to secure their livelihood. These households also tended not to receive significant remittances from outside the area. They are unable to invest in novel agricultural techniques for intensification, usually through a combination of not having access to education or sources of expert information, and not being able to mobilize the resources, labor power and technological inputs as successfully as other households. Consequently, they are liable to be missed in development interventions and projects that are increasingly results driven and small-scale farmer focused, as it is easier to achieve transformation by focusing on those who have the capacity to change.

An important counter to this are the households that are not vulnerable to the same degree. Many of the least vulnerable households observed in the fieldwork based their security primarily on secure, waged employment (teachers, government workers), remittances from relatives or other off-farm sources of income. A significant proportion of the ways by which rural livelihoods are secured are derived from relations with external sources. This is also indicative of how social capital has transformed as networks and relationships are increasingly less place dependent and defined. Following Holler's (2014), these people are the group most likely to take 
advantage of adaptive measures to reduce their vulnerability to climate change and other threats to livelihoods.

Understanding vulnerability as a process necessarily involves assumptions about what drives changing livelihood vulnerability. Conventional approaches, the critique of these approaches and the radical version of vulnerability presented in this article all contain some motive force driving socioecological change.

First, the idea of transformation is found in certain studies that attempt to quantify the impact of climate change on agricultural production and the consequent implications for food security (Mendohlson et al., 2002; Nelson et al., 2014). Inherent in this position is the assumption that changes in precipitation and temperature trends and extremes drive and determine yields, which in turn threaten the ability of people to command satisfactory food resources. The assumption that local food production is determinant in how the vulnerable rural poor access food is an ideological as much as evidence based position. It is not novel to point out that how people access food, and how this access is structured and differentiated, and the ability of individuals and groups to demand food security as an entitlement, are usually significantly more important in reducing both individual and collective vulnerability to the threat of hunger.

Second, a contemporary mainstream development economics perspective on rural transformation. McMillan and Heady (2014) show how economic understanding of rural development is predicated on (labor) productivity in both agricultural and non-agricultural sectors, quantified as the value of goods and services produced for exchange, with increased productivity both the mechanism and the target goal. Development in this paradigm is increased, measurable economic growth, and effort is directed towards transforming the institutions and structures that enable and regulate this activity. Vulnerability is just what happens if people remain poor.

A focus on the question of scale highlights the contradictions inherent in reconciling different ideas of both socioeconomic and environmental vulnerability. Smith (1992) pointed out that scales were frequently jumped, and households in Kilimanjaro face 'jumped scales' not simply in the social world but in the physical world as well. Critical approaches to understanding vulnerability enable these issues to be placed in relation to each other. Broadly, the argument being made here is that biophysical framings of climate change impacts have not successfully scaled down, and that much adaptation to climate change research has not scaled up sufficiently. This expands on criticism made by Head (2010), Shove (2012) and Mascharenas (2000).

The question of scale bedevils the issue of climate change. Climatological, physiographic and coupled human-natural systems research tends to begin with the global scale (Mendelsohn et al, 2007; Turner et al., 2003; IPCC 2001, 2007, 2014). The problems with this are best highlighted by the difficulty in scaling down these models into making accurate predictions regarding the specific temperature and precipitation changes, and consequently the impacts on livelihood production and reproduction. Ahmed et al. (2011) highlight this difficulty in identifying 
predicted climate change impacts on Tanzania. Broad trends in temperature increases are expected, but precipitation trends remain unclear, as does the expected change in climatic variability. On Mt. Kilimanjaro, high variation of precipitation and temperature occurs over a relatively small spatial area, based upon altitude, aspect, and various other micro factors (Bart et al., 2006).

This discussion begins from the household scale. As with much political ecology type research, household surveys, in depth interviews and other mixed methods contributed to an extensive knowledge base regarding local livelihood strategies and landuse practices. It also begins from the household scale because this paper at its core is an exploration of the viability and options for social reproduction of rural livelihoods. At the household scale availability and potential to commodity (often male) labor, female ownership rights of land, and household usufruct access to common resources determine livelihood strategies and contribute to differentiated vulnerability (O'Keefe, 2013).

At community level there has been a collapse of traditional communal and customary coping and adaptations to land ownership, increasingly privatized, to water availability, increasingly scarce for some, to agricultural inputs, which are now market based, and to the collapse of producer coop organizations, especially coffee.

The next scale is local. At this scale it is apparent that the issues of local government commitment supported strongly by the top-down party framework leads to a successful defense against famine conditions, but leaves aside questions about the ongoing existence of chronic malnutrition and hunger. The causes of these issues are multi-scalar, increasing inequality and continued malnutrition in a relatively wealthy part of Tanzania.

At regional level, there is the first appearance of hard physiographic data, especially on climate. However, it is not sufficiently disaggregated to allow community level knowledge, diagnosis and prescription regarding reducing vulnerability and options for adaptation. For example, while extremes appear to be increasing (particularly temperature), there is still a paucity of accurate historical climatological data, it is unclear if contemporary trends will continue at the same rate (Mwandosya et al., 2003; O’Keefe, 2007; Ahmed et al. 2011).

The regional level also contains a substantial change in pastoralism. Although Kilimanjaro Region is dominated symbolically by Kibo peak, the foothills and plains of the region have been an important area for the Maasai and other pastoralist groups. The relative demise of pastoralism and thus the reduction in exchange between the Chagga agriculturalists and pastoralists has coincided with the consolidation of dryland areas that form the 'shambas' (second farms originally assigned through customary means on the basis of need). These ownership patterns are based in part on a failed Ujamaa policy, and more recently with the drive to achieve agricultural modernization (URT, 2010). My research suggested approximately $50 \%$ of households surveyed do not have access to 'shamba' land. This, most importantly and previously alluded to, is where national policy level intervenes. 
The national level is driven by agricultural modernization of dryland areas, thus precluding many Chagga from agricultural expansion. Driven by global emphasis on the need for agricultural development and modernization (World Bank, 2008), with small-scale farmers central to achieving this goal, Tanzania has attempted to intensify agriculture and increase its profitability. Unfortunately, it seems to be doing this by letting lands out to national and international capital at the expense of its own farmers (Coulson, 2014).

The agrarian question of how these rural areas will differentiate as modernization occurs is incredibly pertinent here, yet missing from just about every study of climate change impacts. Also, at a national level, critical off-farm income opportunities are often provided by government services throughout the nation, or found in the largest city, Dar es Salaam (and Arusha). These are some of the few livelihood strategies that are closely associated with less vulnerable households, and indicate again the importance of understanding the root causes of (reducing) vulnerability across scales.

At international level, the vagaries of commodity prices, both exports (coffee and other export crops, also natural gas) and imports (specifically oil and agricultural technology), the limited incountry capital accumulation, and the non-generation of a domestic middle class with enough purchasing power to drive an accumulation strategy, limit contemporary options for development and investment. Marginalized in both the spheres of production and circulation of global commodity chains, somewhat ironically Tanzania is likely to depend on international and bilateral agreements in order to unlock the capital necessary to achieve a reduction in vulnerability and sustainable adaptation options.

This is a broad political economy of scale. How does this relate to vulnerability? First, is that vulnerabilities are generated beyond the control of individual farming households. Secondly, it means that in Kilimanjaro Region in the 21st Century there is an expansion of the geography of dispossession through land lease to national and international companies and capital (Shivji, 2009). Thirdly it means that an increasing proportion of the Kilimanjaro population will become increasingly marginalized, first used a device by Susman et al. (1983). Not least because, of deproletarianization through decreasing formal sector opportunity (Brass, 2004; 2011b). The whole debate needs to be linked to the debate on poverty alleviation, in much the same way that the debate on disaster risk reduction needs to be related the debate on accelerated climate change, especially extremes (Cannon and Muller-Mahn, 2011; Wisner, 2015).

In trying to hold these contradictory, dynamic and multi-scalar relations in a coherent framework it is useful to return to Harvey (1996; 2009; 2014), and also the arguments of Brass (2011a; $2011 \mathrm{~b}$ ). Marginalization means minimal proletarianization is occurring in the region, and without proletarianization there is no basis to obtain from capital what is needed to achieve social reproduction (Brass, 2011b). Vulnerability and marginalization are meso-level concepts and illuminate the range of causes that threaten the viability of household production and social reproduction. However, they must be nested within the macro-level of capitalist accumulation, dominant at a global scale and percolating to all scales. 
Focusing on the changing social relationships that alter vulnerability enables two things. First, to question whether mainstream approaches to achieving 'climate proofed' sustainable development are successful, if they fail to reduce vulnerability of the most precarious. Secondly, it demonstrates that this uneven development and differentiated vulnerability is fundamental to the production and reproduction of specific social formations under capitalism. Exploring the impacts, and especially predicting future trends, of environmental processes on social development is hugely complicated by this unevenness, particularly when observing village, household or individual scales. Almost no climate models for sub-Saharan Africa operate on a resolution finer than $25 \mathrm{~km}$ x $25 \mathrm{~km}$ (Wangui et al., 2012). In the Kilimanjaro Region this geographical space hides vast socioeconomic and environmental variation, therefore modeling alone fetishizes the significant different ion between households, sub-villages and villages. The ability of households to produce secure livelihoods, and to cope with and adapt to existing climatic variability is highly variable, over a small geographical area, and the roots of this vulnerability are found in existing social relations both on the mountain and with the broader political economy.

\section{Conclusion}

This paper has argued that social relations must be central to any analysis of coupled socialnatural processes, and concurrently for the importance of the specific geographical and historical that also codetermine the material reality in which livelihoods are produced and reproduced. These same processes are also those that drive the differentiation of vulnerability and resilience. It validates the arguments made by Tschakert et al., (2013) regarding the importance of understanding structural causes of vulnerability, and supports Holler's (2014) cautionary tale of how the least vulnerable tend to be those benefitting from existing adaptation measures in Kilimanjaro region.

It is difficult to talk of the coproduction of environment and society unless social relations of production and reproduction are predominant. The literature review and the case material showed that for the conventional there was an inclination for environment to dominate and therefore no examination of the coproduction of environment. For the critique of the conventional, there was a tendency for the economic to dominate, and attempts to capture the social dynamic were essentially simplistic and superficial. The difficulty of having a radical approach requires a dialectic that covers the production of nature, the production of uneven development and understanding of place an culture and most importantly an understanding of the various scale factors that impact local livelihoods. In this essay there has been an attempt to address these factors, but any sense of failure is not a sense of failure but the hope of a better dialectical understanding that will lead to real adaptation and disaster risk reduction opportunities. 


\section{Chapter 6: Conclusion}

This dissertation has demonstrated that it is the change in social relations of production and reproduction, driven by changes in capitalism and climate change on Mount Kilimanjaro, that are at the root of differentiated household vulnerability. This vulnerability manifests itself as an inability to cope with drought, an inability to commodify labor and an inability to access the necessary options for social reproduction.

For most households, vulnerability materializes as an inability to access adequate food security. Although hunger does not affect every household, it remains the principal reason for defining a "bad year" for the majority of them. Entitlements, whether customary or state provided, are generally weaker than in the past.

Climate change enters this mix as a 'wicked problem' (Lazarus, 2009) - inextricably related to existing processes. This dissertation has demonstrated that there is no compelling evidence why it will necessarily become the determining factor in the viability of rural livelihoods and the generation of differentiated vulnerability in the case study area. How, then should reducing vulnerability, increasing resilience, and identifying appropriate climate change adaptation responses proceed. There is broad agreement amongst social scientists that climate change adaptation needs to be mainstreamed into development (Ayers and Dodman, 2010). There is increasing recognition that vulnerability reduction/increasing resilience that is not truly transformative is simply, at best, coping within the existing status quo (Smucker et al., 2015). In their discussion of vulnerability in another part of Kilimanjaro Region, Smucker et al. (2015) propose the notion of transformative resilience. This dissertation's findings strongly support this idea, but with one major caveat. Smucker et al. (2015) essentially reject the state as the agent of development: the argument made here is that it is the principal, if not the only actor with the capacity to engender development and hence vulnerability reduction in the case study area.

So what then of the most vulnerable? What are the steps that should be taken to reduce the vulnerability of these households? The nationally supported answer to reducing poverty in rural areas of Tanzania, and consequently in theory reducing vulnerability, is to increase the profitability of agriculture. However, it is already apparent that those who are able to benefit from this are not generally those already on the mountain who engage primarily in agriculture. Rather, it is locals who are able to draw on capital reserves obtained through off-farm income, or external flows of capital coming in.

This dissertation argues for a radical notion of vulnerability as the necessary way forward if the most vulnerable to climate change are to have the greatest chance of adapting. This is particularly important at this current point as the IPCC WG2 has acknowledged the importance of social relations in understanding vulnerability (Tschakert, 2013) and is continually working to incorporate these ideas into its Assessment Reports. Therefore this dissertation contributes to this idea. It does so, however, by showing that a narrow focus on climate change, its impacts and the options for adaptation is actually an ineffective way for reducing the vulnerability that makes households more susceptible to future climate change. It has also shown the limitations of livelihoods, resilience, adaptive capacity and narrow economically or environmentally deterministic versions of vulnerability. 
Smith (2009) in his foreword to the 3rd edition of Uneven Development wrote that a genuine dialectical critique of climate change was necessary and not yet forthcoming. There are many reasons in which this has not materialized as of yet: the catastrophism of some climate change campaigners (Swyngedouw, 2013), the fear of being associated with oil-industry funded astroturfers and climate change deniers prominent amongst them. However, there is genuinely a case that climate change adaptation research has become a black box into which research funding and intellectual decisions are framed around.

Climate change is held by many to be as transformative and determining as capitalist relations of production, reproduction and towards the environment are. This research has shown that this is not the case: it is the production and reproduction of daily life in which both vulnerability is generated and various risks manifest themselves. Marginal increases or decrease in crop yields, which is the principal pathway by which climate change. The evidence from the household level in Tanzania in this dissertation indicates that there is no reason to assume this is the case. Rather, it is in precisely the struggles to achieve control over production and reproduction of everyday life that vulnerability is both generated and experienced.

Historically, the biggest transformations in the systems of social production and reproduction on Mt. Kilimanjaro have occurred as a consequence of exposure and integration into colonial and capitalist relations. The Chagga identity was forged out of different clans on the mountain that spoke, in places, mutually unintelligible languages. This process was driven as much by topdown colonial rule that sought to have an identifiable group in the area, with a hierarchy and leaders who could control the population as much as immanent coming together of those on the mountain (Bart et al., 2006; Shivji, 2009).

A dialectical approach to climate change and vulnerability must rescale from the concrete and empirical to the abstract. This discussion concludes with an attempt to do this, relating processes of vulnerability generation and climate change to other structural drivers of transformation, and macro-level theories of change.

\section{The question of scale}

Scale is fundamental to geography and understanding the relationship between global processes and local manifestations. Unfortunately, much recent work on the question has rejected the idea of scale as incorrigibly hierarchal. This dissertation has led me to believe that the question of scale must be central to discussions of vulnerability, livelihoods and adaptation to predicted climate change.

Based on my experience during fieldwork in Tanzania, it has increasingly being clear that a variety of scales, partially but not deterministically hierarchal, impact on the construction of livelihoods and the generation of differentiated vulnerability on Mt. Kilimanjaro. One example is perhaps enough to highlight the importance of scale when trying to simultaneously explore processes of environmental and socioeconomic change on the mountain. The principal basis for predictions regarding future climate change are General Circulation Models. Global and regional modeling has been developed to generate scenarios of future climate change that can then be compared against existing and past climate and past coping mechanisms to determine how people might adapt or may be forced to react should dramatic climate changes become 
manifest at local scales. These predictions are often made on a regional scale, missing huge degrees of livelihood differentiation. The highest resolution of these models tends to be no smaller than $25 \times 25 \mathrm{~km}$, which simply cannot capture the diversity of environmental and socioeconomic variation in a location like Kilimanjaro.

\section{Scale and Kilimanjaro}

The key question that has emerged from this dissertation is how is scale experienced at household level? Specifically, how do global processes of commodity exchange, climate change, attempts to achieve agricultural modernization and dominant discourses of development trajectories materialize in the lived experience of households? Whilst not an exhaustive list, these processes are highly indicative of how households are acted upon by a range of scales.

The highly variable global price of commodities, in this case study coffee, is a significant source of risk for households. The risks can be moderated somewhat by strong local institutions that are able to guarantee quality of product, and hence its likelihood of finding a buyer. Survey respondents talked about removing coffee trees from their gardens, or ceasing to maintain the bushes, due to it not being economic. It was usually replaced with the planting of maize, which at least offers the potential of both use value and exchange value. These findings tally with Maghimbi (2007), who noted a broad shift in the homegardens of Kilimanjaro from coffee to maize.

Coffee therefore highlights the importance of scale in studies of livelihood vulnerability in two key ways. When coffee was the major source of accumulation on Kilimanjaro, its success was largely based on households scaling up and forming the KNCU, a producers union. Prevailing conditions in the 1930s even enabled an expansion of coffee farming in parallel with a globally depressed price, due to comparative advantage of producing on Kilimanjaro. The strength of the union also enabled local people to take advantage of educational and commercial opportunities, becoming disproportionately influential in the newly independent Tanganyika. Opportunities to jump scales are much more limited now, due to a weakened union, relatively little support for agricultural activities as well as the geographical limits to expanding coffee production on the mountain.

Climate change is therefore a science that cannot predict accurate impacts on production systems at the local scale, and tends to homogenize the huge levels of rural variability under the assumption that most households will be affected by difficulty growing certain crops. And further, that these crops are primarily picked for cultivation on the basis of exclusively climatic factors. This dissertation has indicated that this is not the case.

\section{Scale, livelihoods and vulnerability}

What nobody is talking about is the daily lived experience of social production and reproduction. This is where vulnerability is generated, vulnerability that is dependent primarily on access to these means of social production and reproduction. 
Currently we are, to an extent, jumping on climate change to both explain and provide a mechanism to respond to crisis. What I have shown is that when we look across scale these processes show the relationship back to issues of class, scale and other known processes. We don't know if people respond to climate change or weather variability. We've jumped on climate change as a means to force (or reject) the state to address uneven development.

This dissertation has argued that differentiated household vulnerability is driven by social relations. Differentiated access to land, to secure employment and other strategies to Climate change as one potential multi-scale hazard amongst many. Evidence from this research suggests that it is the processes of social production and reproduction that create a greater risk, and therefore vulnerability, than that of climate change.

This research began with the notion that environmental and socioeconomic processes were, all things being equal, capable of generating vulnerability towards households. What this Tanzanian example shows is that it is in fact social relations that dominate this coproduction. Secondly, the key question of the coproduction of nature is whether capitalism is produced in such a way that the environment becomes in crisis because of capitalism, or the environment becomes in crisis through lack of capitalism. Agreeing with Shivji (2009), it is the lack of capitalism, specifically the inability to commodify labor at a rate that enables social reproduction, allows non-productive social relationships to dominate the Chagga on Kilimanjaro. Bringing Harvey's (2009) framework back in, on the six moments of transition there is incomplete transformation. However, although there are many relics of pre-capitalist social formations in the case study area, the logic of production for surplus value dominates the region overall. If capitalist relations were able to be fully established, it would in theory enable many more households to sell their labor or surplus product (not surplus value) to the regional and world economy.

Using the dialectic, which is frequently seen as being forcefully about purpose, not about projection, leads me in this case study to say there can be a residual to capitalism which is largely without purpose in the contemporary round of accumulation. In other words, it is the opposite of Smith's argument on gentrification - that there was a purposeful capitalist accumulation process. The problem here is that there is none. The dialectic can illustrate results, but can also highlight non-results - this in a sense is a non-result - it is the failure of capitalist relations to fully establish themselves.

This relationship between capitalist transformation, vulnerability and livelihoods is particularly important regarding measures to reduce vulnerability, increase resilience and options to adapt to climate change. Fundamentally, most proposed adaptation measures (especially relevant to this case study is Holler's (2014) identification of potential adaptive options) are in essence 'sticking plaster', ways of attempting to maintain the existing livelihood strategies and social formations in the context of a changing world. New varieties of cops, efficient stoves and other localized measures don't contain any transformative potential within them, and Holler (2014) also notes that even these measures tend to be most available to the better connected, less vulnerable households. If there was a form of capitalism that provided vulnerable households with an opportunity to access employment or more profitable agriculture we would be looking for completely new adaptation mechanisms. 
Many academic arguments are in the past tense, or preserve contemporary conditions in aspic they are about a social formation and a pre-capitalist mode of production that no longer exists. Although we can't be certain of the future tense (dialectically), the defense of only the past tense is a poor argument to defend the people. This dissertation is not predictive, however it has explored the relations of existing conditions and teases out feasible possibilities of future options. It is not the environmental contradictions that drive forward and determine future society, it is only by understanding social relations that can give us a grasp on the future tense.

I believe I have materialized coproduction of nature but in this realization I have sensed that social relations are more important that physical/natural-social relations. I have also sensed that in terms of climate change, with the melting icecaps of Kilimanjaro as an iconic reference, that climate change is relatively unimportant in the transformation of the local livelihood system. Much of the argument is too big and beyond, Kilimanjaro, Tanzania and Africa to quite capture. Central to vulnerability and livelihoods are the relations of capital to property, especially land. Under colonial rule, communal land was allowed but the state became the ultimate proprietor. For Tanzania's future, as a nation state, it means that it has control of land leasing and sales. Currently international markets and institutions look as if they will direct the Tanzanian state to large scale land sales to finance its future. There are many voices against that (Shivji, 2009), or bemoaning that (Wisner, 2015). There are not many voices that speak for the people. This dissertation has argued that vulnerability will be reduced when adaptation occurs because of development, as opposed to others who are broadly trying to keep the old social formation alive. Quite simply adaptive capacity increases through development. Adaptation shouldn't be mainstreamed, it should be subsumed. Because in the absence of development, vulnerable households have virtually no adaptive capacity. Focusing on "bouncebackability" or "bounceforwardability", i.e. focusing on vulnerability or resilience is missing the point. From the perspective of the most vulnerable households, perhaps they don't go forwards, backwards, maybe they don't go anywhere. Just cope and struggle to reproduce the status quo. 


\section{References}

Adger, W.N. (1996). Approaches to Vulnerability to Climate Change. Global Environmental Change Research Papers. Norwich: Centre for Social and Economic Research on the Global Environment.

Adger, W.N. (1999) Social Vulnerability to Climate Change and Extremes in Coastal Vietnam. World Development 27 (2), 249-269

Adger, W.N. (2006) Vulnerability. Global Environmental Change. 16: 268-281

Adger W.N., Huq S., Brown K., Conway D., and Hulme, M. (2003) Adaptation to climate change in the developing world. Progress in Development Studies 3(3): 179-195

Adger W.N., Dessai, S., Goulden, M., Hulme, M., Lorenzoni, I., Naess, L.O., Wolf, J., and Wretford., A. (2009) Are there social limits to adaptation to climate change? Climatic Change. 93: $335-354$

Agrawala, S., Moehna, A., Hemp, A., Van Aalst, M., Hitz, S., Smith, J., Meena, H., Mwakifamba, S., Hyera, T., and Mwaipopo, O. (2003) Development and Climate change in Tanzania: focus on Mount Kilimanjaro. Paris: OECD Environment Directorate

Ahmed S.A., Diffenbaugh N.S., Hertel, T.W., Lobell D.B., Ramankutty N., Rios A.R. and Rowhani, P. (2011) Climate volatility and poverty vulnerability in Tanzania. Global Environmental Change. 21: 46-55

Andalkar, A. (2003) Skiing the Pacific Ring of Fire and Beyond.

http://www.skimountaineer.com/ROF/ROF.php?name=Kilimanjaro, last accessed 08/09/09

Ayers and Dodman (2010) Climate change adaptation and development I: the state of the debate. Progress in Development Studies 10 (2): 161-168

Bart, F., Mbonile, M.J., and Devenne, F. (2006) Kilimanjaro: Mountain, Memory, Modernity. Dar es Salaam: Mkuki na Nyota

Bassett, T.J. (1988) The political ecology of peasant-herder conflicts in the northern Ivory Coast. Annals of the Association of American Geographers. 78 (3): 453-472

Bassett, T.J. and Fogelman, D. (2013). Deja vu or something new? The adaptation concept in the climate change literature. Geoforum. 48: 42-53

Bebbington, A. (2004) NGOs and Uneven Development: geographies of development intervention. Progress in Human Geography 28 (6): 725-745

Berry, S. (1993) No condition is permanent: the social dynamics of agrarian change in subSaharan Africa. University of Wisconsin Press: Madison 
Birkenholtz, T. (2012) Network political ecology: Method and theory in climate change vulnerability and adaptation research. Progress in Human Geography. 36: 295-315

Blaikie, P. (1985) The Political Economy of Soil Erosion. London: Heinemann

Blaikie, P., Cannon, T., Davis, I., and Wisner., B (1994) At Risk. 1st Edition London: Heinemann

Brass, T. (2000) Peasants, Populism and Postmodernism: The return of the Agrarian Myth. London: Frank Cass

Brass, T. (2004) 'Medieval working practices?' British agriculture and the return of the gangmaster. The Journal of Peasant Studies 31(2): 313-340

Brass, T. (2011a) Primitive accumulation, capitalist development and socialist transition: still waiting for Godot? Journal of Contemporary Asia 41 (1): 1-24

Brass, T. (2011b) Unfree labour as primitive accumulation? Capital and Class 35(1): 23-38

Bryceson, D., Kay, C. and Mooij, J. (2000) Disappearing Peasantries: Rural Labour in Africa, Asia and Latin America. London: Intermediate Technology Publications

Burton, I. (1963) The Quantitative Revolution and Theoretical Geography. The Canadian Geographer. 7 (4): 151-162

Burton, I., Kates, R. and White, G. (1993) The Environment as Hazard. London: Guildford Press.

Cannon, T. and Muller-Mahn, D. (2011) Vulnerability, resilience and development discourses in context of climate change. Natural Hazards. 55: 621-635

Carvalho, S. and White, H. (1997) Combining the quantitative and qualitative approaches to poverty measurement and analysis: the practice and the potential. World Bank Technical Paper 366

Castree, N. (1996) Birds mice, and geography: Marxisms and dialectics. Transactions of the Institute of British Geographers, New Series. Vol 21. 342-362

Chambers, R. (1994) Participatory rural appraisal (PRA): analysis of experience. World Development 22(9): 1253-1268

Christiaensen, L and Sarris, A. (2007) Rural Household Vulnerability and insurance against commodity risks. FAO: Rome

Collier, P and Dercon, S. (2014) African Agriculture in a changing world: smallholders in a rapidly changing world. World Development. 63(3): 92-101

Collinson, S. (2002) Politically informed Humanitarian Programming: Using a Political economy Approach. Network Paper 41. London: Humanitarian Practice Network 
Conway, D. (2011) Adapting climate research for development in Africa. WIREs Climate Change. 2: $428-450$

Coulson, A. (1982) Tanzania: a political economy. Oxford: Clarendon Press

Coulson, A. (2014) Tanzania: a political economy (2 ${ }^{\text {nd }}$ ed.). Oxford : Clarendon Press

DFID (Department for International Development) (1999) Sustainable livelihoods guidance sheets: Section 2 (Framework). Accessed via, http://www.livelihoods.org/info/guidance_sheets_pdfs/section2.pdf

DFID (Department for International Development) (2000) Sustainable livelihoods guidance sheets: Section 4 (i) (Methods). Accessed via, http://www.livelihoods.org/info/guidance_sheets_pdfs/section4_1.pdf

Eakin, H. (2005) Institutional Change, Climate Risk, and Rural Vulnerability: Cases from Central Mexico. World Development. 33 (11): 1923-1938

Eakin, H. (2006) Weathering risk in Rural Mexico. Tucson: University of Arizona Press)

Eakin, H. and Wehbe, M. (2009) Linking local vulnerability to system sustainability in a resilience framework: two cases from Latin America. Climatic Change. 93: 355-377

Ellis, F. (1998) Household strategies and rural livelihood diversification. Journal of Development Studies. 35 (1): 1-38.

Ellis, F. and Mdoe, N. (2004) Livelihoods and Poverty Reduction in Tanzania. World Development 31 (8), 1367-1384

Engle, N. (2011) Adaptive capacity and its assessment. Global Environmental Change. 21: 647656

Eriksen, S., Brown, K., and Kelly, M., (2005) The dynamics of vulnerability: locating coping strategies in Kenya and Tanzania. The Geographical Journal 171 (4): 287-305

Fairhead, J., Leach, M., and Scoones, I. (2012) Green grabbing: a new appropriation of nature? Journal of Peasant Studies 39 (2): 237-261

Ferguson, J. (1990) The anti-politics machine: "development", Depoliticization and Bureaucratic Power in Lesotho. Cambridge: Cambridge University Press

Fernandes, E.C.M. (1984) The Chagga homegardens: a multi-storeyed agroforestry cropping system on Mount Kilimanjaro. Agroforestry Systems 2, 73-86

Folke, C. (2006) Resilience. Global Environmental Change 16: 253-267

Glassman, J. (2006) Primitive accumulation, accumulation by dispossession, accumulation by 'extra-economic' means. Progress in Human Geography 30: 608-627

Harvey, D. 1982. The Limits to capital. Oxford: Blackwell 
Harvey, D, 1996. Justice, Nature and The geography of difference. Oxford: Blackwell

Harvey, D. (2003) The New Imperialism. Oxford: Blackwell

Harvey, D. 2006. Spaces of Capital: Towards a theory of uneven development. Oxford: Blackwell

Harvey, D. 2009. On the deep relevance of a certain footnote in Marx's Capital. Human Geography 1 (2), 26-31

Harvey, D. (2014) Seventeen contradictions and the end of capitalism. Oxford: Oxford University Press

Head, L. 2010. Cultural Ecology: adaptation - retrofitting a concept? Progress in Human Geography. 34 (2): 234-242

Holler, J. (2014) Is Sustainable Adaptation possible? Determinants of adaptation on Mt. Kilimanjaro. The Professional Geographer. 66(4): 526-537

Howard, M. and Millard, A.V. (1997) Hunger and Shame: Child Malnutrition and Poverty on Mount Kilimanjaro. Routledge: New York

Huq, S. and Reid, H. (2004) Mainstreaming Adaptation in development. IDS Bulletin 35(3): 159170

IPCC, (2012): Managing the Risks of Extreme Events and Disasters to Advance Climate Change Adaptation. A Special Report of Working Groups I and II of the Intergovernmental Panel on Climate Change [Field, C.B., V. Barros, T.F. Stocker, D. Qin, D.J. Dokken, K.L. Ebi, M.D. Mastrandrea, K.J. Mach, G.-K. Plattner, S.K. Allen, M. Tignor, and P.M. Midgley (eds.)]. Cambridge University Press, Cambridge, UK, and New York, NY, USA, 582 pp.

IPCC, 2014: Climate Change 2014: Impacts, Adaptation, and Vulnerability. Part B: Regional Aspects. Contribution of Working Group II to the Fifth Assessment Report of the Intergovernmental Panel on Climate Change [Barros, V.R., C.B. Field, D.J. Dokken, M.D. Mastrandrea, K.J. Mach, T.E. Bilir, M. Chatterjee, K.L. Ebi, Y.O. Estrada, R.C. Genova, B. Girma, E.S. Kissel, A.N. Levy, S. MacCracken, P.R. Mastrandrea, and L.L. White (eds.)]. Cambridge University Press, Cambridge, United Kingdom and New York, NY, USA, 688 pp.

Hare, F, Kates, B and Warren A. 1977. The making of deserts: climate, ecology and society. Economic Geography 53(4): 332-346 Kates

Kelman, I. 2008. Critique of Some Vulnerability and Resilience Papers. Version 2, 17 November 2008 (Version 1 was 7 July 2008). Downloaded from http://www.islandvulnerability.org/docs/vulnrescritique.pdf

Klein R., Eriksen S., Naess L., Hammill A., Tanner T., Robledo C. \& O’Brien K. (2007) Portfolio Screening to support the mainstreaming of adaptation to climate change into development assistance. Climatic Change. 84: $23-44$

Laws, S., Harper, C. and Marcus, R. (2003) Research for development. London: Sage 
Leichenko, R.M. and O'Brien, K.L. (2008) Environmental Change and Globalization: Double Exposures. Oxford University Press: Oxford

Leichenko, R.M. and O'Brien, K.L. (2010) Climate change and the global financial crisis: a case of double exposure. Annals of the AAG. 100(4): 963-972

Levin, K., Cashore, B., Bernstein, S., and Auld, G. (2012) "Overcoming the tragedy of super wicked problems: constraining our future selves to ameliorate global climate change". Policy Sciences 45 (2): 123-152.

Levins, R., (1998) 'Dialectics and Systems Theory’, Science and Society. 62 (3): 375-399

Luxemburg, R. (1913) The accumulation of capital. Accessed from Marxists.org 5/5/15

Maghimbi S. (2007) Recent crop changes in crop patterns in the Kilimanjaro region: the decline of coffee and the rise of maize and rice. African Study Monographs. Suppl. 35: 73-83

Manji, A. (2006) The Politics of Land Reform in Africa. London and New York: Zed Books

Manyena, S.B. (2006) The concept of resilience revisited. Disasters. 30(4): 434-450

Marx, K. (1852) $18^{\text {th }}$ Brumaire of Louis Bonaparte. Accessed from Marxists.org 5/5/15

Mascarenhas, A. (2000). Poverty, environment and livelihoods along thegradients of the Usambaras, Tanzania. REPOA, Dar es Salaam

McCusker, B. and Carr, E. (2009) The coproduction of landuse and livelihoods change: Implications for development interventions. Geoforum 40 (4): 568-579

McCusker, B., O'Keefe, P.J.M., O'Keefe, P. and O'Brien, G. (2013) Peasants, pastoralists and proletarians: trajectories of agrarian change, livelihoods and landuse. Human Geography 6(3): 3-11

McMillan, S. and Heady, D. (2014) Understanding Structural transformation in Africa. World Development. 63: 1-10

Mdoe, N., and Wiggins, S. (1997). Returns to smallholder dairying in the Kilimanjaro region, Tanzania. Agricultural Economics. 17, 75-87

Mendelsohn R, Nordhaus WD, Shaw D (1994) The impact of global warming on agriculture: a Ricardian analysis. Am Econ Rev 84(4):753-771

Mendelsohn, R., Basist, A., Kurukurasuliya, P., and Dinar, A. (2007) Climate and rural income, Climatic Change, 81:101-118.

Mertz, O., Halsnaes, K, Olesen, J.E., Rasmussen, K. (2009) Adaptation to climate change in developing countries. Environmental Management. 43: 743-752

Middleton, N and O'Keefe, P. (1998). Disaster and Development. London: Pluto Press 
Mongi, H., Majule, A.E. and Lyimo, J.G. Vulnerability and adaptation of rain fed agriculture to climate change and variability in semi-arid Tanzania. African Journal of Environment Science and Technology. 4 (6): 371-381

Moore, S. F., (1986). Social Facts and Fabrications: Customary law on Mount Kilimanjaro. New York: Cambridge University Press.

Moyo, S. and Yeros, P. (2007) The Radicalised State: Zimbabwe's Interrupted Revolution. Review of African Political Economy. 34 (111) 103-121

Munishi, P.K.T. (2007). Agroforestry/Small Holder Tree Management Potential in the Highlands of Tanzania - Contribution to Livelihoods and Environmental Protection. Presentation given at CEEST working seminar on climate adaptation, Moshi July $16^{\text {th }}-18^{\text {th }} 2007$.

Mwandosya, M., B. Nyenzi, and M. Luhanga. (1998): The Assessment of Vulnerability and Adaptation to Climate Change Impacts in Tanzania. Centre for Energy, Environment, Science and Technology, Dar es Salaam, Tanzania

Nelson, G.C., H. Valin, R.D. Sands, P. Havlík, H. Ahammad, D. Deryng, J. Elliott, S. Fujimori, T. Hasegawa, E. Heyhoe, P. Kyle, M. Von Lampe, H. Lotze-Campen, D. Mason d'Croz, H. van Meijl, D. van der Mensbrugghe, C. Müller, A. Popp, R. Robertson, S. Robinson, E. Schmid, C. Schmitz, A. Tabeau, and D. Willenbockelo, 2014: Climate change effects on agriculture: Economic responses to biophysical shocks. Proc. Natl. Acad. Sci., 111, no. 9, 3274-3279,

NBS (National Bureau of Statistics) and Kilimanjaro Regional Commissioners Office (2002) Socio-economic Profile of Kilimanjaro Region. Dar es Salaam

NBS (National Bureau of Statistics) (2005) Tanzania Demographic and Health Survey 20042005. Dar es Salaam

O'Brien, K. L., and Leichenko, R. M. (2000). Double exposure: Assessing the impacts of climate change within the context of economic globalization. Global Environmental Change, 10(3), 221232.

O’Brien and Leichenko (2008) Double Exposures. Oxford University Press

O’Brien G., O’Keefe P., Meena H., Rose J., Wilson L. (2008) Climate adaptation from a poverty perspective. Climate Policy 8: 194-201

O'Brien, G and O'Keefe, P. (2013) Managing adaptation to climate risk: beyond fragmented responses. Routledge: London

O'Connor, J. (1998) Natural Causes: essays in ecological Marxism. London: Guildford Press

O'Keefe and Middleton (1998) Disaster and Development. London: Pluto Press

O'Keefe, P., Westgate, K., and Wisner, B., (1976) Taking the naturalness out of natural disasters. Nature. 260: 566-567 
O'Keefe, P.J.M. (2013) Vulnerability and Livelihoods on Mt. Kilimanjaro. Human Geography. 6 (3): $30-45$

O'Keefe, P.J.M. (2015) (forthcoming). Exploring radical conceptions of vulnerability in Tanzania.

Ollman, B. (1993) Dialectical Investigations. New York: Routledge

Ollman, B. (1998) 'Why Dialectics? Why Now?', Science and Society. 62 (3): 338-357

Ollman, B. 2003. Dance of the Dialectic: Steps in Marx's Method. Urbana and Chicago: University of Illinois Press

Paavola, J. (2008) Livelihoods, vulnerability and adaptation to climate change in Morogoro, Tanzania. Environmental Science and Policy. 11: 642-654

Peet, J. (1985) The social origins of environmental determinism. Annals of the Association of American Geographers. 75 (3): 309-333

Potts, D. (2006) Tanzania, Development and Liberalization. 89-108, in Carling, A. (2006) Globalization and Identity: Development and Integration in a Changing World. New York: I B Tauris

Sarantakos, S. (2005) Social Research (Third edition). Basingstoke: Palgrave Macmillan

Scoones, I. (1998) Sustainable Rural Livelihoods: A Framework for Analysis. IDS Working Paper 72. Brighton: Institute for Development Studies

Scoones, I. (2009). Livelihoods perspectives and rural development. Journal of Peasant Studies. 36(1): 171-196

Scott, J.C. (1978) The Moral Economy of the Peasant. New Haven: Yale University Press

Scott, J.C. (1998) Seeing like a state: How certain schemes to improve the human condition have failed. New Haven: Yale University Press

Scott, J.C. (2009) The Art of not being governed: an anarchist history of upland southeast Asia. New Haven: Yale University Press

Sen, A., (1981) Poverty and Famines: An Essay on Entitlement and Deprivation. Clarendon Press, Oxford

Shivji, I.G. (2006) Let the people speak: Tanzania down the road to neoliberalism. Mkuki na Nyota: Dar es Salaam

Shivji, I.G. (2009) Accumulation in an African Periphery. Mkuki na Nyota: Dar es Salaam

Shove, E. (2010) Social theory and climate change: questions often, sometimes and not yet asked. Theory, Culture, Society. 27 (2-3): 277-288

Silva, J.A., Eriksen, S. and Ombe, Z.A. (2010) Double exposure in Mozambique's Limpopo River Basin. The Geographic Journal. 176 (1): 6-24 
Simon, J. (1972) Theories of bounded rationality. Decision and Behavior. 161-177

Sithole, A. and Murewi, C. (2009) Climate Variability and change over southern Africa: impacts and challenges. African Journal of Ecology. 47 (Supplement 1): 17-20

Smith, N. (1984) Uneven Development: nature, capital and the production of space. Oxford (UK): Blackwell

Smith, N. (1992) Contours of a spatialized politics: homeless vehicles and the production of geographical scale. Social Text. 33: 54-81

Smith, N. (2009) Uneven Development: nature, capital and the production of space (3rd ed.). Athens: University of Georgia Press

Smith, N., and O'Keefe, P. (1980). Geography, Marx and the Concept of Nature. Antipode. 12: 30-39

Soini, E., (2005). Changing livelihoods on the slopes of Mt. Kilimanjaro, Tanzania: Challenges and opportunities in the Chagga homegarden system. Agroforestry Systems. 64, 157-167

Smucker T.A. and Wisner B. (2008) Changing household responses to drought in Tharaka, Kenya: vulnerability, persistence and challenge. Disasters. 32(2): 190-215

Smucker, T.A., Wisner, B., Mascarenhas, A>, Munishi, P., Wangui, E.E. and Sinha, G. (2015). Differentiated livelihoods, local institutions and the adaptation imperative: assessing climate change adaptation policy in Tanzania. Geoforum 59 (39-50)

Tschakert, P., van Oort, B., St Clair, A.L. and LaMadrid, A. (2013) Inequality and Transformation Analyses: a complementary lens for addressing vulnerability to climate change. Climate and Development. 5 (4): 340-350

Turner II, B.L., Kasperson, R.E., Matson, P.A., McCarthy, J.J., Corell, R.W., Christensen, . . Schiller, A. (2003). A frame- work for vulnerability analysis in sustainability science. PNAS, 100, 8074-8079

UNDP (United Nations Development Program) (2006). Human Development Report 2006. Accessed via, http://hdr.undp.org/reports/global/2006/

United Republic of Tanzania (2006a). Small Holder Agriculture. Livestock Sector - National Report. Dar-es-Salaam.

United Republic of Tanzania (2006b) National Sample Census of Agriculture: Smallholder Characteristics and Access to Services and Natural Resources. Dar es Salaam

Wainwright, J. (2008) Decolonizing Development: Colonial Power and the Maya. Malden: Blackwell

Wangui, E.E., Smucker, T.A, Wisner, B., Lovell, E., Mascarenhas, A., Solomon, M., Weiner, D., Munna, A., Sinha, G., Bwenge, C., Meena, H., and Munishi, P. (2012) Integrated development, 
risk management and community-based climate change adaptation in a mountain-plains system in Northern Tanzania. Journal of Alpine Research 100(1): 2-16

Watts, M. (1983) Silent Violence. University of California Press: Berkeley

WCED (World Comission on Environment and Development) (1987). Our Common Future. Oxford: Oxford University Press

White. G.F. (1945) Human Adjustment to floods. Research Paper No. 29. Chicago:

University of Chicago, Department of Geography

White, H. (2002) Combining Quantitative and Qualitative Approaches to Poverty Analysis. World Development. 30 (3): 511-522

Wijkman, A. and Timberlake, L. (1984). Natural Disasters: Acts of God or acts of Man? London: IIED and the Swedish Red Cross

Wisner, B., Blaikie, P., Cannon, T. and Davis, I. (2004). At Risk (Second Edition): Natural Hazards, people's vulnerability and disasters. London: Routledge 